University of Tennessee Health Science Center

UTHSC Digital Commons

\title{
$5-2011$
}

\section{The Biochemical Pathway Leading to Lpa Generation Upon Blood Coagulation}

\author{
Alyssa Lynn Jefferson Bolen \\ University of Tennessee Health Science Center
}

Follow this and additional works at: https://dc.uthsc.edu/dissertations

Part of the Medical Cell Biology Commons, and the Medical Molecular Biology Commons

\section{Recommended Citation}

Bolen, Alyssa Lynn Jefferson , "The Biochemical Pathway Leading to Lpa Generation Upon Blood Coagulation" (2011). Theses and Dissertations (ETD). Paper 27. http://dx.doi.org/10.21007/ etd.cghs.2011.0031.

This Dissertation is brought to you for free and open access by the College of Graduate Health Sciences at UTHSC Digital Commons. It has been accepted for inclusion in Theses and Dissertations (ETD) by an authorized administrator of UTHSC Digital Commons. For more information, please contact jwelch30@uthsc.edu. 


\title{
The Biochemical Pathway Leading to Lpa Generation Upon Blood Coagulation
}

\author{
Abstract \\ Platelet activation initiates an upsurge in 18:2 and 20:4 lysophosphatidic acid (LPA) production. The \\ biochemical pathway responsible for LPA production during blood clotting is not fully understood. We \\ have purified a phospholipase $A_{1}\left(P L A_{1}\right)$ from thrombin-activated human platelets using sequential \\ chromatographic steps followed by fluorophosphonate-biotin affinity labeling and proteomics. We \\ identified acyl-protein thioesterase 1 (aka. lysophospholipase A1, accession code 075608) as a novel \\ $\mathrm{PLA}_{1}$. Addition of this recombinant PLA 1 significantly increased the production of sn-2-esterified \\ polyunsaturated LPCs and the corresponding LPAs in plasma. We next examined the regioisomeric \\ preference of lysophospholipase D/autotaxin (ATX), which is the subsequent step in LPA production. To \\ prevent acylmigration regioisomers of oleyl-sn-glycero-3-phosphocholine (LPAF) were synthesized. ATX \\ preferred the $s n-1$ over the $s n-2$ regioisomer of LPAF. We propose the following LPA production pathway \\ in blood: 1) Activated platelets secrete PLA1. 2) PLA1generates a pool of sn-2 lysophospholipids. 3) \\ These newly generated $s n-2$ lysophospholipids undergo acyl migration to yield $s n-1$ lysophospholipids, \\ which are the preferred substrates of ATX. 4) ATX cleaves the sn-1 lysophospholipids to generate sn-1 \\ LPA species predominant with 18:2 and 20:4 fatty acids.

\section{Document Type} \\ Dissertation \\ Degree Name \\ Doctor of Philosophy (PhD) \\ Program \\ Biomedical Sciences \\ Research Advisor \\ Gabor J. Tigyi, M.D., Ph.D. \\ Keywords \\ Autotaxin, Lysophosphatidic acid, Phospholipase A1 \\ Subject Categories \\ Medical Cell Biology | Medical Molecular Biology | Medical Sciences | Medicine and Health Sciences
}


THE BIOCHEMICAL PATHWAY LEADING TO LPA GENERATION UPON BLOOD COAGULATION

\author{
A Dissertation \\ Presented for \\ The Graduate Studies Council \\ The University of Tennessee \\ Health Science Center \\ In Partial Fulfillment \\ Of the Requirements for the Degree \\ Doctor of Philosophy \\ From The University of Tennessee
}

By

Alyssa Lynn Jefferson Bolen

May 2011 
Chapter 2 (c) 2011 by American Society for Biochemistry and Molecular Biology. All other material (C) 2011 by Alyssa L. Bolen.

All rights reserved. 


\section{DEDICATION}

This dissertation is dedicated to my family:

Karen and Ken Jefferson

Andrea Jefferson

James Boler 


\section{ACKNOWLEDGEMENTS}

I am greatly thankful to my advisor, Dr. Gabor Tigyi, who has taught me so much. Through his love of science he has taught me to overcome the obstacles and disappointments and to see the positive side. He has trained me to be a leader and encouraged me to step out of the norm and push my boundaries. He taught me to follow where life leads, keep an open mind, and to be confident in my work and my choices.

I am also grateful to all the wonderful members of his lab, past and present: Shuyu E, James Fells, Ryoko Tsukahara, Tomatsu Tsukahara, Yuko Fujiwara, Daniel Osborne, Diana Liu, Billy Valentine, and Gyongi Kiss.

I am indebted to the support that Dr. Naren, Dr. Beranova-Giorgianni, and Dr. Baker have given me over the years, not only science but also in overcoming obstacles and not giving up.

I would also like to sincerely thank my committee members: Dr. John Fain, Dr. Suzanne Jackowski, Dr. Edwards Park, and Dr. Sarka Beranova-Giorgianni for all their guidance and help throughout my graduate career.

My parents and sister have always been the constant encouragement throughout my entire life. I could not have made it this far without their support and love.

James Boler is the stable foundation in my life. I am grateful for his steady encouragement and love.

I greatly appreciate the support from the Gerwin Scholarship and the American Heart Association.

I thank Prof. Akira Tokumura (University of Tokushima) for his help with the LC-MS protocol. 


\begin{abstract}
Platelet activation initiates an upsurge in 18:2 and 20:4 lysophosphatidic acid (LPA) production. The biochemical pathway responsible for LPA production during blood clotting is not fully understood. We have purified a phospholipase $\mathrm{A}_{1}\left(\mathrm{PLA}_{1}\right)$ from thrombin-activated human platelets using sequential chromatographic steps followed by fluorophosphonate-biotin affinity labeling and proteomics. We identified acyl-protein thioesterase 1 (aka. lysophospholipase A1, accession code O75608) as a novel PLA . $_{1}$ Addition of this recombinant $\mathrm{PLA}_{1}$ significantly increased the production of $s n$-2-esterified polyunsaturated LPCs and the corresponding LPAs in plasma. We next examined the regioisomeric preference of lysophospholipase D/autotaxin (ATX), which is the subsequent step in LPA production. To prevent acylmigration regioisomers of oleyl-sn-glycero-3-phosphocholine (LPAF) were synthesized. ATX preferred the $s n-1$ over the $s n-2$ regioisomer of LPAF. We propose the following LPA production pathway in blood: 1) Activated platelets secrete $\mathrm{PLA}_{1}$. 2) PLA $\mathrm{PL}_{1}$ generates a pool of $s n-2$ lysophospholipids. 3) These newly generated sn-2 lysophospholipids undergo acyl migration to yield $s n-1$ lysophospholipids, which are the preferred substrates of ATX. 4) ATX cleaves the $s n-1$ lysophospholipids to generate $s n-1$ LPA species predominant with 18:2 and 20:4 fatty acids.
\end{abstract}




\section{TABLE OF CONTENTS}

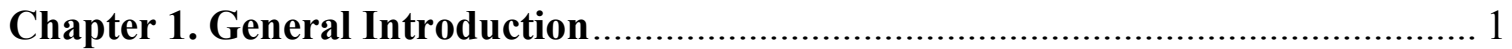

1.1 Phospholipid Production ........................................................................... 1

1.1.1 Lysophosphatidic Acid ...................................................................

1.1.2 The GPAT Pathway of LPA Synthesis ...............................................

1.1.3 LPA Generation by MAGK ............................................................

1.1.4 LPA Synthesis from PA .................................................................

1.1.5 LPA Production via PLA $\mathrm{PL}_{2}$ Hydrolysis................................................3

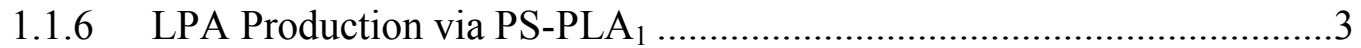

1.1.7 LPA Production during LDL Oxidation.............................................

1.1.8 LPA Generation by Phospholipase and Lysophospholipase D

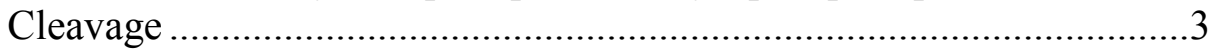

1.1.9 LPA Upregulation during Blood Coagulation......................................

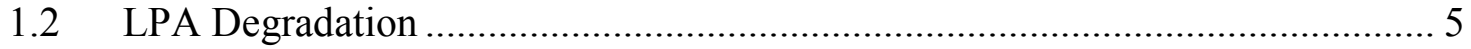

1.2.1 LPA Degradation by Phosphatases ................................................5

1.2.2 LPA Degradation by Lysophospholipases ..........................................5

1.2.3 LPA Degradation by Acyltransferases .................................................5

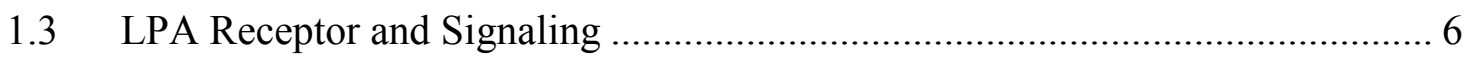

1.3.1 Plasma Membrane Receptors ...........................................................6

1.3.2 Intracellular Receptor, PPAR $\gamma$.....................................................

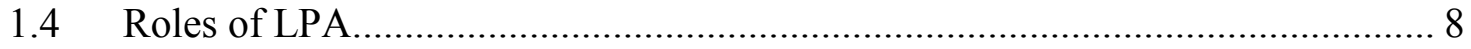

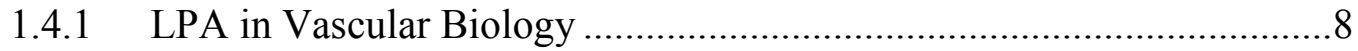

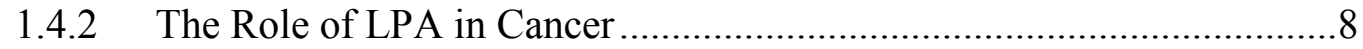

1.4.3 LPA in Cell Survival and Apoptosis ...................................................

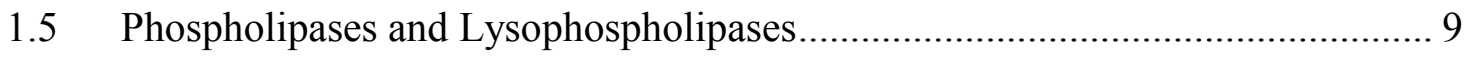

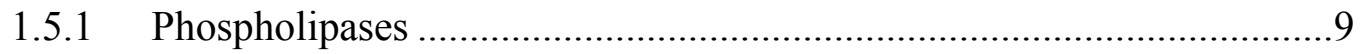

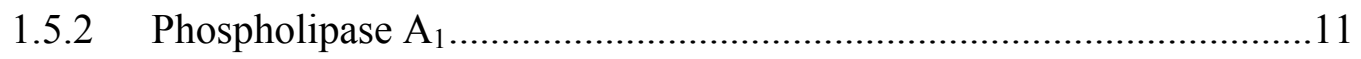

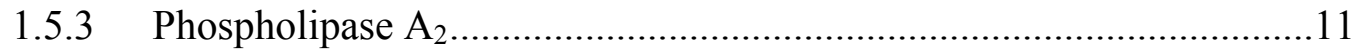

1.5.4 Lysophospholipase D ............................................................ 12

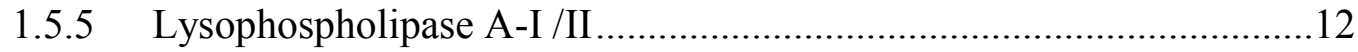




\section{Chapter 2. The Phospholipase A Activity of Lysophospholipase A-I Links

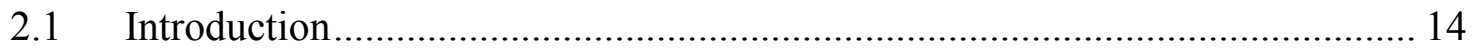

2.2 Materials and Methods......................................................................... 16

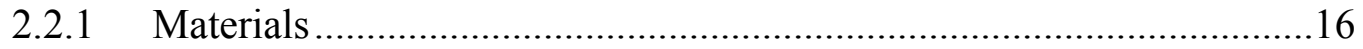

2.2.2 Isolation and Activation of Human Platelets..........................................16

2.2.3 Measurement of Phospholipase $\mathrm{A}_{1}$ Activity ........................................16

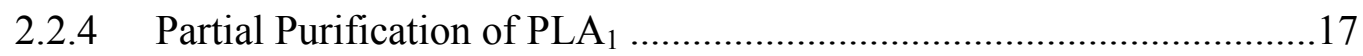

2.2.5 FP-Rhodamine Labeling...............................................................18

2.2.6 FP-Biotin Labeling and Purification ..................................................18

2.2.7 Proteomic Analysis of FP-Biotin-Labeled Products in Partially Purified Platelet Supernatants ............................................................19

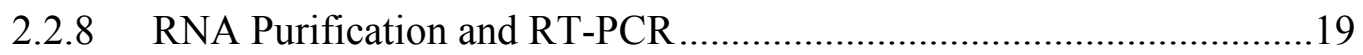

2.2.9 MGLL Activity Assay ...................................................................20

2.2.10 Construction of Recombinant LYPLA-I/APT1 Expression Plasmid....20

2.2.11 Recombinant LYPLA-I/APT1 Purification.............................................21

2.2.12 Monitoring LPC and LPA Production in Plasma ..................................21

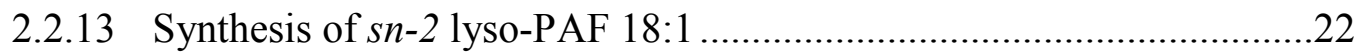

2.2.14 Determinination of Regioisomeric Selectivity of ATX against Two

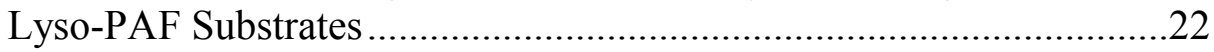

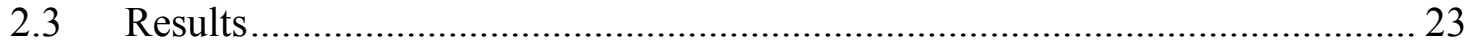

2.3.1 Phospholipases Released from Activated Platelets Generate Lysophospholipids but LPA Production Requires ATX from Plasma

2.3.2 Partial Purification of Phospholipase $A_{1}$ from Supernatants of Activated Human Platelets ....................................................................23

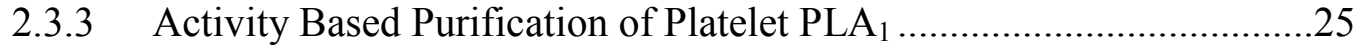

2.3.4 Identification of Serine Hydrolases Secreted from Thrombin Activated Human Platelets

2.3.5 Recombinant Human LYPLA-I/APT1 Acts Primarily as a Phospholipase $\mathrm{A}_{1}$ and Does Not Break Down LPA.............................28

2.3.6 LYPLA-I/APT1 Contributes to the Production of LPA during Blood Coagulation

2.3.7 Regioisomeric Preference of ATX …………………...........................33

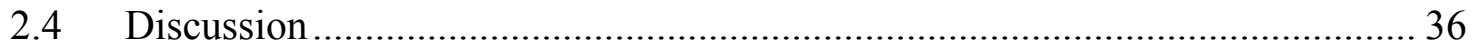

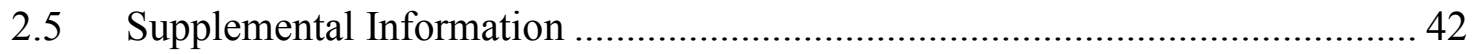


Chapter 3. Quantification of sn-1 and sn-2 Regioisomers of LPA and LPC 46

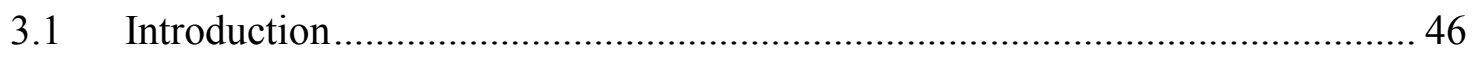

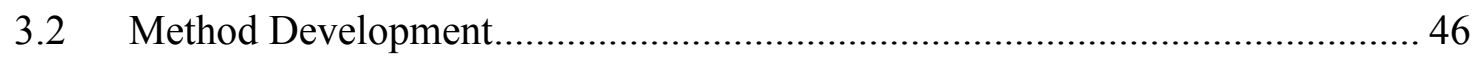

3.2.1 Production of the $s n-2$ Regioisomer of LPC and LPA.........................46

3.2.2 LC-MS/MS Method Development for Separation of the $s n-1$ and sn-2 Regioisomers of LPA ...............................................................47

3.2.3 Stability of the $s n-2$ Regioisomers of LPA and LPC .........................50

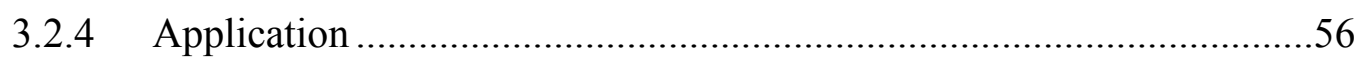

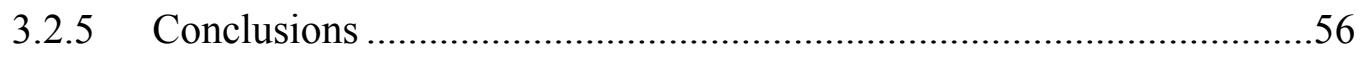

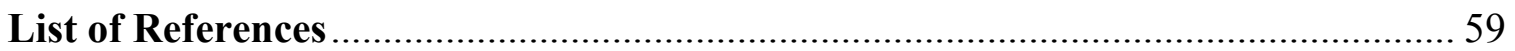

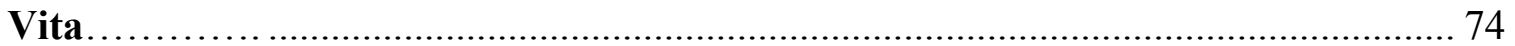




\section{LIST OF TABLES}

Table 2.1 Summary of chromatographic steps................................26

Table 2.2 LC-MS/MS candidate protein peptide sequences............................ 29

Table 2.3 Kinetic parameters for ATX-mediated hydrolysis of LPAF $18: 1 \ldots \ldots \ldots \ldots \ldots 38$

Table 3.1 Retention times of LPA and LPC species under varying conditions............ 53 


\section{LIST OF FIGURES}

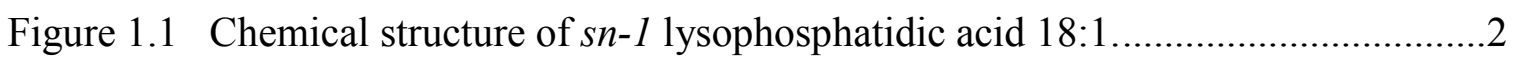

Figure 1.2 Specificity of phospholipases ................................................................ 10

Figure 2.1 ATX is required for LPA production in activated platelet supernatant........ 24

Figure 2.2 FP-Rhodamine binds to PLA 1 inhibiting activity and NBD-LPS production

Figure 2.3 Human recombinant LYPLA-I/APT1 with and without a GST tag are purified for analysis ....................................................................... 30

Figure 2.4 Human recombinant LYPLA-I/APT1 acts first as a PLA 1 then also has lysophospholipase activity when incubated with NBD-PC

Figure 2.5 Human recombinant LYPLA-I/APT1 increases the amount of LPA 18:2 and LPA 20:4 in a time-dependent manner.

Figure 2.6 Human recombinant LYPLA-I/APT1 increases the amount of LPA

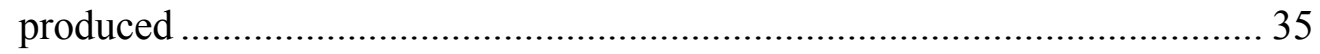

Figure 2.7 Comparison of the cleavage of $s n-1$ with $s n-2$ LPAF 18:1 by ATX ............ 37

Figure 3.1 HPLC-MS/MS chromatogram of LPA 20:0 regioisomers under varying conditions

Figure 3.2 HPLC-MS/MS chromatogram of LPA 18:1 and 20:0 regioisomers ............ 49

Figure 3.3 HPLC-MS/MS chromatogram of LPA 18:2 regioisomers......................... 51

Figure 3.4 HPLC-MS/MS chromatogram of separation of LPA 18:2

regioisomers

Figure 3.5 HPLC-MS/MS chromatogram of sn-2 LPA 18:2 at varying time points post synthesis

Figure 3.6 HPLC-MS/MS chromatogram of sn-2 LPC 18:1 at varying time points post synthesis....

Figure 3.7 HPLC-MS/MS chromatogram of LPC 18:1 at varying time points in plasma and serum.

Figure 3.8 HPLC-MS/MS chromatogram of LPA 18:2 at varying time points in plasma and serum. 


\section{LIST OF ABBREVIATIONS}

ADP

AGPAT

ATP

ATX

C1P

$\mathrm{cPLA}_{2}$

ERK1/2

FP

GPAT

GPCR

$\mathrm{iPLA}_{2}$

LDL

LPA

$\mathrm{LPA}_{1-7}$

LPAAT

LPAF

LPC

LPLD

LPS

LYPLA1

MAGK

MMP

MRM

NHERF2

NPP

PA

PC

PDZ domain

$\mathrm{PLA}_{1}$ adenosine diphosphate

1-acylglycerol 3-phosphate acyltransferase

adenosine triphosphate

autotaxin

ceramide-1-phosphate

cytosolic PLA 2

extracellular signal-regulated kinase

fluorophosphonate

glycerophosphate acyltransferase

G protein coupled receptor

calcium independent phospholipase $\mathrm{A}_{2}$

low density lipoprotein

lysophosphatidic Acid

LPA receptor 1-7

lysophosphatidic acid acyltransferases

lyso platelet activating factor

lysophosphatidyl choline

lysophospholipase D

lysophosphatidyl serine

lysophospholipase A-I

monoacylglycerol kinase

matrix metalloproteinases

multiple reaction monitoring

$\mathrm{Na}^{+} / \mathrm{H}^{+}$exchanger regulatory factor-2

nucleotide pyrophosphatase/phosphodiesterase

phosphatidic acid

phosphatidyl choline

PSD-95/Disc-large/ZO-1 domain

phospholipase $\mathrm{A}_{1}$ 


$\begin{array}{ll}\text { PLA }_{2} & \text { phospholipase } \mathrm{A}_{2} \\ \text { PLB } & \text { phospholipase B } \\ \text { PLC } & \text { phospholipase C } \\ \text { PPAR } & \text { peroxisome proliferator-activated receptor gamma } \\ \text { PRP } & \text { platelet rich plasma } \\ \text { PS } & \text { phosphatidyl serine } \\ \text { PS-PLA } & \text { phosphatidyl serine specific PLA } 1 \\ \text { S1P } & \text { sphingosine-1-phosphate } \\ \text { SPLA } & \text { secretory phospholipase } A_{2} \\ \text { TLC } & \text { thin layer chromatography } \\ \text { TRIP 6 } & \text { thyroid receptor-interacting protein } 6 \\ \text { VEGF } & \text { vascular endothelial growth factor }\end{array}$




\section{CHAPTER 1. GENERAL INTRODUCTION}

\subsection{PHOSPHOLIPID PRODUCTION}

\subsubsection{Lysophosphatidic Acid}

Lysophosphatidic acid (LPA; Figure 1.1) has been studied by many chemists, biochemists, biologists, and physicians since it was first identified in 1957 as the active ingredient of a smooth muscle-stimulating substance, Darmstoff (Vogt, 1957a; b). Many advances have been made throughout the years in determining the production, breakdown, and receptors for LPA, but many aspects of LPA are still unknown.

Various species of LPA, dominated by 16-, 18-, and 20- carbon long acyl chains, are produced in cells as an intermediate to lipid synthesis and extracellularly in many biological fluids. The different species of LPA provides a unique opportunity for specificity within the receptors. For example, most LPA GPCRs prefer unsaturated species.

\subsubsection{The GPAT Pathway of LPA Synthesis}

LPA is generated via many different mechanisms. One pathway of LPA production is through glycerophosphate acyltransferase (GPAT). GPAT acylates glycerol 3-phosphate to generate LPA in the endoplasmic reticulum and mitochondria (Das and Hajra, 1984; Aoki, 2004; Gendaszewska-Darmach, 2008). This LPA may be quickly broken down into phosphatidic acid (PA) by monoacylglycerolphosphate acyltransferase, but some of this LPA may contribute to the intracellular LPA.

\subsubsection{LPA Generation by MAGK}

A lipid kinase involved in the pathway of LPA production was identified in 1962 (Pieringer and Hokin, 1962). This kinase was later identified as monoacylglycerol kinase and the phosphorylation of monoacylglycerol by this enzyme within the plasma membrane contributes to the production of LPA (Bektas et al., 2005).

\subsubsection{LPA Synthesis from PA}

LPA is also generated via the hydrolysis of fatty acids at either the $s n-1$ position or the $s n-2$ position of PA by (phospholipase $\mathrm{A}_{1}$ ) $\mathrm{PLA}_{1}$ or (phospholipase $\mathrm{A}_{2}$ ) PLA 2 enzymes respectively. PA-specific PLA 1 and PLA $_{2}$ enzymes have been reported in human (Billah et al., 1980; Sano et al., 2002; Sonoda et al., 2002), horse (Billah et al., 1981), and pig (Inoue and Okuyama, 1984) platelets. However this is shown to only 


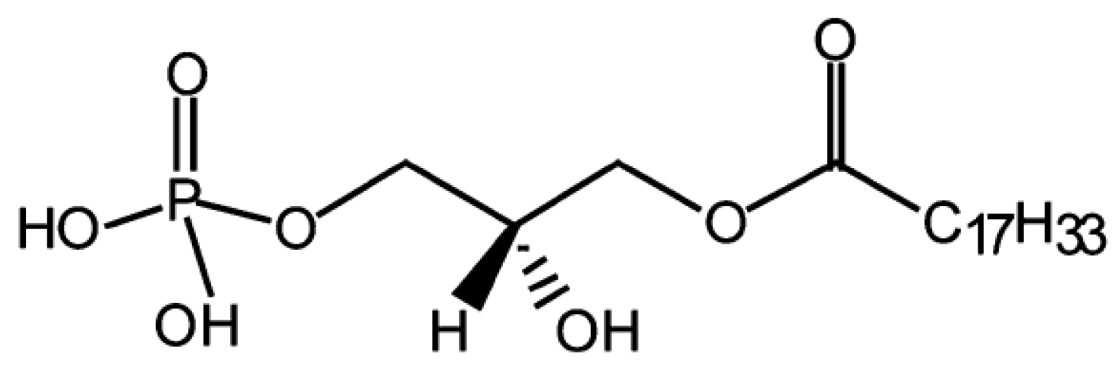

Figure 1.1 Chemical structure of sn-1 Lysophosphatidic acid 18:1. 
produce a small portion (10\%) of LPA detected in serum (Gaits et al., 1997; Aoki et al., 2002b; Cummings et al., 2002; Sano et al., 2002; Aoki, 2004).

\subsubsection{LPA Production via PLA 2 Hydrolysis}

LPA is also produced by a secretory or type II phospholipase $\mathrm{A}_{2}\left(\mathrm{sPLA}_{2}\right)$ (Fourcade et al., 1995). LPA has also been shown to be generated in a spatially regulated fashion by the $\mathrm{Ca}^{2+}$-independent $\mathrm{PLA}_{2}$ at the leading edge of migrating monocytes (Carnevale and Cathcart, 2001; Mishra et al., 2008).

\subsubsection{LPA Production via PS-PLA}

Another pathway of LPA production involves a phosphatidylserine (PS)-specific

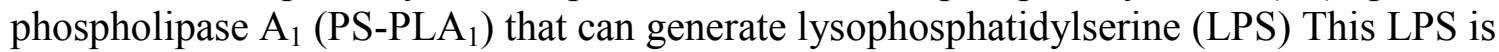
then converted into LPA by intracellular phospholipase D action (Nagai et al., 1999, Aoki et al., 2002a).

\subsubsection{LPA Production during LDL Oxidation}

Low density lipoprotein (LDL) often gets oxidized which produces many lipid constituents. Mildly oxidized low density lipoprotein (moxLDL) induces platelet and endothelial cell shape changes (Siess et al., 1999). The pro-thrombotic and proatherogenic properties of the moxLDL are due to LPA.

\subsubsection{LPA Generation by Phospholipase and Lysophospholipase D Cleavage}

Lysophospholipase D (LPLD) activity is present in most biological fluids. LPLDmediated production of LPA was first projected in the early 1980's in rat plasma (Tokumura et al., 1986). LPLD acts on LPLs by removing the headgroup from LPLs resulting in LPA. This enzymatic pathway for LPA production will be described in greater detail in a subsequent section.

\subsubsection{LPA Upregulation during Blood Coagulation}

Although many pathways are responsible for LPA production, perhaps the most significant pathway is a multi-step process linked to activation of platelets (Mauco et al., 1978; Schumacher et al., 1979; Eichholtz et al., 1993; Gaits et al., 1997; Sano et al., 2002; Aoki et al., 2008). This multistep mechanism involves the release of unidentified $\mathrm{PLA}_{1}$ and/or PLA 2 enzymes from activated platelets generating a new pool of lysophospholipids (LPLs), which in turn are cleaved by a lysophospholipase D also known as autotaxin (ATX) (Tokumura et al., 2002; Umezu-Goto et al., 2002). 
Under normal circumstances, LPA levels in plasma are less than $100 \mathrm{nM}$ and the rank order of species is 18:2 $>18: 1>18: 0>16: 0>20: 4$. These levels increase during blood coagulation to reach up to $10 \mu \mathrm{M}$ and show an increase in the unsaturated species (Baker et al., 2001; Sano et al., 2002; Watanabe et al., 2007; Hosogaya et al., 2008). The rank order of LPA species in serum is 20:4 > 18:2 > 16:0 > 18:1 > 18:0 (Sano et al., 2002).

The mechanism behind the increase in LPA upon blood coagulation is still unknown. It was first proposed that platelets were the source of high levels of LPA in serum. However, the amount of LPA released from activated platelets is insufficient to explain the large amount of LPA in serum. Tigyi, et. al. first showed that platelets secrete enzymes that act on plasma phospholipids that in turn generate LPA, which has been confirmed by other groups (Baker et al., 2001; Aoki et al., 2002a). Linoleoyl- (18:2) and arachidonoyl (20:4) species make up $84 \%$ of the LPA found in serum (Baker et al., 2001). The difference in the abundance of molecular species between serum and plasma leads to the hypothesis that LPA present in serum is generated via a pathway distinct from that of LPA present in plasma. Furthermore, the dominating abundance of the arachidonoyl (20:4) and linoleoyl (18:2) species of LPA in serum suggests that these LPAs are derived through a PLA $_{1}$ enzymatic mechanism because these two lipids are esterified to the $s n-2$ position of plasma lipids.

Preliminary data support this hypothesis of LPA production. It has been shown that the incubation of NBD fluorescent labeled phosphatidylcholine (PC), phosphatidylserine (PS) and phosphatidylethanolamine (PE) with supernatant from thrombin stimulated platelets are converted into lysophospholipids by PLA $\mathrm{P}_{1}$ activity. When spiked into serum or plasma these lysophospholipids are then converted into LPA (Baker et al., 2001). Previous studies have shown that lysophospholipase D (LPLD) is capable of generating LPA in plasma by preferentially acting on unsaturated lysophosphatidylcholine (Tokumura et al., 1998). This suggests that thrombin activated platelets produce LPA through the cleavage of phospholipids to lysophospholipids by platelet derived PLA 1 and to a much lesser extent PLA 2 and then LPC is further cleaved by LPLD into LPA. It is well established that fatty acids esterified to the $s n-2$ position are unstable and undergo acyl migration in minutes to yield a more stable $s n-1$ regioisomer (Pluckthun and Dennis, 1982; Sano et al., 2002). Thus, we predict that the arachidonoyl- and linoleoyl-LPA are first derived as a $s n-2$ regioisomers from the corresponding lysophospholipids and then rapidly undergo acyl migration to yield the $s n$ 1 isomers that are stable and have been detected in serum. 


\subsection{LPA DEGRADATION}

\subsubsection{LPA Degradation by Phosphatases}

Lysophospholipids are dephosphorylated by the lipid phosphate phosphohydrolase family (LPP) (Brindley and Waggoner, 1998). There are four known isoforms that have been cloned and characterized in mammals, LPP1/PAP-2a/PAP2 $\alpha 1$ (Kai et al., 1997), LPP1a/PAP-2 $\alpha 2$ (Leung et al., 1998), LPP2/PAP-2c/PAP-2 $\gamma$ (Roberts et al., 1998), and LPP3/PAP-2b/PAP-2 $\beta$ (Kai et al., 1997). Each member of the LPP family exhibits selectivity for various phospholipid substrates. The LPP1 family prefers LPA as a substrate followed by PA, sphingosine 1-phosphate (S1P), and ceramide 1-phosphate (C1P) (Waggoner et al., 1996). LPP2/PAP-2c/PAP- $2_{\gamma}$ prefers PA, then C1P, LPA, and S1P (Roberts et al., 1998). Lastly, LPP3/PAP-2b/PAP-2 $\beta$ converts PA and LPA with the same efficiency and to a much lesser extent will convert S1P and C1P. LPA degradation occurs by the removal of the phosphate group by phosphatases to yield monoacylglycerol. LPA is also degraded by a nuclear LPA phosphohydrolase which is yet unidentified (Baker and Chang, 2000).

\subsubsection{LPA Degradation by Lysophospholipases}

LPA can also be degraded by the hydrolysis of the acyl group from the glycerol backbone by lysophospholipase enzymes. Whereas many lysophospholipids prefer LPC substrates over LPA, LPA has been reported in rabbit neuronal nuclei to act as a competitive inhibitor of LPC lysophospholipase activity (Baker and Chang, 2000). It has also been reported that LPA is a substrate of a distinct LPA lysophospholipase activity (Baker and Chang, 2000).

A lysophospholipase with LPA lysophospholipase activity has been purified from rat brain (Thompson and Clark, 1994). It is an $80 \mathrm{kDa}$ enzyme and prefers 1-oleoyl and 1stereoyl LPA species followed by 1-palmitoyl and 1-myristoyl LPA. The purified enzyme does not hydrolyze LPE, LPI, or LPS (Thompson and Clark, 1994).

\subsubsection{LPA Degradation by Acyltransferases}

1-acylglycerol 3-phosphate acyltransferase (AGPAT), also known as lysophosphatidic acid acyltransferases (LPAAT) catalyzes the transfer of an acyl group from acyl-CaA to LPA to form PA. Five members of the LPAAT family have been identified: LPAAT $\alpha / 1$-AGPAT 1 (Kume and Shimizu, 1997; Aguado and Campbell, 1998), LPAAT $\beta / 1$-AGPAT 2 (Aguado and Campbell, 1998), LPAAT $\gamma / 1$-AGPAT 3 , LPAAT $\delta / 1-A G P A T$, and LPAATE/1-AGPAT 5. LPAAT $\alpha$ and LPAAT $\beta$ have a much higher catalytic activity than the other family members (Leung, 2001) and therefore contribute most of the LPAAT activity in cells. LPAAT $\alpha$ shows a marked preference for LPA over the other members of the family. LPAAT $\alpha$ is found consistently in most 
tissues, however LPAAT $\beta$ is differentially expressed and elevated in many tumor tissues relating the overproduction of PA to many cancer types.

It is important to note that LPAAT esterifies the $s n-2$ position of LPA to produce PA using acyl-CoAs as substrates and has been shown to prefer arachidonloyl (20:4)CoA (Yuki et al., 2009; Koeberle et al., 2010). This generates unsaturated fatty acids in the $s n-2$ position of PA, which can then receive a choline or serine headgroup and become a prime substrate for a PLA $_{1 / 2}$ enzyme.

\subsection{LPA RECEPTOR AND SIGNALING}

\subsubsection{Plasma Membrane Receptors}

LPA is a phospholipid mediator that acts through multiple targets that include $\mathrm{G}$ protein-coupled receptors (GPCRs) and a nuclear receptor, peroxisome proliferatoractivated receptor gamma (PPARgamma) as well as enzymes. To date there are eight known LPA-specific receptors (LPA $1-8)$. $\mathrm{LPA}_{1-3}$ are members of the endothelial differentiation gene (EDG) family (Tigyi and Parrill, 2003; Choi et al., 2008; Mutoh and Chun, 2008; Rivera and Chun, 2008; Ishii et al., 2009; Noguchi et al., 2009; Peyruchaud, 2009; Tigyi, 2010). These three members share $45-56 \%$ overall amino acid identity. The transmembrane domains of the human LPA EDG family receptors share $81 \%$ homology with one another, however only $6 \%$ is conserved within the $\mathrm{C}$-terminal tail. There are also five S1P-specific receptors that are included in this gene cluster of GPCRs: S1P $\mathrm{S}_{1} \mathrm{P}_{2}, \mathrm{~S}_{1} \mathrm{P}_{3}, \mathrm{~S}_{1} \mathrm{P}_{4}$, and $\mathrm{S}_{1} \mathrm{P}_{5}$.

$\mathrm{LPA}_{1} / \mathrm{EDG} 2 \mathrm{mRNA}$ is highly abundant in brain tissue, and to a lesser extent in heart tissue, the gastrointestinal tract, and the reproductive system (An et al., 1997; Tigyi, 2010). It has also been found in the rabbit cornea (Wang et al., 2002). LPA 1 /EDG2 elicits its actions through the activation of heterotrimeric $\mathrm{G}$ proteins which results in the inhibition of adenylyl cyclase (Hecht et al., 1996), DNA synthesis, $\mathrm{Ca}^{2+}$ signaling, phospholipase C activation (An et al., 1998), activation of the serum response element (Contos and Chun, 1998), and stimulation of Rho signaling (Fukushima et al., 1998).

$\mathrm{LPA}_{2}$ is found primarily in testis and leukocytes (An et al., 1998; Tigyi, 2010). It is also found in embryonic and neonatal mouse brain tissue. It elicits its actions through $\mathrm{G}$ protein pathways that mediate intracellular $\mathrm{Ca}^{2+}$ mobilization, which activates MAP kinase and serum response element (An et al., 1998; Bandoh et al., 1999).

$\mathrm{LPA}_{3}$ mRNA is mainly expressed in the human heart, prostate, testis, pancreas (Bandoh et al., 1999; Im et al., 2000), rat kidney and testis (Im et al., 2000), and rabbit cornea (Wang et al., 2002). $\mathrm{LPA}_{3}$ is similar to $\mathrm{LPA}_{2}$ in that it activates the MAP kinase pathway however; in addition, it also stimulates adenylyl cylclase (Bandoh et al., 1999). 
$\mathrm{LPA}_{4} / \mathrm{p} 2 \mathrm{y} 9 / \mathrm{GPR} 23$ (Noguchi et al., 2003; Yanagida et al., 2007), LPA 5 /GPR92 (Kotarsky et al., 2006; Lee et al., 2006; Williams et al., 2009; Yin et al., 2009), $\mathrm{LPA}_{6} / \mathrm{GPR} 87$ (Tabata et al., 2007), LPA $/ \mathrm{p} 2 \mathrm{y} 5$ (Pasternack et al., 2008; Shimomura et al., 2008), and $\mathrm{LPA}_{8} / \mathrm{p} 2 \mathrm{y} 10$ (Murakami et al., 2008) are more closely related to the purinoreceptor cluster of GPCR and only share about $20 \%$ homology with the LPA EDG family receptors.

$\mathrm{LPA}_{4} / \mathrm{p} 2 \mathrm{y} 9 / \mathrm{GPR} 23$ is found primarily in the ovary, uterus, and placenta (Ishii et $a l ., 2009)$. It has also been found in the brain and been shown to cause LPA-dependent growth cone collapse and neurite retraction through $\mathrm{G}_{12 / 13}$-RhoA-Rho-associated kinase (ROCK) activation (Lee et al., 2007). The ligand preference of $\mathrm{LPA}_{4} / \mathrm{p} 2 \mathrm{y} 9 / \mathrm{GPR} 23$ is LPA 18:1 $>18: 0>16: 0>14: 0>1-\mathrm{O}$-alkyl glycerophosphate $>1$-O-alkenyl glycerophosphate (Noguchi et al., 2003).

$\mathrm{LPA}_{5} / \mathrm{GPR} 92$ is found in the heart, placenta, dorsal root ganglia, small intestine, spleen, brain, B cells, intestinal CD8 ${ }^{+}$lymphocytes, and platelets (Kotarsky et al., 2006). The ligand preference of $\mathrm{LPA}_{5} / \mathrm{GPR} 92$ is 1-O-alkyl glycerophosphate 18:1 1-1-O-alkyl glycerophosphate 18:0 $>$ LPA 18:1>20:4=16:0=18:3>farnesyl monophosphate $>$ farnesyl diphosphate>LPA 18:0 (Noguchi et al., 2003).

$\mathrm{LPA}_{6} / \mathrm{GPR} 87$ is typically found in brain, skeletal muscle, and the reproductive organs. $\mathrm{LPA}_{7} / \mathrm{p} 2 \mathrm{y} 5$ is found in the skin and hair. Its ligand preference is LPA 18:2>18:1>20:4>18:0>16:0>14:0 (Yanagida et al., 2009). $\mathrm{LPA}_{8} / \mathrm{p} 2 \mathrm{y} 10$ has been found in the uterus, prostate, brain, lung, placenta, and skeletal muscle (Murakami et al., 2008).

The various species of LPA allows for the activation of specific LPA targets. In addition to the different species, the $\mathrm{LPA}_{3}$ and P2RY5 receptors have shown a slight preference for the $s n-2$ regioisomer over the $s n-1$ (Bandoh et al., 2000a; Yanagida et al., 2009). However, the stability of the $s n-2$ regioisomer is still uncertain.

\subsubsection{Intracellular Receptor, PPAR $\gamma$}

PPAR $\gamma$ is crucial for many biological responses. It is an active component of regulating lipid and glucose homeostasis (Evans, 2005), cell proliferation (Mueller et al., 1998), apoptosis (Elstner et al., 1998), and inflammation (Ricote and Glass, 2007; Tigyi, 2010). Due to these responses it plays a critical role in many diseases such as diabetes (Lehmann et al., 1995), atherosclerosis (Li et al., 2000), and cancer (Sarraf et al., 1998). PPAR $\gamma$ has been shown to only be activated by unsaturated LPA species and the Sstereoisomer. 


\subsection{ROLES OF LPA}

\subsubsection{LPA in Vascular Biology}

LPA plays an important role in angiogenesis (Osborne and Stainier, 2003) arteriosclerosis, inflammation, thrombosis, and is present in atherosclerotic lesions (Siess and Tigyi, 2004). Atherosclerosis is the primary cause of heart disease and stroke underlying about $50 \%$ of deaths in developed countries (Libby, 2002; Steinberg, 2002; Zhang et al.; 2004). LPA has been identified as a biologically active lipid in mildlyoxidized LDL (mox-LDL), human atherosclerotic plaques, and supernatant of activated platelets (Libby, 2002; Sano et al., 2002; Zhang et al., 2004). It is also known that serum LPA level is significantly elevated in patients with acute myocardial infarction. More importantly, mox-LDL and the lipid-rich core of human atherosclerotic plaques have been shown to stimulate platelets through the activation of LPA receptors. Atherosclerosis begins with neointima formation via the proliferation and migration of vascular smooth muscle cells (VSMC) from the media to the intima. This results in accumulation of lipids in the arterial intima, activation of macrophages, dedifferentiation of vascular smooth muscle cells and endothelial injury (Libby, 2002). LPA has been shown to elicit neointima formation when applied topically to the arterial wall (Zhang et al., 2004).

\subsubsection{The Role of LPA in Cancer}

LPA provides cell survival advantages in an autocrine or paracrine fashion. ATX has been found in many cancer cell types which provides a mechanism for generation of LPA. One well established instance in which LPA has a role in cancer pathology is ovarian cancer. Reports have shown that LPA levels in ovarian cancer ascites are highly elevated (Xu et al., 1995; Baker et al., 2002; Sutphen et al., 2004) presumably due to an increase in ATX expression (Xu et al., 1998; Dimova et al., 2006).

Expression of $\mathrm{LPA}_{2}$ mRNA was also shown to be upregulated in ovarian cancer cells (Goetzl et al., 1999a) providing evidence of its involvement in ovarian cancer. $\mathrm{LPA}_{2}$ supports the aggressiveness of ovarian cancer in two different ways. First, it provides a feed-forward loop by increasing the production of vascular endothelial growth factor (VEGF), urokinase (uPA), and matrix metalloproteinases (MMP) (Zebrowski et al., 1999; Hu et al., 2001; Huang et al., 2004; So et al., 2004; So et al., 2005) which in turn upregulates ATX production and results in increased LPA levels (Ptaszynska et al., 2008). Secondly, the $\mathrm{LPA}_{2}$ receptor mediates chemoresistance through its $\mathrm{C}$-terminal interaction of the thyroid receptor-interacting protein 6 (TRIP 6), Siva-1, and PDZ binding proteins: NHERF2 and MAGI-3 (Yamada et al., 2005; Lin et al., 2007; Zhang et al., 2007a; Zhang et al., 2007b; E et al., 2009). These findings provide a basis for the importance of discovering receptor antagonists and ATX inhibitors for potential anticancer therapeutics. 


\subsubsection{LPA in Cell Survival and Apoptosis}

Through its pro-mitotic and anti-apoptotic properties, LPA promotes cell survival. LPA inhibits the activation of the mitochondrial apoptotic pathway which is further linked to the activation of the ERK1/2 and Akt kinases (Goetzl et al., 1999b; Deng et al., 2003; Radeff-Huang et al., 2004).

Because of its anti-apoptotic properties, LPA has been studied in a clinical role. LPA can be used to reduce the side effects of radiation and chemotherapy in nonintestinal cancer patients because it reduces the damage to the intestinal epithelial cells induced by gamma radiation and chemical agents that cause apoptosis (Deng et al., 2002).

\subsection{PHOSPHOLIPASES AND LYSOPHOSPHOLIPASES}

\subsubsection{Phospholipases}

Phosphatidic acid contains two fatty acid chains and a phosphate esterified to a glycerol backbone. The hydroxyl group at the $\mathrm{C} 3$ position of the glycerol is esterified to phosphoric acid and is termed the $s n-3$ position. All major phosphoglycerides are derived from phosphatidate. An ester bond is formed between the phosphate group of phosphatidate and the hydroxyl group of an alcohol such as serine or choline. Phospholipases cleave phospholipids to yield lysophospholipids. Phospholipase $\mathrm{A}_{1}$ $\left(\mathrm{PLA}_{1}\right)$ cleaves at the $s n-1$ position whereas phospholipase $\mathrm{A}_{2}\left(\mathrm{PLA}_{2}\right)$ cleaves at the $s n-2$ position. A phospholipase B (PLB) enzyme will cleave at both the $s n-1$ and $s n-2$ position and Phospholipase C (PLC) and phospholipase D (PLD) cleave on either side of the phosphate group. The specificities of the phospholipases are shown in Figure 1.2.

Phospholipases are typically serine hydrolases, which are important in blood coagulation, inflammation, and angiogenesis (Liu et al., 1999). Most serine hydrolases are potently inhibited by fluorophosphonates (FP) or fluorophosphonate derivatives. However fluorophosphonates do not inhibit cysteine, aspartyl, or metalloproteases (Liu et al., 1999). FP's reactivity requires that the serine hydrolase be in a catalytically active state (Leung et al., 2003). This allows for much greater selectivity. Radiolabeled, rhodamine-labeled, or biotin-labeled fluorophosphonate probes are available (Patricelli et al., 1999). The rhodamine and biotin-labeled probes are rapid, selective and highly sensitive. These probes have the fluorescent reactive group and the biotin tag coupled through a long alkyl chain and two amide bonds (Liu et al., 1999).

FP- Rhodamine labeled probes can be used to label all active serine hydrolases within a compound sample. Typical SDS gel electorphoresis can be used to separate proteins and the fluorescent label can then be visualized using a flat-bed Infra-red scanner. The biotinylated probes can be bound to avidin or streptavidin and separated 


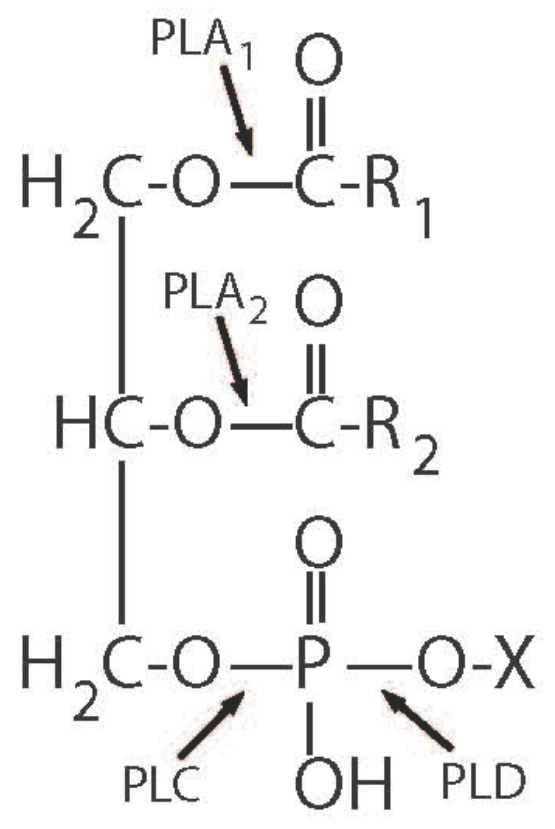

Figure 1.2 Specificity of phospholipases. Arrows indicate cleavage site of the indicated phospholipase. 
from all other proteins. The biotinylated probe-bound serine hydrolase can then be digested or boiled off the avidin beads and then this highly purified product can be analyzed using LC-MS or gel electrophoresis.

\subsubsection{Phospholipase $\mathrm{A}_{1}$}

$\mathrm{PLA}_{1}$ catalyzes the cleavage of a glycerophospholipid at the $s n-1$ position generating a sn-2 lysophospholipid and a fatty acid. Whereas many PLA 2 isoforms have been purified, cloned, and characterized, little is known of PLA $\mathrm{P}_{1}$. A similar PLA $\mathrm{P}_{1}$ to the one we are studying has been described to some degree by Smith and Silver (Smith et al., 1973). It has an acidic $\mathrm{pH}$ optimum of 4.8 , but has not been biochemically identified and cloned.

To date, there are two phosphatidic acid-selective cytosolic PLA $\mathrm{A}_{1} \mathrm{~s}$ named mPAPLA $_{1} \alpha$ and $\mathrm{mPA}-\mathrm{PLA}_{1} \beta$ which are specifically expressed in human testis (Verheij et al., 1981). It was shown that mPA-PLA $1 \alpha$ and mPA-PLA $\beta$ hydrolyzed the ester bond at the sn-1 position of phosphatidic acid to generate LPA, but did not hydrolyze the ester bond of PC, PS, or PE (Verheij et al., 1981; Aoki, 2004).

Another known type of PLA $_{1}$ is phosphatidylserine-specific PLA (PS-PLA $_{1}$ ). PS$\mathrm{PLA}_{1}$ is secreted from rat platelets, but is not found in mouse or human platelets (Aoki et al., 2002a; Smart et al., 2004). PS-PLA 1 hydrolyzes PS, but does not hydrolyze PC, PE, PI, or PA. PS-PLA 1 is approximately $55 \mathrm{kDa}$, stored intracellularly, and is secreted when the cells are activated by thrombin, collagen, or calcium ionophore A23187 (Smart et al., 2004). This suggests that under physiological conditions PS-PLA 1 is secreted during rat blood coagulation.

\subsubsection{Phospholipase $A_{2}$}

Many forms of mammalian $\mathrm{PLA}_{2} \mathrm{~s}$ have been identified. These include group IVA $\mathrm{Ca}^{2+}$-dependent cytosolic PLA $2\left(\mathrm{cPLA}_{2}\right)$ (Leslie, 1997), group $\mathrm{VI} \mathrm{Ca}^{2+}$-independent PLA 2 $\left(\mathrm{iPLA}_{2}\right)\left(\right.$ Balsinde and Dennis, 1997), and secretory PLA $2\left(\mathrm{sPLA}_{2}\right)($ Valentin and Lambeau, 2000).

Group IVA $\mathrm{Ca}^{2+}$-dependent cytosolic $\mathrm{PLA}_{2}\left(\mathrm{cPLA}_{2}\right)$ are $85 \mathrm{kDa}$ and are typically located in the cytosol and translocated to the nuclear envelope and endoplasmic reticulum upon activation (Schievella et al., 1995; Pouliot et al., 1996). $\mathrm{cPLA}_{2} \mathrm{~s}$ have been shown to play an important role in the arachidonic acid release, eicosanoid production and signal transduction (Clark et al., 1995; Kramer and Sharp, 1997; Leslie, 1997).

Group VI Ca ${ }^{2+}$-independent $\mathrm{PLA}_{2}\left(\mathrm{iPLA}_{2}\right)$ are also $85 \mathrm{kDa}$ and have been shown to play a key role in apoptosis and mediating basal phospholipid remodeling (Balsinde and Dennis, 1996; Atsumi et al., 1998). It has been reported that this enzyme works as a 
multimeric complex of 270-350kDa through protein-protein interactions mediated by ankyrin repeats (Ackermann et al., 1994; Larsson et al., 1998).

Secretory $\mathrm{PLA}_{2}$ s have a molecular weight of 14-19kDa (Murakami and Kudo, 2004) and hydrolyze the ester bond at the $s n-2$ position of phosphoglycerides releasing fatty acids and lysophospholipids. To date, ten secretory phospholipase $\mathrm{A}_{2} \mathrm{~S}\left(\mathrm{sPLA}_{2} \mathrm{~s}\right)$ have been identified in mammals (IB, IIA, IIC, IID, IIE, IIF, III, V, X, and XIIA) (Schaloske and Dennis, 2006). Humans possess all except IIC (Murakami and Kudo, 2004). The mammalian family of $\mathrm{SPLA}_{2} \mathrm{~S}$ are $\mathrm{Ca}^{2+}$ dependent. There are many known inhibitors of $\mathrm{sPLA}_{2} \mathrm{~S}$ including Me-Indoxam which is the most potent inhibitor for most sPLA $_{2}$ s (Bacha et al., 2006).

\subsubsection{Lysophospholipase D}

Plasma lysoPLD cleaves lysophospholipids to produce LPA and was recently identified as autotaxin (ATX) (Tokumura et al., 2002; Umezu-Goto et al., 2002), a $125 \mathrm{kDa}$ glycoprotein. ATX has been shown to promote tumor cell motility, metastasis, and angiogenesis via a pertussis toxin-sensitive mechanism (Stracke et al., 1997; Nam et al., 2001; Lee et al., 2002). LPLD/ATX is a member of the nucleotide pyrophosphatase/phosphodiesterase (NPP) family and is also known as NPP2. NPP family-members are capable of hydrolyzing adenosine triphosphate (ATP) and adenosine diphosphate (ADP) in order to generate nucleoside 5'-monophosphates which distinguishes them from other members of the lipase superfamily.

ATX contains a short N-terminal tail, a transmembrane domain, two cysteine-rich somatomedin B-like domains, and a C-terminal catalytic domain. ATX mRNA is widely expressed in the brain, ovary, lung, intestine, and kidney (Tice et al., 2002; Mills and Moolenaar, 2003). ATX shows product feedback inhibition which is thought to contribute to maintaining plasma levels of LPA in the nanomolar range (Durgam et al., 2005; van Meeteren et al., 2005).

ATX has long been known as a tumor-motility factor which provides a link between ATX and cancer. ATX has numerously been shown to be upregulated in several human cancers and has been shown to enhance tumor aggressiveness (Nam et al., 2000) perhaps through the generation of LPA.

\subsubsection{Lysophospholipase A-I /II}

As mentioned previously, lysophospholipases contribute to the breakdown of LPLs by hydrolyzing the ester bond to produce a free fatty acid and a glycerolphosphate derivative. There are large molecular mass Lysophospholipase As (LYPLAs) and small molecular mass LYPLAs. Low molecular mass LYPLAs have been reported to be found in rabbit heart (Gross and Sobel, 1983), pig gastric mucosa (Sunaga et al., 1995), murine macrophage $\mathrm{P}_{388 D_{1}}$ (Zhang and Dennis, 1988; Zhang et al., 1991), rat and beef liver (de 
Jong et al., 1974; Sugimoto et al., 1996), and human HL60 cells (Garsetti et al., 1992). Many of these tissues contain two isoforms: LYPLA-I and LYPLA-II which are similar in size and have similar properties. For example, both enzymatic activities are independent of $\mathrm{Ca}^{2+}, \mathrm{Mg}^{2+}$, and EDTA (Zhang et al., 1991; Garsetti et al., 1992; Sunaga et al., 1995; Sugimoto et al., 1996). Despite their similarities, much evidence has been reported to recommend that these enzymes are two distinct proteins. For example, LYPLA-I has a much broader LPL substrate specificity than its LYPLA-II counterpart. LYPLA-I has been shown to actively cleave LPC, LPE, LPG, LPI, LPS, and the acyl analog of PAF, whereas LYPLA-II will only cleave LPE and LPC (Garsetti et al., 1992; Sunaga et al., 1995; Sugimoto et al., 1996). LYPLA-I hydrolyzes both $s n-1$ and $s n-2$ regioisomers of LPC at identical rates (Wang et al., 1997).

Neither enzyme has been shown to have significant PLA or PLA $_{2}$ activity in rabbit heart, pig gastric mucosa, murine machrophage $\mathrm{P} 388 \mathrm{D}_{1}$, or human HL60 cells (Gross and Sobel, 1983; Zhang and Dennis, 1988; Zhang et al., 1991; Garsetti et al. 1992; Sunaga et al., 1995). However, these enzymes were only extensively characterized using lysophospholipids substrates and human platelets have not been tested previously for activity.

It is not uncommon for many phospholipases to show lysophospholipase activity and all are typically grouped into the large molecular mass LYPLAs. Group IV $\mathrm{Ca}^{2+}-$ dependent cytosolic PLA 2 exhibits strong lysophospholipase activity for $s n-1$ LPC but shows little activity when presented with sn-2 LPC (Loo et al., 1997). Cytosolic $\mathrm{Ca}^{2+}-$ independent phospholipase $\mathrm{A}_{2}\left(\mathrm{iPLA}_{2}\right.$ ) also exhibits lysophospholipase activity along with PLA $_{1}$, transacylase, and PAF acetylhydrolase activity which has been shown to be dependent on substrate presentation (Wolf and Gross, 1996; Lio and Dennis, 1998). PSPLA $_{1}$ (Higashi et al., 1988; Yokoyama et al., 1995; Sato et al., 1997) and PA-PLA 1 (Higgs and Glomset, 1996) also exhibit lysophospholipase activity as well as phospholipase activity.

Another function of LYPLA-I/APT1 is the deacylation/depalmitoylation of G proteins, ghrelin, and other thioacylated protein substrates (Duncan and Gilman, 1998; 2002; Hirano et al., 2009; Satou et al., 2010). The $\mathrm{K}_{\mathrm{m}}$ of the lysophospholipase activity is about 8 times higher than the $\mathrm{K}_{\mathrm{m}}$ value of the thioesterase activity of the enzyme (Hirano et al., 2009) indicating that LYPLA-I/APT1 has a much higher thioesterase activity than lysophospholipase activity. However, the subcellular localization of the enzyme plays an important role in the function of the enzyme. 


\section{CHAPTER 2. THE PHOSPHOLIPASE A ACTIVITY OF LYSOPHOSPHOLIPASE A-I LINKS PLATELET ACTIVATION TO LPA PRODUCTION DURING BLOOD COAGULATION*}

\subsection{INTRODUCTION}

Lysophosphatidic acid (LPA) is a multifunctional phospholipid mediator and second messenger responsible for a wide variety of cellular responses (Pages et al., 2001; Mills and Moolenaar, 2003; Tigyi and Parrill, 2003; Tigyi, 2010). LPA elicits its actions through cell surface G protein-coupled receptors (Pages et al., 2001; Mills and Moolenaar, 2003; Tigyi and Parrill, 2003; Tigyi, 2010) and through the nuclear peroxisome proliferator activating receptor $\gamma$ (PPAR $\gamma$,Tsukahara et al.). LPA has been shown to play a role in many physiological functions and human diseases (Pages et al., 2001; Mills and Moolenaar, 2003; Tigyi and Parrill, 2003; Tigyi, 2010). The biochemical pathways involved in LPA production in biological fluids are not yet fully understood.

LPA can be produced by several intra- and extracellular biochemical pathways. Intracellularly, LPA is synthesized by a glycerophosphate acyl transferase-catalyzed reaction of glycerol-3-phosphate with acyl-CoA in the endoplasmic reticulum and mitochondria (Aoki, 2004; Gendaszewska-Darmach, 2008). LPA has also been shown to be generated in a spatially regulated fashion by the $\mathrm{Ca}^{2+}$-independent phospholipase $\mathrm{A}_{2}$ at the leading edge of migrating monocytes (Carnevale and Cathcart, 2001; Mishra et al., 2008). Third, acylglycerol kinase phosphorylates monoacylglycerol to form LPA (Bektas et al., 2005). A fourth pathway in humans, involves phosphatidylserine (PS)-specific phospholipase $\mathrm{A}_{1}$ (PS-PLA1) that generates lysophosphatidylserine (LPS), which in turn is converted to LPA by phospholipase D in mast cells (Nagai et al., 1999; Aoki et al., 2002a).

Extracellularly, LPA can be produced by a secretory phospholipase $\mathrm{A}_{2}\left(\mathrm{PLA}_{2}\right)$ (Fourcade et al., 1995), oxidative modification of low density lipoprotein (Siess et al., 1999), or by the action of phosphatidic acid-specific phospholipase $A_{1}$ (Aoki et al., 2002a; Cummings et al., 2002). However, the most important pathway is a multi-step process linked to the activation of platelets (Mauco et al., 1978; Schumacher et al., 1979; Eichholtz et al., 1993; Gaits et al., 1997; Sano et al., 2002; Aoki et al., 2008). This mechanism involves release of unidentified PLA 1 and/or PLA $\mathrm{PL}_{2}$ enzymes from activated platelets generating a new pool of lysophospholipid (LPL) substrates, which in turn are

* Adapted by permission: Alyssa L. Bolen, Anjaparavanda P. Naren, Sunitha Yarlagadda, Sarka Beranova-Giorgianni, Li Chen, Derek Norman, Daniel L. Baker, Meng M. Rowland, Michael D. Best, Takamitsu Sano, Tamotsu Tsukahara, Karoly Liliom, Yasuyuki Igarashi, Gabor Tigyi. The Phospholipase $A_{1}$ Activity of Lysophospholipase A-I Links Platelet Activation to LPA Production During Blood Coagulation. Journal of Lipid Research 2011, March 9. [Epub ahead of print]. 
cleaved by the lysophospholipase D, autotaxin (ATX) (Tokumura et al., 2002; UmezuGoto et al., 2002). As a result of this mechanism, plasma LPA concentration rises from a steady state concentration of approximately $100 \mathrm{nM}$ to serum concentrations up to $10 \mu \mathrm{M}$, with a significant increase in the content of polyunsaturated acyl species (Baker et al., 2001; Sano et al., 2002; Hosogaya et al., 2008). The role of ATX in LPA production has been clearly demonstrated by the decreased plasma LPA level in ATX knockout mice (Tanaka et al., 2006; van Meeteren et al., 2006).

The rank order of the acyl species of LPA in normal human plasma is 18:2 $>18: 1$ $>18: 0>16: 0>20: 4$. In contrast, the rank order of the LPA acyl species in serum changes to 20:4 $>18: 2>16: 0>18: 1>18: 0$ (Sano et al., 2002). The various acyl species of LPA also have differing ligand properties at target LPA GPCR (Fujiwara et al., 2005). In addition to the differences in carbon chain length and degree of unsaturation, the $\mathrm{LPA}_{3}$ and P2RY5(LPA $)$ receptors also show a preference for the $s n-2$ over the $s n-1$ acyl regioisomer of LPA (Bandoh et al., 2000b, Yanagida et al., 2009). However, the $s n-2$ LPA regioisomer is relatively unstable. At neutral $\mathrm{pH}$ acyl migration begins immediately to yield the more thermodynamically stable $s n-1$ regioisomer, an equilibrium ratio of 9:1 occurs between the two forms (Pluckthun and Dennis, 1982).

The linoleoyl- (18:2) and arachidonoyl (20:4) species make up 84\% of the LPA found in serum (Sano et al., 2002). The mechanism behind the enrichment and increase in polyunsaturated LPA species upon blood coagulation is still unknown. Because plasma phospholipids containing 18:2 and 20:4 fatty acids are almost exclusively esterified to the $s n-2$ glycerol carbon, we hypothesized that LPA in serum enriched in these fatty acyl species must be generated by the action of a PLA 1 enzyme (Sano et al., 2002). This hypothesis implies that the nascent $s n-2$ LPL generated by PLA 1 will either be rapidly cleaved by ATX and then undergo acyl migration or alternatively, undergo acyl migration prior to headgroup cleavage. Distinguishing between the latter two possibilities is challenging due to the short half-life of the $s n$-2 LPLs that precludes the use of classical biochemical separation and analytical techniques.

In the present study, we sought to identify the putative PLA $A_{1}$ enzymes released from activated platelets that are responsible for the generation of polyunsaturated LPL. Starting with the supernatants from thrombin-activated human platelets, we isolated lysophospholipase A1/acyl protein thioesterase (LYPLA-I/APT1) using a series of chromatographic steps and fluorophosphonate-biotin affinity labeling-based proteomics. LYPLA-I/APT1 transcripts were subsequently shown to be abundantly expressed in platelets and in megakaryocytes. LYPLA-I/APT1 was found to posses PLA 1 activity against plasma phospholipids, did not degrade LPA, and increased LPA production when added to plasma through the production of a pool of LPL, which is further cleaved by ATX. 


\subsection{MATERIALS AND METHODS}

\subsubsection{Materials}

Fluorescently labeled 1-oleoyl-2-\{12-[(7-nitro-2-1,3-benzoxadiazol-4yl)amino]lauroyl\}-sn-glycero-3-phosphoserine (NBD-PS 18:1-12:0), 1-oleoyl-2-[12-[(7nitro-2-1,3-benzoxadiazol-4-yl)amino]lauroyl]-sn-glycero-3-phosphocholine (NBD-PC 18:1-12:0), dioleoyl phosphatidylserine (PS), linolenoyl phosphatidylcholine (PC), oleoyl lysophosphatidic acid (LPA), LPC 17:0, and LPA 17:0 were purchased from Avanti Polar Lipids, Inc. (Alabaster, AL). 1-Oleyl-sn-glycero-3-phosphocholine (LPAF 18:1) was purchased from Bachem (Torrance, CA). Fluorophosphonate-Rhodamine (FP$\mathrm{RH}$ ) and fluorophosphonate-biotin (FP-Biotin) were a gift from Dr. Ben Cravatt (Scripps Institute, La Jolla CA). Freshly expired apheresis platelets were provided by The Regional Medical Center (Memphis, TN), Methodist University Hospital (Memphis, $\mathrm{TN}$ ), or purchased from Key Biologics, Inc. (Memphis, TN). PGE 1 and thrombin were obtained from Sigma-Aldrich (St. Louis, MO). Trizol and Superscript III OneStep RTPCR was purchased from Invitrogen (Carlsbad, CA).

\subsubsection{Isolation and Activation of Human Platelets}

The procedures detailed below were reviewed and approved by the Institutional Review Board of the University of Tennessee Health Science Center. Small-scale batches of platelet rich plasma (PRP) were prepared by adding $3.6 \mathrm{~mL}$ acidic citrate dextrose (ACD, $0.8 \%$ citric acid, $2.2 \%$ sodium-citrate, $2.45 \%$ glucose) to $20 \mathrm{~mL}$ of cubital venous blood drawn from a volunteer donor and centrifuged at $180 \mathrm{x} g$ for $15 \mathrm{~min}$. The top layer of platelet rich plasma $(\sim 10 \mathrm{~mL})$ was transferred to a new tube. For large scale purifications, units of freshly expired apheresis platelets in ACD were obtained (approximately $60 \mathrm{~mL}$ per unit). Then $10 \mathrm{~mL}$ of the PRP from the small scale purification or $10 \mathrm{~mL}$ of the aphersis platelets were diluted with $34 \mathrm{~mL}$ Buffer A $(138 \mathrm{mM} \mathrm{NaCl}$, 3.3mM NaH2PO4, 2.9mM KCl, $1 \mathrm{mM} \mathrm{MgCl2,} \mathrm{20mM} \mathrm{HEPES,} 1 \mathrm{mg} / \mathrm{mL}$ glucose, $\mathrm{pH}$ 7.5), and $1 \mu \mathrm{M} \mathrm{PGE}_{1}$ was added. The diluted PRP was centrifuged at $1400 \mathrm{x} \mathrm{g}$ at room temperature for $15 \mathrm{~min}$. The supernatant was discarded and the pellet containing the platelets was reconstituted in $2 \mathrm{~mL}$ buffer $\mathrm{A}$ and $2 \mathrm{mM} \mathrm{Ca}^{2+}$ was added. The platelets were activated using $1 \mathrm{U}$ thrombin per $1 \mathrm{~mL}$ sample at $37^{\circ} \mathrm{C}$ for $20 \mathrm{~min}$ and the aggregate formed was centrifuged at 9,300 $\mathrm{x}$ g for $5 \mathrm{~min}$ to yield supernatant 1 (Sup1). The Sup1 was then centrifuged again at $100,000 \mathrm{x} \mathrm{g}$ for $45 \mathrm{~min}$ to remove platelet microvesicles. This preparation was designated as supernatant 2 (Sup2).

\subsubsection{Measurement of Phospholipase $A_{1}$ Activity}

$\mathrm{PLA}_{1}$ activity was measured by determining the amount of lysophosphatidylcholine (LPC) or lysophosphatidylserine (LPS) generated after incubation of sample with phosphatidyl choline (PC) or phosphatidyl serine (PS). NBD- 
PC or NBD-PS (45ng to $2 \mu \mathrm{g}$ ) was incubated in $10 \mathrm{mM}$ Tris ( $\mathrm{pH} 7.5)$ or Sup2 (pH 7.5) at $37^{\circ} \mathrm{C}$ for $1 \mathrm{~min}$ to 1 hour with or without the presence of an equal weight of BSA in water. For quantification, $900 \mathrm{ng}, 90 \mathrm{ng}$, and $9 \mathrm{ng}$ of the fluorescent substrates were incubated without enzyme for construction of a standard curve by plotting fluorescence intensity as a function of substrate mass. Water-saturated butanol $(\mathrm{BuOH})$ was added $(30-120 \mu \mathrm{l})$ to stop the reaction and extract the lipids. Samples $(10 \mu 1)$ were spotted on Silica Gel 60 thin layer chromatography (TLC) plates. The plates were then developed with solvent A consisting of chloroform:methanol:ammonium hydroxide (V/V/V, 6:4:1) for NBD-PS and solvent $\mathrm{B}$ consisting of chloroform:methanol:28\% ammonium hydroxide:water (V/V/V/V, 50:40:8:2) for NBD-PC. The products were visualized using a Fotodyne imager (Hartland, WI) and quantified by the TotalLab100 software. The amount of the product generated was determined by interpolation from the standard curve. The Rf values for the various lipids were as follows: NBD-PC: 0.54, NBD-LPC: 0.38, NBD-FA: 0.77, NBD-PS: 0.45, NBD-LPS: 0.33, NBD-FA: 0.67 .

For unlabeled substrates, $10 \mu \mathrm{g}$ PC, PS, or LPA was digested at $37^{\circ} \mathrm{C}$ for 1 hour in the presence of 10 $\mu \mathrm{g}$ BSA. LPC 17:0 and LPA 17:0 (500-2000 ng in DMSO) internal standards were added prior to addition of $60 \mu \mathrm{BuOH}$. The samples were vortexed for $1 \mathrm{~min}$ and the $\mathrm{BuOH}$ phase was isolated by centrifugation at $14000 \mathrm{x}$ g for $1 \mathrm{~min}$ and dried under argon. The lipid extract was reconstituted in $30 \mu 1$ methanol:acetonitrile:Isopropanol:water (V/V/V/V, 1:1:1:1). LPC and LPA concentrations were determined by liquid chromatography-mass spectrometry (LCMS/MS) using an Applied Biosystems Sciex ABI 4000 QTRAP tandem mass spectrometer (Foster City, CA) equipped with a Turboionspray ${ }^{\mathrm{TM}}$ interface, a Shimadazu LC-10ADvp HLPC pump (Columbia, MD) with a Leap HTS PAL autosampler (Carrboro, NC). Samples $(10 \mu 1)$ were injected onto a Tosoh TSK-ODS-100Z silica column (150 mm x 2mm; 5- $\mu \mathrm{m}$ particle size) with a solvent consisting of methanol/water $(\mathrm{V} / \mathrm{V}, 95: 5), 5 \mathrm{mM}$ ammonium formate using an isocratic flow rate of $0.22 \mathrm{~mL} / \mathrm{min}$ (Tokumura et al., 2009). The spectra were processed using Analyst software, version 1.5. The molecular species of LPC and LPA were analyzed by multiple reaction monitoring (MRM) in positive ion mode for LPC and negative ion mode for LPA. The Q3 (product ion) was set at $\mathrm{m} / \mathrm{z} 184.0$ for LPC and 153.0 for LPA (glycerophosphate moiety) (Tokumura et al., 2009). Q1 was set for the neutral molecular ion for all LPLs. Quantification was done by calculating the ratio of peak area to that of the appropriate LPC/LPA 17:0 internal standard.

\subsubsection{Partial Purification of PLA}

PLA $_{1}$ was partially purified using sequential chromatography on an AKTA FPLC system (GE Biosciences, Piscataway, NJ) by loading 330mg (75mg/ml) Sup2 to a Q Sepharose Fast Flow ion exchange chromatography column (GE Biosciences, $2 \mathrm{~cm}$ x 10 $\mathrm{cm})$. The column was eluted with a $\mathrm{NaCl}$ gradient $(0-1 \mathrm{M})$ at a $1 \mathrm{~mL} / \mathrm{min}$ flow rate over $20 \mathrm{~min}$ with buffer $\mathrm{C}(3.3 \mathrm{mM} \mathrm{NaH} 2 \mathrm{PO} 4,2.9 \mathrm{mM} \mathrm{KCl}, 1 \mathrm{mM} \mathrm{MgCl} 26 \mathrm{H} 2 \mathrm{O}, 20 \mathrm{mM}$ HEPES, $\mathrm{pH} 7.5)$. The $\mathrm{PLA}_{1}$ active fractions were combined and $5 \mathrm{~mL}(\sim 30 \mathrm{mg})$ was loaded onto a Butyl-Sepharose hydrophobic interaction chromatography column (GE 
Biosciences, $0.7 \mathrm{~cm} \times 2.5 \mathrm{~cm}, 20 \mathrm{mg} / \mathrm{mL}$ medium). The column was eluted using a gradient from $1.7 \mathrm{M}$ to $0 \mathrm{M}\left(\mathrm{NH}_{4}\right) \mathrm{SO}_{4}$ over $20 \mathrm{~min}$ in $0.05 \mathrm{M} \mathrm{Na}_{2} \mathrm{HPO}_{4}$ buffer ( $\left.\mathrm{pH} 7.6\right)$. The active fractions were combined and $5 \mathrm{~mL}(\sim 2.5 \mathrm{mg})$ was loaded onto a HiTrap Blue affinity chromatography column (GE Biosciences, $0.7 \mathrm{~cm} \times 2.5 \mathrm{~cm}$ ). The column was eluted by increasing $\left(\mathrm{NH}_{4}\right) \mathrm{SO}_{4}$ from 0 to $1.7 \mathrm{M}$ over $20 \mathrm{~min}$ in $0.05 \mathrm{M} \mathrm{Na}_{2} \mathrm{HPO}_{4}$ buffer $(\mathrm{pH} 7.6)$. $3 \mathrm{~mL}$ Fractions were collected at each step. $100 \mu \mathrm{l}$ of each fraction was used for $\mathrm{PLA}_{1}$ activity measurement using $1 \mu \mathrm{g}$ NBD-PS substrate at $37^{\circ} \mathrm{C}$ for 2 hours. $120 \mu 1$ watersaturated $\mathrm{BuOH}$ was added to stop the reaction and extract the lipids. The samples were vortexed and centrifuged for $1 \mathrm{~min}$ at $14,000 \mathrm{x}$. $10 \mu 1$ of the $\mathrm{BuOH}$ phase was spotted to a Silica Gel 60 TLC plate. The plate was developed with solvent A and the products were visualized. The fractions with PLA $_{1}$ activity from each chromatographic step were combined, activity was determined as described, and protein concentration was determined by BCA protein assay (Pierce, Rockford, IL) following the manufacturer's protocol.

\subsubsection{FP-Rhodamine Labeling}

An amount of $50 \mu \mathrm{g}$ protein of the $\mathrm{PLA}_{1}$ active Butyl-Sepharose pooled fractions $(\sim 100 \mu \mathrm{l})$ and $0.9 \mu \mathrm{g}$ NBD-PS substrate was incubated at $37^{\circ} \mathrm{C}$ for 3 hours with $0.03,0.1$, $0.3,1,3,10$, and $30 \mu \mathrm{M}$ FP-Rh. Then $60 \mu \mathrm{l}$ water-saturated $\mathrm{BuOH}$ was used to stop the reaction and extract the lipid products. After mixing, the samples were centrifuged for $1 \mathrm{~min}$ at $14000 \mathrm{x}$ g. Then $10 \mu \mathrm{l}$ of the $\mathrm{BuOH}$ phase was spotted to a Silica Gel 60 TLC plate and developed with solvent $\mathrm{A}$. The products were visualized using a Photodyne imager and quantified using standards run alongside the samples on the same TLC plate.

\subsubsection{FP-Biotin Labeling and Purification}

The activity-based proteomic probe, FP-Biotin, was used to label all serine

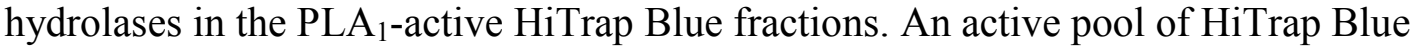
chromatography fractions was concentrated using an Amicon concentrator (Millipore, Billerica, MA) with a $5 \mathrm{kDa}$ molecular weight cutoff. An amount of $1 \mathrm{mg}$ protein $(1 \mathrm{mg} / \mathrm{mL})$ was incubated for 2 hours with a final concentration of $5 \mu \mathrm{M}$ FP-Biotin. Streptavidin beads (Pierce, Rockford, IL) were then pre-washed three-times with binding buffer $(0.1 \mathrm{M}$ sodium phosphate, $0.15 \mathrm{M} \mathrm{NaCl}, \mathrm{pH} 7.0)$ followed by centrifugation $(3000 \mathrm{x}$ $\mathrm{g}$ for $1 \mathrm{~min}$ ) and the supernatant was discarded. The protein complex was added to $50 \mu 1$ resin and incubated with mixing for $1 \mathrm{hr}$ at room temperature. Streptavidin-bound FPBiotinylated proteins were washed with binding buffer in the presence of $4 \mathrm{M}$ urea, $0.1 \%$ SDS (W/V), and $0.2 \%$ TritonX-100 (V/V) (pH 7.2) and centrifuged for $1 \mathrm{~min}$ at $3000 \mathrm{x} \mathrm{g}$. The supernatant was removed and the wash procedure was repeated four times. The beads were reconstituted in $1 \mathrm{~mL} 50 \mathrm{mM}$ TRIS-HCl $(\mathrm{pH} 7.2)$ centrifuged for $4 \mathrm{~min}$ at $10000 \mathrm{x} g$ and the supernatant was decanted. $200 \mu 150 \mathrm{mM}$ TRIS-HCl (pH 7.2) was added to reconstitute the final pellet. 


\subsubsection{Proteomic Analysis of FP-Biotin-Labeled Products in Partially Purified Platelet Supernatants}

The bead-bound FP-Biotin-labeled proteins were first reduced with $5 \mathrm{mM}$ dithiothreitol for 30min at room temperature and alkylated with $10 \mathrm{mM}$ iodoacetamide at room temperature in the dark for 30min. The sample was centrifuged for $4 \mathrm{~min}$ at 10000 $\mathrm{x} \mathrm{rpm}$ and $100 \mu \mathrm{l}$ of supernatant was removed. A total of $300 \mu 150 \mathrm{mM}$ TRIS (pH 7.2) buffer and $1.5 \mu \mathrm{l}$ of $0.5 \mu \mathrm{g} / \mu \mathrm{l}$ trypsin (sequencing grade, Sigma-Aldrich, St. Louis, MO) was added and incubated at $37^{\circ} \mathrm{C}$ for 12 hours. The sample was centrifuged for $4 \mathrm{~min}$ at $10000 \mathrm{x} \mathrm{rpm}$ and the supernatant containing the peptide digest was transferred to a new tube; formic acid was added to a final concentration of $5 \%(\mathrm{~V} / \mathrm{V})$. The volume of the peptide sample was reduced to $40 \mu \mathrm{l}$ in a vacuum centrifuge. The peptides were desalted with a Zip Tip C18 microcolumn (Millipore, Billerica, MA) using the procedure recommended by the manufacturer. Peptides were eluted using $4 \mu 1$ of $50 \%$ acetonitrile $/ 0.1 \%$ trifluoroacetic acid (V/V). Four microliters of water/acetic acid $(0.5 \%)$ were added to the sample. LC-MS/MS experiments were performed on an LTQ linear ion trap mass spectrometer (Thermo Scientific, Waltham, MA) coupled to a nanoflow LC system (Dionex, Sunnyvale, CA). The peptide sample was injected onto a fused-silica capillary column/spray needle (15 cm length, $75 \mu \mathrm{m}$ ID; New Objective, Woburn, MA) packed in-house with C18 stationary phase (Michrom Bioresources, Auburn, CA). The peptides were separated with a 90 min-gradient from $0 \%$ to $90 \%$ of mobile phase $\mathrm{B}$. The composition of mobile phase B was $90 \% \mathrm{MeOH} / 10 \%$ water $/ 0.05 \% \mathrm{HCOOH}$; the composition of mobile phase A was $2 \% \mathrm{MeOH} / 98 \%$ water $/ 0.05 \% \mathrm{HCOOH}$. Mass spectrometric data acquisition was performed in the data-dependent mode; one cycle encompassed a full-range MS scan followed by $7 \mathrm{MS} / \mathrm{MS}$ scans on the most abundant ions from the MS scan. The LC-MS/MS data were used to search the SwissProt protein sequence database (subset of human proteins), using the program Bioworks/Sequest (Thermo Scientific).

\subsubsection{RNA Purification and RT-PCR}

A total of $100 \mathrm{ml}$ of venous blood was drawn into $20 \mathrm{~mL}$ ACD, $1 \mu \mathrm{M} \mathrm{PGE}_{1}$. The blood was centrifuged at $180 \mathrm{x} g$ and the platelet rich plasma was filtered through a PL6T leukocyte reduction filter (Pall, Inc., Port Washington, NY). Buffer A $(68 \mathrm{~mL})$ and $12 \mathrm{~mL}$ ACD was added to the sample and centrifuged at $1400 \mathrm{x}$ g. The supernatant was removed, the platelet pellet was resuspended in $1 \mathrm{~mL}$ Trizol (Invitrogen) and RNA was extracted following the manufacturer's protocol. Two gene- and species-specific primers for each candidate protein were designed. Each primer was designed to produce a product between 250 and 350 basepairs-long and span an intron of more than 1000 base pairs so that DNA contamination would easily be identifiable by the size of the product. The following primers were used: LYPLA-I/APT1 1: 5'-GCAGAAGCCTT TGCAGGTAT 3', forward 5'-ATTGCCATTCTTCACTTCTTGAT-3', reverse; LYPLA-I/APT1 2: 5'ACTCAGTTGCTGGCTTCCAC-3', forward 5'-TGCTTGACATCCATCATTTCC-3', reverse; MGLL 1: 5'-GCTGGACCTGCTGGTGTT-3', forward 5'- 
TGTTGCAGATTCAGGATTGG-3', reverse; MGLL 2: 5'-

AAGGGGCCTACCTGCTCAT-3', forward 5'-TGGCTGTCCTTTGAGAGACC-3', reverse; PLA1A 1: 5'-CCAATGATGTGGATTGAGGA-3', forward 5'-

GAAGCCATCCACACAGACAC-3', reverse; PLA1A 2: 5'-

GCTGTGGGCAGCTAGTAGAAC-3', forward 5'-CCAATGATGTGGA TTGAGGA-

3', reverse; LCAT 1: 5'--3', forward 5'--3', reverse; LCAT 2: 5'-GCTCCTCAAT

GTGCTCTTCC-3', forward 5'-CGGTAGCACATCCAGTTCAC-3', reverse. Reversetranscription polymerase chain reaction was done using the Superscript III kit

(Invitrogen). 30 cycles were performed using 400ng RNA template. The PCR products were separated on $2 \%$ agarose gels and visualized with ethidium bromide staining.

\subsubsection{MGLL Activity Assay}

Human recombinant MGLL was purchased from Abnova Corporation (Jhongli, Taiwan) and $0.5 \mu \mathrm{g}$ enzyme was incubated with NBD-PS $(0.9 \mu \mathrm{g})$ for 3 hours at $37^{\circ} \mathrm{C}$ in $20 \mu 110 \mathrm{mM}$ TRIS ( $\mathrm{pH} 7.5$ ). Then $30 \mu 1$ water-saturated $\mathrm{BuOH}$ was added to extract the lipids and $10 \mu 1$ of the extract was spotted on a TLC plate. The plates were then developed with solvent A consisting of chloroform:methanol:ammonium hydroxide (V/V/V, 6:4:1). The products were visualized using a Fotodyne imager (Hartland, WI) and quantified by the TotalLab100 software. The amount of the product generated was determined by interpolation from the standard curve.

Recombinant monoglyceride lipase (MGLL) was purchased from Abnova Corporation (Jhongli, Taiwan) and tested for activity using an assay kit from Cayman Chemicals (Ann Arbor, Michigan) that utilizes the hydrolysis of the thioester bond of arachidonoyl-1-thio-glycerol to produce a free thiol that reacts with 5,5'-dithiobis-(2nitrobenzoic acid) (DTNB). Recombinant MGLL $(0.3 \mu \mathrm{g}$ or $0.5 \mu \mathrm{g})$ or $100 \mu 1$ PLA $_{1}$-active Blue-Sepharose fraction was added in $150 \mu$ l total volume with assay buffer $(10 \mathrm{mM}$ TRIS-HCl, 1mM EDTA, pH 7.2), to a $2.7 \mathrm{mM}$ ethanolic solution of arachidonoyl-1-thioglycerol and incubated at room temperature for $5 \mathrm{~min}$. The absorbance was read at $415 \mathrm{~nm}$ using a BioTek microplate reader.

\subsubsection{Construction of Recombinant LYPLA-I/APT1 Expression Plasmid}

Human full length LYPLA-I/APT1 (Accession \# AF081281) was PCR-amplified. The PCR products were cleaned using the Qiagen PCR purification kit and eluted in $20 \mu 1$ DNA grade water. The DNA was used for ligation independent cloning (LIC) using the Ek/LIC cloning kit from Novagen (EMD, Gibbstown, NJ). Primers used for LIC cloning were: LYPLA-I/APT1-full-length-LIC Forward: GACGACGACAAGATGTGCGGCAA TAACATGTCAACC and LYPLA-I/APT1-full-length-LIC Reverse: GAGGAGAAG CCCGGTTCAATCAATTGGAGGTAGGAG. PCR-purified DNA (14.6 $\mu 1)$ was taken into a sterile centrifuge tube and $2 \mu 1$ each of 10-times concentrated T4 DNA polymerase buffer and $25 \mathrm{mM}$ dATP were added. Dithiothreitol $1 \mu 1,100 \mathrm{mM}$ and $0.4 \mu \mathrm{l}$ of T4 DNA polymerase were added to start the reaction with gentle stirring at $22^{\circ} \mathrm{C}$ for $30 \mathrm{~min}$. The 
reaction was stopped by incubation at $75^{\circ} \mathrm{C}$ for $20 \mathrm{~min}$. This T4 DNA polymerase-treated insert can be annealed into any Ek/LIC vectors including the pET-41 vector used here. For the ligation reaction, $1 \mu \mathrm{l} \mathrm{Ek/LIC} \mathrm{vector} \mathrm{(pET-41)} \mathrm{and} 2 \mu 1$ of T4 DNA polymerasetreated insert were used and incubated at $22^{\circ} \mathrm{C}$ for $5 \mathrm{~min}$. Then, $1 \mu 1$ of $25 \mathrm{mM}$ EDTA was added for $5 \mathrm{~min}$ at $22^{\circ} \mathrm{C}$. The ligated product was transformed into Novablue cells (EMD biosciences, Gibbstown, NJ). Three transformants were picked, and plasmid DNA was isolated and sequenced. The sequences were confirmed to be that of LYPLA-I/APT1.

\subsubsection{Recombinant LYPLA-I/APT1 Purification}

GST-LYPLA-I/APT1 was purified from transformed BL21-DE3 E. coli bacteria. Protein expression was induced using $200 \mu \mathrm{M}$ isopropyl $\beta$-D thiogalactopyranoside. Bacteria were pelleted by centrifugation and resuspended in lysis buffer (50mM TRIS base, $1 \mathrm{mM}$ EDTA, and 10\% sucrose containing the protease inhibitors; aprotinin $1 \mu \mathrm{g} / \mathrm{mL}$, leupeptin $1 \mu \mathrm{g} / \mathrm{mL}$, pepstatin $1 \mu \mathrm{g} / \mathrm{mL}$, and PMSF $500 \mu \mathrm{M})$. Lysozyme $(1 \mathrm{mg} / \mathrm{mL})$ was added to the resuspended bacteria and allowed to mix at $4^{\circ} \mathrm{C}$ for $30 \mathrm{~min}$. NP40 was added to the suspension ( $0.2 \%$ final concentration) and allowed to mix at $4^{\circ} \mathrm{C}$ for $30 \mathrm{~min}$. The suspension was cleared by centrifugation at $14000 \mathrm{x}$ g for $30 \mathrm{~min}$ at $4{ }^{\circ} \mathrm{C}$. Glutathione beads (ThermoFisher Scientific; $2 \mathrm{~mL}$ of $50 \%$ slurry) were added to the cleared supernatant and allowed to mix for 2 hours at $4{ }^{\circ} \mathrm{C}$. Glutathione beads were retrieved by centrifugation and washed with $0.2 \%$ Triton-X-100 (V/V) in phosphate buffered saline (PBS) three-times, followed by a wash with PBS plus protease inhibitors. A $20 \mu \mathrm{L}$ sample of the protein bound to the glutathione beads was eluted using Laemmli sample buffer and run on a $4-15 \%$ gel to visualize the quantity and purity of the isolated protein. Protein was eluted from the beads using $20 \mathrm{mM}$ reduced glutathione $(\mathrm{pH} 7.8)$ and dialyzed against an appropriate buffer and protein and stored in small aliquots at $-80^{\circ} \mathrm{C}$.

The GST- tag was removed by thrombin cleavage using $1 \mathrm{mg}$ of GST-LYPLAI/APT1 mixed with 2.5 units of biotinylated thrombin (Novagen, Darmstadt, Germany) in

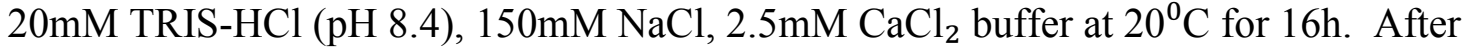
cleavage, the biotinylated thrombin was removed using streptavidin-agarose (Novagen, Darmstadt, Germany) using a ratio of 16:1 settled resin per unit of enzyme.

Recombinant protein was tested for PLA $\mathrm{P}_{1}$ activity by incubating $0.5 \mu \mathrm{g}$ of LYPLA-I/APT1 or $0.05 \mu \mathrm{g}$ GST-LYPLA-I/APT1 with $0.9 \mu \mathrm{g}$ BSA and $0.9 \mu \mathrm{g}$ NBD-PS in $20 \mu \mathrm{l}$ of $10 \mathrm{mM}$ TRIS-HCl ( $\mathrm{pH} 7.6$ ) for $15 \mathrm{~min}$ at $37^{\circ} \mathrm{C}$. Water-saturated $\mathrm{BuOH}(30 \mu \mathrm{l})$ was added to stop the reaction and extract the lipids after centrifugation. Samples $(10 \mu 1)$ of the $\mathrm{BuOH}$ phase were spotted on Silica Gel 60 TLC plates which were developed with solvent $\mathrm{A}$. The products were visualized using a Fotodyne imager.

\subsubsection{Monitoring LPC and LPA Production in Plasma}

Blood $(5 \mathrm{ml})$ was drawn into a heparinized or non-treated Vacutainer tubes. Blood was centrifuged at $14000 \mathrm{x}$ g for $1 \mathrm{~min}$ and the PRP was transferred to a new tube. The 
PRP from the tube with no additive was allowed to clot to generate serum. An amount of $10 \mu \mathrm{g}$ recombinant LYPLA-I/APT1 enzyme was added to $1 \mathrm{~mL}$ activated plasma and incubated at $37^{\circ} \mathrm{C}$ for 24 hours alongside $1 \mathrm{~mL}$ activated plasma without addition of the enzyme. The internal standards 17:0 LPA and 17:0 LPC (20ng each) were added to $200 \mu 1$ of the fresh PRP or to $200 \mu \mathrm{l}$ of the serum samples after $24 \mathrm{~h}$ incubation. A total of $200 \mu \mathrm{l}$ of citrate phosphate buffer ( $30 \mathrm{mM}$ citric acid and $\left.40 \mathrm{mM} \mathrm{Na}_{2} \mathrm{HPO}_{4}, \mathrm{pH} 4.0\right), 400 \mu \mathrm{l}$ methanol, and $200 \mu \mathrm{l}$ chloroform were added to the samples and centrifuged at $14000 \mathrm{x} \mathrm{g}$ for $1 \mathrm{~min}$. The chloroform layer was transferred to a new tube, dried under argon gas and reconstituted in $30 \mu 1$ methanol:acetonitrile:isopropanol:water (1:1:1:1). LPA 18:2 and LPA 20:4 were quantified by LC-MS/MS/MS as described above.

\subsubsection{Synthesis of $s n-2$ lyso-PAF 18:1}

Synthesis and characterization of $s n-2$ lyso-PAF 18:1 is described in the accompanying Supplemental information.

\subsubsection{Determinination of Regioisomeric Selectivity of ATX Against Two Lyso-PAF Substrates}

Serial dilutions of either $s n-1$ or $s n-2$ LysoPAF 18:1 $(2 \mathrm{mM}-31.25 \mu \mathrm{M}$, in $20 \mu \mathrm{l}$ assay buffer, $50 \mathrm{mM}$ TRIS, $\mathrm{pH} 7.4,5 \mathrm{mM} \mathrm{CaCl} 2,1 \mathrm{mg} / \mathrm{mL}$ BSA) were added to the wells in a 96 well, half area plate. A total of $20 \mu 1$ of either 10nM ATX (final concentration) or assay buffer were also added to the wells along with $20 \mu \mathrm{l}$ Amplex Red cocktail $(10 \mu \mathrm{M}$ Amplex Red, $0.1 \mathrm{Unit} / \mathrm{mL}$ choline oxidase (CO), and $1 \mathrm{unit} / \mathrm{mL}$ horse radish peroxidase (HRP), final concentration (Amplex Red, Invitrogen, Carlsbad CA; CO, MP Biomedical, Solon OH; HRP, ThermoFisher Scientific, Waltham, MA). The plate was incubated at $37^{\circ} \mathrm{C}$ for 6 hours and was read at excitation/emission wavelengths of $530 / 590 \mathrm{~nm}$ every 2 minutes with a BioTek Synergy 2 plate reader (Winooski, VT). A linear segment of time $v s$ concentration of product was plotted for each substrate concentration to determine initial reaction velocity. In order to calculate product concentration, a linear segment of absorbance values of serial dilutions of resorufin $(2000-0.0004768 \mu \mathrm{M})$ was used to establish a calibration curve of resorufin fluorescence. Resorufin and product concentration are directly proportional in the Amplex Red assay, thus experimental absorbance values were then interpolated on the calibration curve to determine product concentration. Substrate concentration vs initial velocity was then plotted using GraphPad Prism ${ }^{\circledR}$ version 5.0a for Mac OS X, and a rectangular hyperbolic curve fit was used to define kinetic parameters. 


\subsection{RESULTS}

\subsubsection{Phospholipases Released from Activated Platelets Generate Lysophospholipids but LPA Production Requires ATX from Plasma}

Platelet activation triggers an upsurge in production of LPA molecular species predominantly with 18:2 and 20:4 fatty acids (Mauco et al., 1978; Schumacher et al., 1979; Eichholtz et al., 1993; Gaits et al., 1997; Baker et al., 2001; Sano et al., 2002; Aoki et al., 2008). Using biosynthetic labeling of platelet phospholipids it has been shown that only trace amounts of ${ }^{32} \mathrm{P}$-LPA were found in the supernatant of activated platelets (Sano et al., 2002). To extend this observation concerning the lack of LPA production by platelets we tested the hypothesis that platelets secrete phospholipase(s) that de novo generate a pool of LPL that in turn serve as substrates for ATX constitutively present in plasma (Tokumura et al., 1986; Tokumura et al., 1998; Tokumura et al., 2000). The first question we raised in pursuing this hypothesis was whether platelet activation by thrombin leads to the release of $\mathrm{PLA}_{1}$ detectable in the supernatant. To determine this PC18:2 (Figure 2.1A), PS18:1 (Figure 2.1B), NBD-PC (Figure 2.1C), or NBD-PS (Figure 2.1D) were incubated with Sup2 in the presence or absence of ATX. We found significant LPC generation in Sup2 regardless of whether we used PC 18:2 or NBD-PC as substrate. However, very little LPA was produced. Using the fluorescent NBD-PC substrate LPA production was below the level of detection of our assay; however, using mass spectrometry we detected a $0.028 \pm 0.06 \mathrm{ng} / \mu \mathrm{g} / \mathrm{h}$ rate of LPA production. When PS 18:1 was used for substrate we observed the production of LPS 18:1 and a higher rate of LPA production amounting to $4.2 \pm 0.8 \mathrm{ng} / \mu \mathrm{g} / \mathrm{h}$. However, using NBD-PS we still were unable to detect LPA production. In contrast, when recombinant human ATX was added, a 9.5 fold increase in the amount of LPA generated from LPC and a 2 fold increase in the amount of LPA generated from LPS with a concomitant decrease in the LPC or LPS was observed. When NBD-PC or NBD-PS analogs were used, essentially the same findings were noted validating the applicability of these fluorescent analogs for monitoring LPL production. The finding of high rates of LPC and LPS production in the Sup2 suggest that phospholipases are secreted from platelets, but lysophospholipase D is not present in sufficient quantity to provide for substantial LPA production. The results with NBD phospholipids indicate that substantial amounts of PLA 1 activity are present in Sup2 because the predominant product formed was NBD-LPC and NBD-LPS with the fluorescent label in the $s n-2$ position. We hypothesized that phospholipase(s) $\mathrm{A}_{1}$ are secreted upon activation of platelets and we next attempted to purify these enzymes.

\subsubsection{Partial Purification of Phospholipase $A_{1}$ from Supernatants of Activated Human Platelets}

To further substantiate the hypothesis that a novel PLA 1 is secreted from platelets we partially purified this enzyme from Sup2. Sup2 from human platelets was prepared and applied to Q Sepharose Fast Flow ion exchange chromatography using an AKTA FPLC system. Fractions $(3 \mathrm{~mL})$ were collected and each fraction was assayed for PLA . $_{\text {. }}$ 


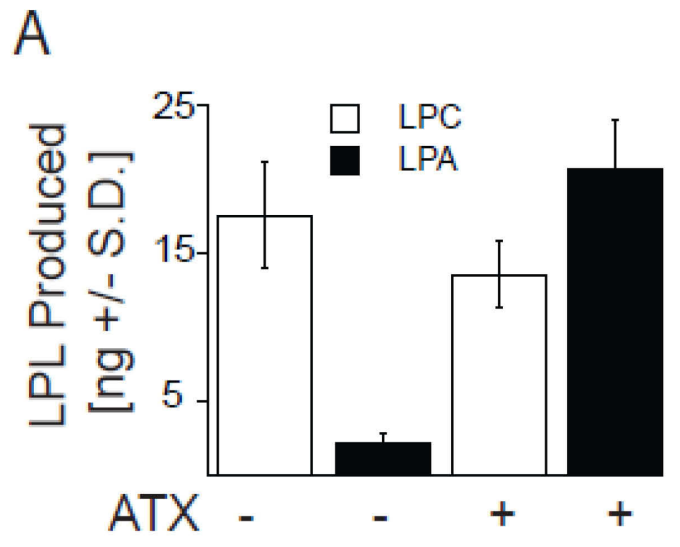

B
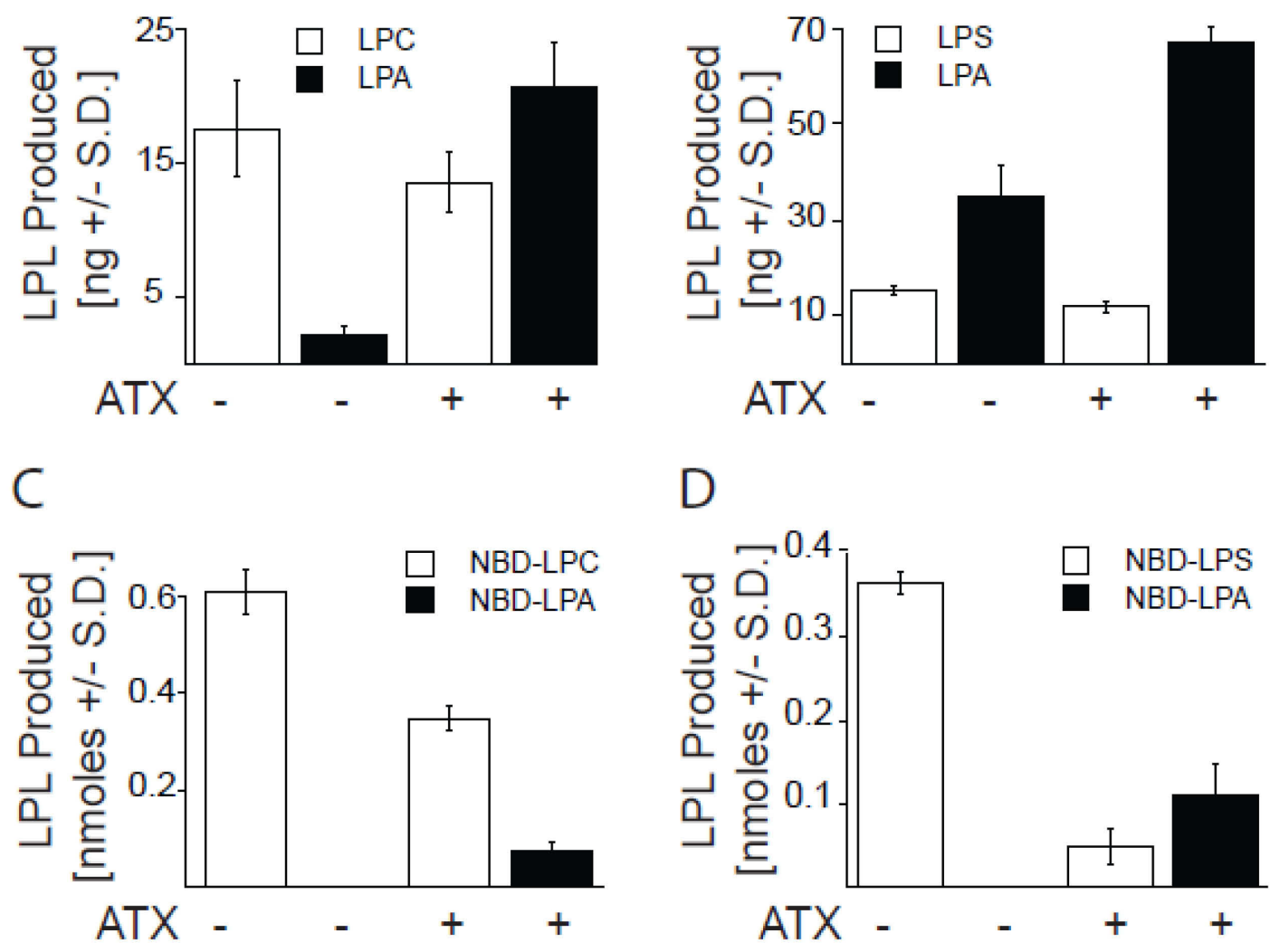

Figure 2.1 ATX is required for LPA production in activated platelet supernatant. Supernatant from thrombin-activated human platelets was incubated in the absence or presence of recombinant human ATX with 10 $\mu \mathrm{g}$ PC 18:2 (panel A), 10 $\mu \mathrm{g}$ PS 18:1 (panel B), $1 \mu \mathrm{g}$ NBD-PC 18:1/12:0 (panel C), or 1 $\mu \mathrm{g}$ NBD-PS 18:1/12:0 (panel D) supplemented with $250 \mu \mathrm{M}$ BSA and $135 \mathrm{mM} \mathrm{NaCl}$ in the presence or absence of $200 \mathrm{nM}$ ATX at $37^{\circ} \mathrm{C}$ for 1 hour. Generation of the corresponding LPC and LPA species was quantified using LC/MS (panels A \& B) or TLC (panels C \& D). In the absence of added ATX very little LPA was produced. In sharp contrast, LPC was abundantly generated by a PLA activity. Addition of ATX leads to a 9.5-fold increase in the amount of LPA generated from LPC and a 2-fold increase in the amount of LPA generated from LPS with a concomitant decrease in the LPC or LPS. When the unnatural NBD-PC/PS analogs were used, essentially the same findings were noted validating the usability of these fluorescent analogs for monitoring LPA production. Bars are the mean of 3 independent determinations \pm S.D. 
activity using NBD-PS as a substrate. Most PLA 1 activity with low PLA 2 activity contamination was found in the last portion of the flow-through fractions and no PLA 1 activity was detected in the bound fractions. The active fractions were combined and concentrated using a $5 \mathrm{kDa}$ Amicon concentrator to exchange the buffer and load onto a Butyl-Sepharose column. The resulting active fractions were then loaded onto a HiTrap Blue affinity chromatography column to eliminate albumin from the sample and the $\mathrm{PLA}_{1}$ was recovered from the flow through and concentrated as above. The specific PLA 1 activity present in the various pooled fractions is shown in Table 2.1. The three chromatographic steps resulted in a 1500-fold purification of PLA 1 activity

\subsubsection{Activity Based Purification of Platelet PLA}

Even though the multistep chromatographic purification yielded a 1500 -fold

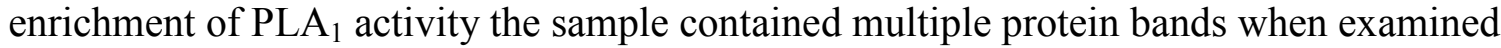
using SDS-PAGE. Further chromatographic purification led to loss of activity necessitating a change in the purification strategy. Most phospholipases contain a serine in the catalytic site which selectively reacts with fluorophosphonate (FP) (Leung et al., 2003). Most serine hydrolases are potently inhibited by FP or its derivatives. However, FPs do not inhibit cysteine, aspartyl, or metalloproteases (Liu et al., 1999). Rhodamineand biotin-labeled FP probes are rapid, selective, and are highly sensitive affinity labels for serine hydrolases. In these probes the fluorescent reactive group or the biotin tag is coupled through a long alkyl chain and two amide bonds (Liu et al., 1999).

We first determined if the $\mathrm{PLA}_{1}$ activity present in platelets reacted with a FP probe. A Butyl Sepharose fraction was incubated with incremental amounts of FP-RH and NBD-PS substrate. An increase in concentrations of FP-RH produced a decrease in NBD-LPS production presumably due to a competition between FP-RH and NBD-PS for the catalytic site of $\mathrm{PLA}_{1}$ (Figure 2.2A). This experiment provided evidence that $\mathrm{PLA}_{1}$ was a serine hydrolase and reacted with FP probes. FP-RH optimally inactivated PLA 1 at $5 \mu \mathrm{M}$ and $2 \mathrm{~h}$ of incubation (data not shown).

\subsubsection{Identification of Serine Hydrolases Secreted from Thrombin Activated Human Platelets}

Since we determined that $\mathrm{PLA}_{1}$ reacted with the FP probes, we then labeled the partially purified PLA 1 obtained after the HiTrap Blue chromatography step with FPbiotin. The FP probe allowed us to selectively label all serine hydrolases present in our sample and the biotin allowed us to isolate the labeled proteins using streptavidin beads. We analyzed samples from three different purifications. Tandem mass spectrometry (MS/MS) data were obtained for the tryptic peptides present in the digest. The MS/MS data, which are diagnostic of the peptide sequences, were used to identify the proteins of interest through protein database searches. Based on LC-MS/MS data, four relevant candidate proteins were identified: lecithin-cholesterol acyltransferase (LCAT), phosphatidylserine specific phospholipase $\mathrm{A}_{1}$ (PS-PLA 1 ), monoglyceride lipase (MGLL), 
Table 2.1 Summary of chromatographic steps.

\begin{tabular}{|c|c|c|c|}
\hline Step & $\mu \mathrm{g}$ protein $/ \mu \mathrm{l}$ & $\begin{array}{l}\text { Specific activity } \\
\text { (units } * / \mu \mathrm{g} \text { ) }\end{array}$ & $\begin{array}{l}\text { Purification } \\
\text { (fold) }\end{array}$ \\
\hline $\begin{array}{c}\text { Platelet } \\
\text { supernatant } \\
\text { (Sup2) }\end{array}$ & $75.3+/-6.2$ & $0.10+/-0.03$ & 1 \\
\hline Q sepharose & $16.2+/-1.7$ & $1.6+/-0.4$ & 16 \\
\hline $\begin{array}{c}\text { Butyl } \\
\text { sepharose }\end{array}$ & $0.08+/-0.02$ & $89.2+/-4.4$ & 872 \\
\hline HiTrap blue & $0.03+/-0.01$ & $159.5+/ 27.6$ & 1560 \\
\hline
\end{tabular}

$*$ Units defined in nanomoles of LPS formed/h at $37^{\circ} \mathrm{C}$. 


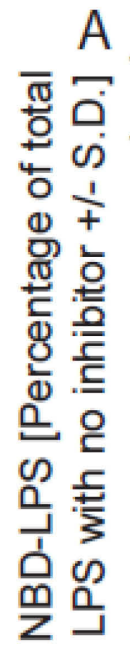

A

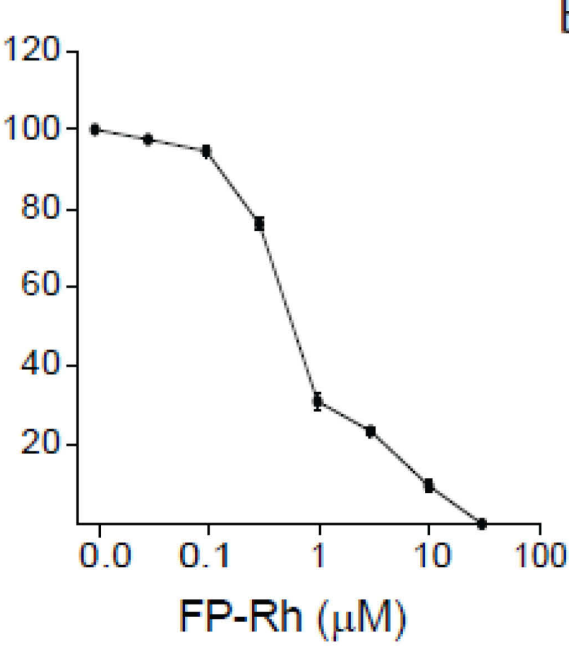

B

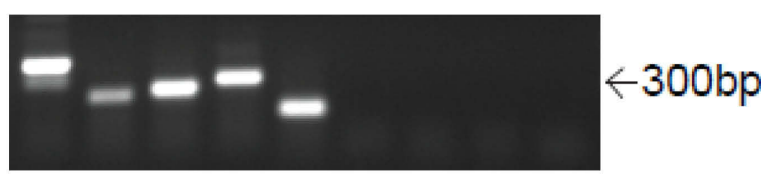

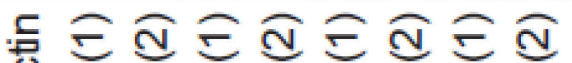

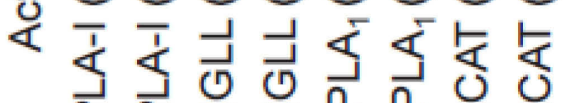

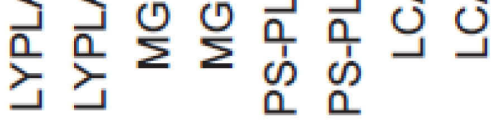

$\mathrm{D}$
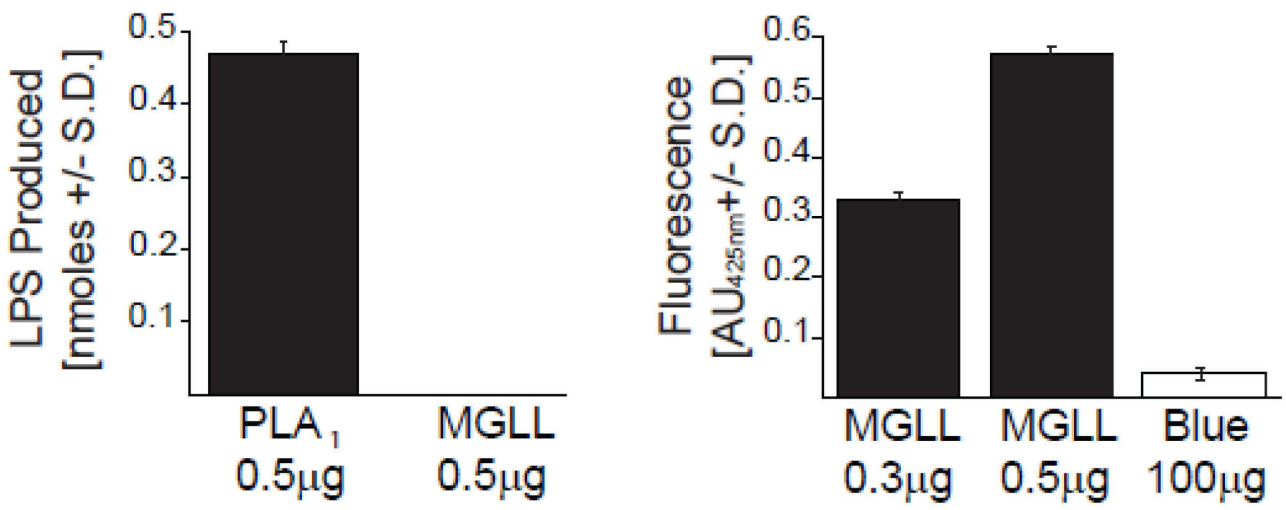

Figure 2.2 FP-Rhodamine binds to PLA $A_{1}$ inhibiting activity and NBD-LPS

production. Incremental amounts of FP-Rhodamine were incubated with NBD-PS and a phospholipase A1 active Butyl Sepharose fraction (panel A). The production of NBDLPS decrease with increasing amounts of FP-RH. Expression of serine hydrolase transcripts in human platelets (panel B). RT-PCR for LYPLA-I/APT1, MGLL, PS-PLA 1 and LCAT was performed using two different gene-specific primer pairs (denoted $1 \& 2$ ) using mRNA isolated from human purified platelets. Only LYPLA-I/APT1 and MGLL amplification yielded PCR products of the expected size indicating the expression of these enzymes in human platelets. These results have been confirmed with platelets from 5 other donors of both sexes. MGLL does not possess PLA activity (panels C \& D). When incubated with NBD-PS no LPS was formed thereby indicating MGLL does not possess PLA activity (panel C). Human recombinant MGLL was shown to have MGL activity to prove functionality (panel D). Bars are the mean of 3 independent determinations \pm S.D. 
and lysophospholipase A-I also known as acyl protein thioesterase 1 (LYPLA-I/APT1) (Table 2.2).

Because we used platelet rich plasma as a starting material, plasma protein contamination in our sample was a possibility, hence it was important to determine whether the proteins identified in the sample were expressed in platelets. To this end, mRNA was isolated from human platelets and RT-PCR for LYPLA-I/APT1, MGLL, PLA1A and LCAT was performed using two different gene-specific primer pairs (denoted $1 \& 2$, Figure 2.2B). The eight primer sets were validated to amplify the appropriate transcripts derived from selected tissues. Only two of the four lipases identified by LC-MS/MS, namely LYPLA-I/APT1 and MGLL, yielded PCR products of the expected size indicating the expression of these enzymes in human platelets.

We hypothesized that either MGLL, LYPLA-I/APT1, or both might play a role in LPA production during blood coagulation. In order to determine whether any of these proteins is involved in LPA production we needed to first establish if either enzyme

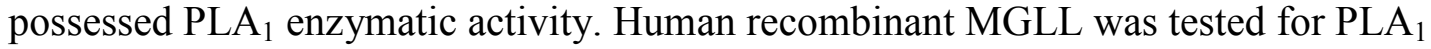
activity (Figure 2.2C). No cleavage of NBD-PS or generation of NBD-LPDS product was

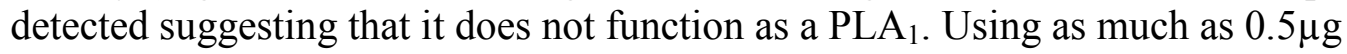
recombinant MGLL in a MGL activity assay (Figure 2.2D) we verified that the enzyme was active even though it lacked PLA 1 activity. Furthermore, using the Blue-Agarose fraction rich in $\mathrm{PLA}_{1}$ activity we were unable to detect MGLL activity using this same assay. These results suggested that MGLL does not have PLA 1 activity and therefore is unlikely to contribute to the production of LPA during blood coagulation.

We next tested whether LYPLA-I/APT1 functioned as a PLA 1 . Human recombinant GST-LYPLA-I/APT1 was expressed and purified from transformed E.coli. Coomassie Blue stained SDS-PAGE showed that the purified GST-tagged LYPLAI/APT1 and the LYPLA-I/APT1 with the GST-tag removed yielded a single protein band

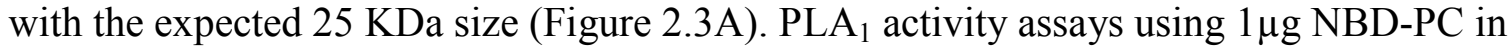
$20 \mu 110 \mathrm{mM}$ TRIS ( $\mathrm{pH} \mathrm{7.9)}$ at $37^{\circ} \mathrm{C}$ for $10 \mathrm{~min}$ performed on GST-tagged LYPLA-I/APT1 and thrombin-cleaved LYPLA-I/APT showed no detectable PLA 1 activity with GSTtagged enzyme (Figure 2.3B). In contrast, the LYPLA-I/APT1 with the tag removed showed activity when incubated with NBD-PC indicating that the GST tag inhibits activity of the enzyme and that LYPLA-I/APT1 possesses phospholipase $A_{1}$ activity.

\subsubsection{Recombinant Human LYPLA-I/APT1 Acts Primarily as a Phospholipase $A_{1}$ and Does Not Break Down LPA}

LYPLA-I/APT1 has two known functions to date. As an acyl-protein thioesterase it has been shown to deacylate $G$ proteins and other thioacylated protein substrates (Duncan and Gilman, 1998). As a lysophospholipase it cleaves the remaining fatty acid from either carbon of the glycerol backbone of lysophosphatidylcholine or 
Table 2.2 LC-MS/MS Candidate protein peptide sequences.

\begin{tabular}{|c|c|c|c|c|c|}
\hline Protein name & Entry name & $\begin{array}{l}\text { Accession } \\
\text { code }\end{array}$ & $\begin{array}{c}\text { Theoretical } \\
\text { molecular } \\
\text { weight } \\
(\mathrm{kDa})\end{array}$ & Peptide sequence* & $\begin{array}{l}\text { Occurrence of } \\
\text { peptide found } \\
\text { in samples }\end{array}$ \\
\hline $\begin{array}{l}\text { Lecithin-cholesterol } \\
\text { acyltransferase }\end{array}$ & LCAT_HUMAN & P04180 & 67 & $\begin{array}{c}\text { DLLAGLPAPGVEVYC*L } \\
\text { YGVGLPTPR } \\
\text { TYSVEYLDSSK } \\
\text { SSGLVSNAPGVQIR } \\
\text { LDKPDVVNWM\#C*YR } \\
\text { ITTTSPWMFPSR } \\
\text { TYIYDHGFPYTDPVGVL } \\
\text { YEDGDDTVATR }\end{array}$ & $\begin{array}{l}3 \\
2 \\
4 \\
3 \\
3 \\
2\end{array}$ \\
\hline $\begin{array}{l}\text { Lysophospholipase } \\
\text { A-I }\end{array}$ & LYPA1_HUMAN & O75608 & 25 & $\begin{array}{c}\text { LAGVTALSC*WLPLR } \\
\text { ASFPQGPIGGANR } \\
\text { TYEGMMHSSC*QQEMM } \\
\text { DVK } \\
\text { TLVNPANVTFK }\end{array}$ & $\begin{array}{l}3 \\
5 \\
5\end{array}$ \\
\hline $\begin{array}{l}\text { Phosphatidyl-serine } \\
\text { specific PLA }\end{array}$ & PLA1A_HUMAN & Q53H76 & 55 & $\begin{array}{c}\text { FC*TALLPVNDR } \\
\text { C*ADFQSANLFEGTDLK }\end{array}$ & $\begin{array}{l}1 \\
1\end{array}$ \\
\hline $\begin{array}{c}\text { Monoglyceride } \\
\text { Lipase }\end{array}$ & MGLL_HUMAN & Q99685 & 59 & LTVPFLLLQGSADR & 1 \\
\hline
\end{tabular}

* $\mathrm{C} *$ indicates carbamidomethylated cysteine. M\# indicates oxidized methionine. 


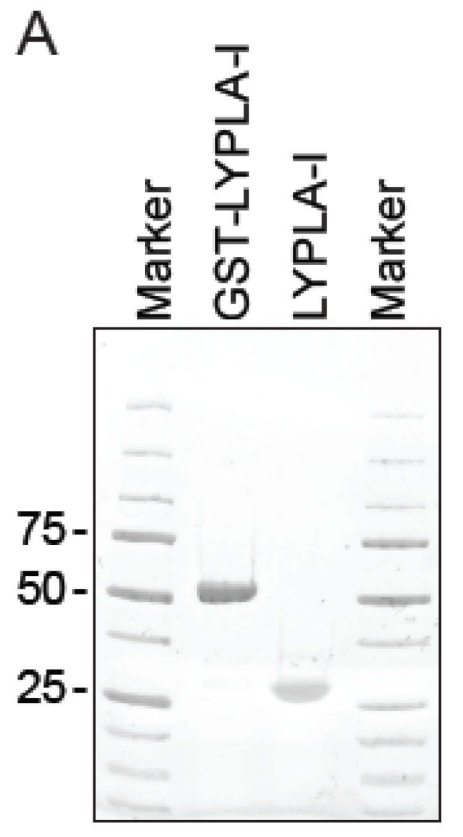

B

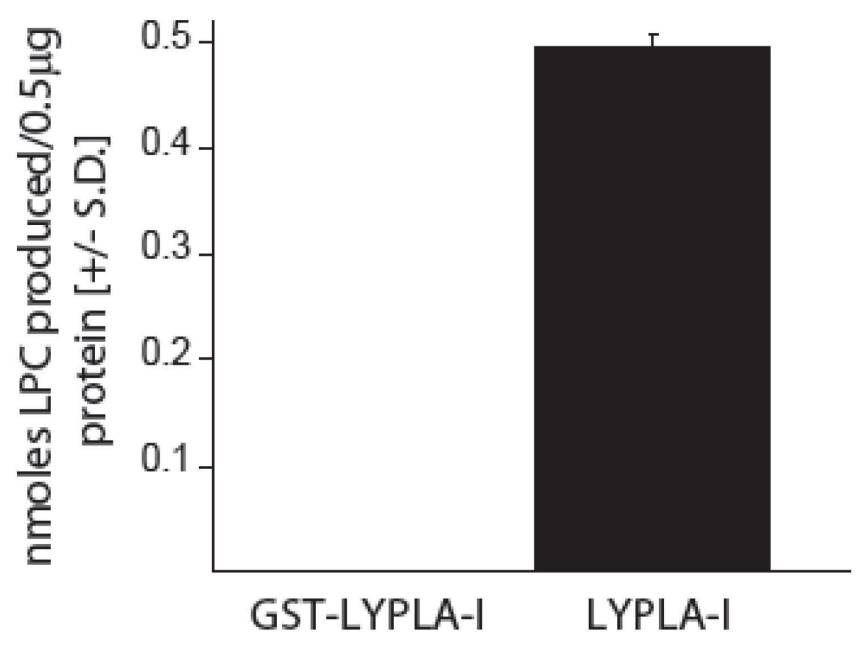

Figure 2.3 Human recombinant LYPLA-I/APT1 with and without a GST tag are purified for analysis. Coomassie Blue stained SDS-PAGE gels show the protein profiles of the GST tagged LYPLA-I/APT1 protein and the thrombin-cleaved LYPLA-I/APT1 protein $(5 \mu \mathrm{g}$ each). Human recombinant LYPLA-I/APT1 must be unlabeled for functionality (panel B). PLA activity assay was performed on both GST tagged LYPLAI/APT1 and thrombin-cleaved untagged LYPLA-I/APT1 ( $0.5 \mu \mathrm{g}$ each). No activity was found when the GST tag was present. The thrombin-cleaved version of LYPLA-I/APT1 has abundant PLA1 activity when incubated with NBD-PC in the presence of BSA. Bars are the mean of 3 independent determinations \pm S.D. 
lysophosphatidylserine. Because this protein has lysophospholipase activity, it was challenging to separate the PLA 1 activity from the lysophospholipase activity as the product of the PLA 1 activity is also the substrate of the lysophospholipase activity. Using

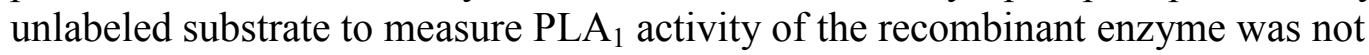
feasible, as we were unable to distinguish how much of the product was being cleaved by the lysophospholipase activity precluding the determination of the specific PLA $\mathrm{A}_{1}$ catalytic activity. In order to establish a timeline for the dual activities of the same enzyme we used NBD-PC, which allowed us to independently monitor the generation of NBD-LPC (product of PLA 1 cleavage) and NBD-FA (product of LYPLA-I/APT1 cleavage) products for both enzymatic activities and at least initially monitor reaction preference. NBD-PC, NBD-LPC, and NBD-FA were quantified as percentage of total substrate and product (Figure 2.4A). Eleven percent of added NBD-PC was converted to NBD-LPC within 1 min indicating the robust $\mathrm{PLA}_{1}$ activity of the enzyme. In contrast, NBD-FA production reached a comparable amount, only after $5 \mathrm{~min}$ of incubation, signifying further that the initial and preferred product of LYPLA-I/APT1 was NBD-LPC. NBD-LPC reached a maximum steady-state level of $25 \%$ after $5 \mathrm{~min}$, whereas NBD-FA generation continued steadily with the availability of NBD-LPC substrate for the LYPLA-I/APT1 activity of the enzyme. NBD-FA product could also be generated by PLA 2 cleavage of NBD-PC; however, this product was not seen initially making such catalytic activity unlikely. Along with the generation of NBD-LPC and NBD-FA there was a continuous decrease in the NBD-PC substrate. This time course is consistent with the hypothesis that human recombinant LYPLA-I/APT1 acts preferentially as a PLA $_{1}$ and only secondarily as a LYPLA-I/APT1.

The hypothesis that LYPLA-I/APT1 would supply LPL to ATX and thereby contribute to LPA production can only be sustained if LYPLA-I/APT1 would not cleave LPA and degrade it. To test this hypothesis recombinant LYPLA-I/APT1 was incubated with LPA 18:1 for up to 1 hour and the amount of LPA degraded was quantified by LCMS/MS (Figure 2.4B). The amount of LPA did not decrease during the 1-h-long incubation indicating that LYPLA-I/APT1 is not a substrate for LYPLA-I/APT1 and therefore, it does not contribute to the break-down of LPA.

\subsubsection{LYPLA-I/APT1 Contributes to the Production of LPA during Blood Coagulation}

The predominance of 18:2 and 20:4 LPA species in serum indicate that PLA 1 cleavage must be involved in this biochemical pathway because these fatty acids are overwhelmingly esterified to the $s n-2$ carbon of phospholipids. ATX has low, but constitutive activity for $s n-1$ LPC present in plasma indicated by the low concentration of LPA and the rather slow increase in LPA in heparinized plasma ex vivo (Figure 2.5A \& 2.5B) (Sano et al., 2002). Therefore, ATX alone cannot account for the upsurge in LPA production subsequent to activation of blood clotting. We hypothesized that LYPLAI/APT1 release from activated platelets is, at least in part, responsible for the increase in 


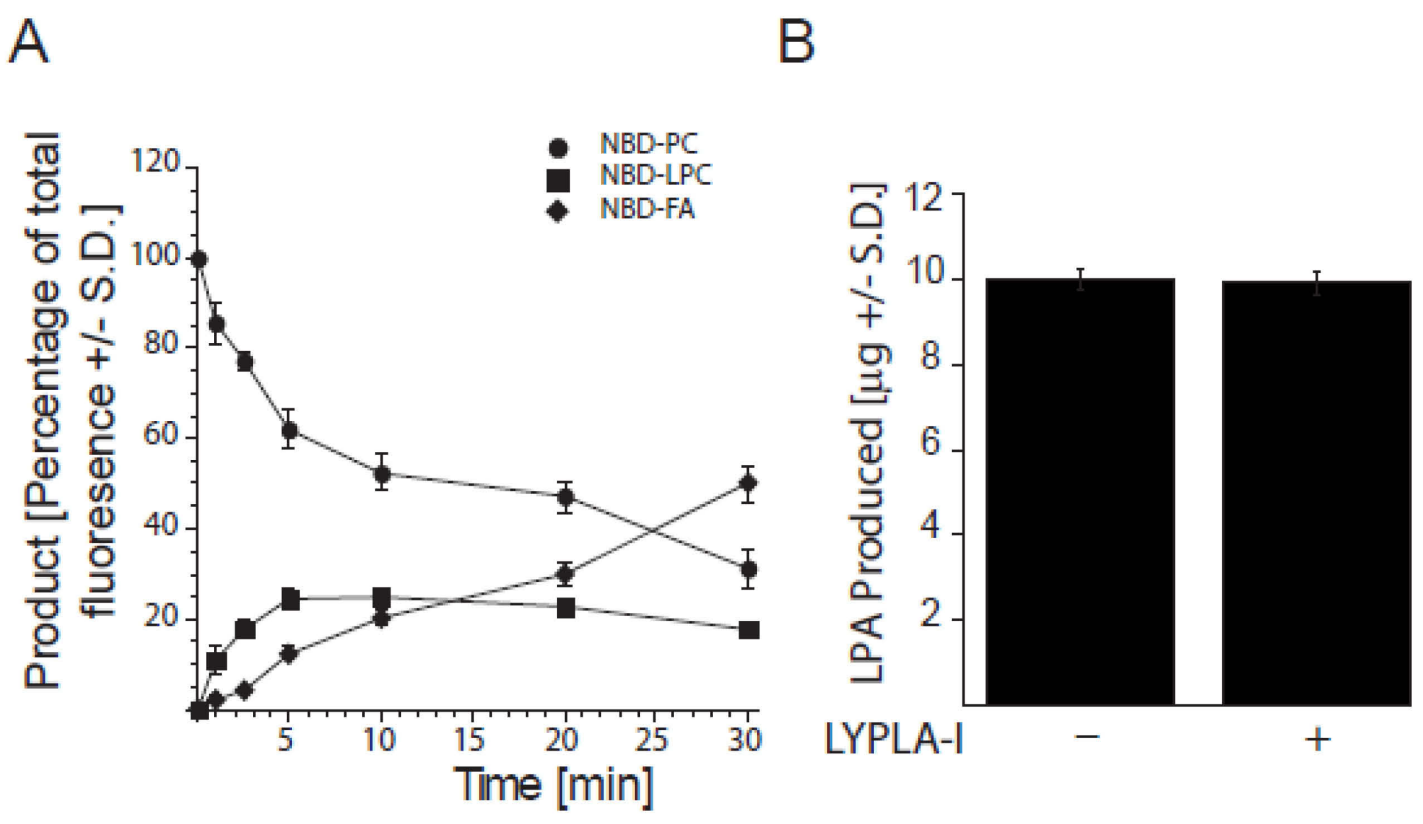

Figure 2.4 Human recombinant LYPLA-I/APT1 acts first as a PLA then also has lysophospholipase activity when incubated with NBD-PC. Purified human

recombinant LYPLA-I/APT1 was incubated with NBD-PC and BSA for 0, 1, 2.5, 5, 10,

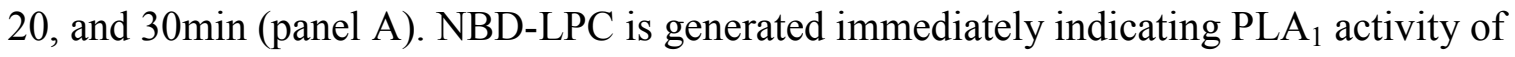
the enzyme. After the initial generation of NBD-LPC, NBD-FA is generated indicating a lysophospholipase activity of the enzyme with a simultaneous decrease in the starting substrate. Human recombinant LYPLA-I/APT1 does not cleave LPA and therefore does not contribute to the break-down of LPA (panel B). LYPLA-I/APT1 was incubated with LPA 18:1 in the presence of BSA for 1 hour. The amount of LPA did not decrease during incubation indicating that LPA is not a substrate for LYPLA-I/APT1. Bars are the mean of 3 independent determinations \pm S.D. 
LPA production by supplying a newly formed pool of LPL to ATX upon the activation of platelets. To examine this, heparinized plasma and human activated plasma generated by physiological means in venous blood were incubated with or without exogenously added human recombinant LYPLA-I/APT1 for 24 hours and the production of polyunsaturated LPA species was quantified using LC-MS/MS. Upon addition of LYPLA-I/APT1, LPA 18:2 (Figure 2.5A) and LPA 20:4 (Figure 2.5B) began increasing in a time-dependent manner in physiologically-activated plasma. By the end of the 24-h incubation, addition of LYPLA-I/APT1 to activated plasma significantly increased the amount of LPA 18:2 and 20:4. The generation of these LPA species in activated plasma without the addition of LYPLA-I/APT1 also increased but to a much lower extent compared to the LYPLAI/APT1 spiked samples. It is important to note that these samples contain endogenous LYPLA-I that also contributes to the production of LPC. There was no significant increase in either LPA species when platelet activation was prevented by heparin and the removal of plasma from the blood cells within $5 \mathrm{~min}$ of blood collection. However, there was a small increase at $24 \mathrm{~h}$ with the addition of LYPLA-I/APT1 to heparinized plasma suggesting the enzyme could utilize physiological substrates. We also determined that heparin $(18.75 \mathrm{U} / \mathrm{mL})$ used for anticoagulation of blood inhibited $90 \%$ of the activity of ATX although it did not inhibit the phospholipase $A_{1}$ activity of LYPLA-I/APT1 (data not shown).

To extend these observations we tested the effect of exogenous LYPLA-I/APT1 addition on LPA 18:2 and LPA 20:4 production in a small sample of human donors from both sexes. Activated plasma was incubated with or without $10 \mu \mathrm{g} / \mathrm{mL}$ human recombinant LYPLA-I/APT1 for 24 hours and the amount of LPC 18:2, LPC 20:4, LPA 18:2 and LPA 20:4 was quantified using LC-MS/MS. LPC 18:2 (Figure 2.6C) increased significantly by 1.5 -fold with the addition of LYPLA-I/APT1 in contrast to a 1.3-fold increase without LYPLA-I/APT1. Similarly, LPC 20:4 (Figure 2.6D) increased 2.8-fold with the addition of LYPLA-I/APT1 and 2.5-fold without LYPLA-I/APT1. In the same samples, LPA 18:2 (Figure 2.6A) increased 3.5-fold over 24h in comparison to 2.6-fold without LYPLA-I/APT1. LPA 20:4 (Figure 2.6B) increased 4.6-fold without the addition of LYPLA-I/APT1 relative to the level found at the beginning of the incubation and 5.8fold with the addition of LYPLA-I/APT1. The addition of LYPLA-I/APT1 significantly increased ( $p<0.05$ compared to time 0 analyzed by one-way ANOVA) the production of polyunsaturated LPC and LPA indicating that this enzyme contributes to the production of LPA during blood coagulation.

\subsubsection{Regioisomeric Preference of ATX}

To further understand the mechanism of LPA production upon blood coagulation we wanted to determine the regioisomeric preference of ATX. We have determined that LYPLA-I/APT1 cleaves phospholipids to yield sn-2 LPLs. These LPLs can either undergo acyl migration and then be further cleaved by ATX to yield sn-1 LPA or the sn-2 LPLs can first be cleaved by ATX yielding $s n-2$ LPA that then undergoes acyl migration 

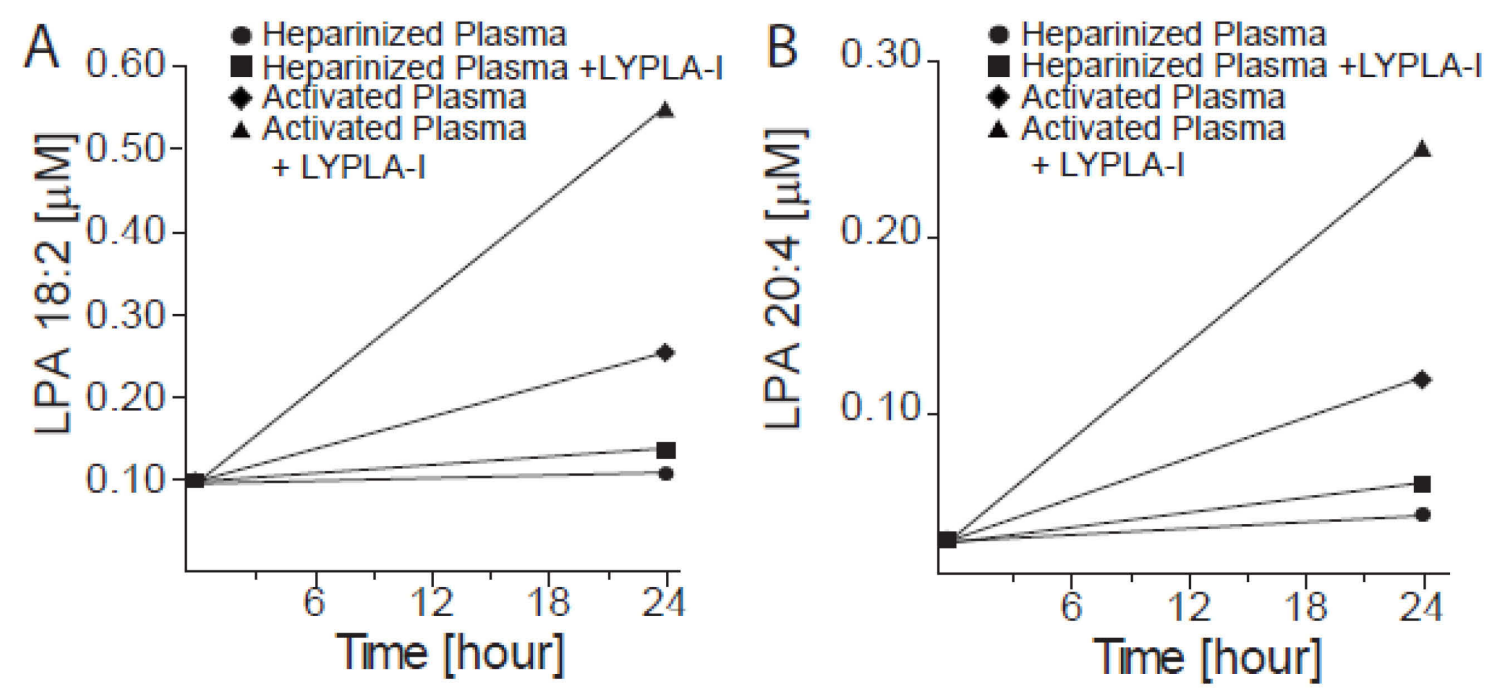

Figure 2.5 Human recombinant LYPLA-I/APT1 increases the amount of LPA 18:2 and LPA 20:4 in a time-dependent manner. Physiologically activated plasma and plasma with heparin additive were incubated with or without human recombinant LYPLA-I/APT1 for 24 hours. LPA 18:2 and LPA 20:4 in activated plasma began increasing after 3 hours and increased greatly at 24 hours. In contrast, in heparinized plasma LPA 18:2 and LPA 20:4 showed no increase except in the sample with LYPLAI/APT1 at 24 hours. 

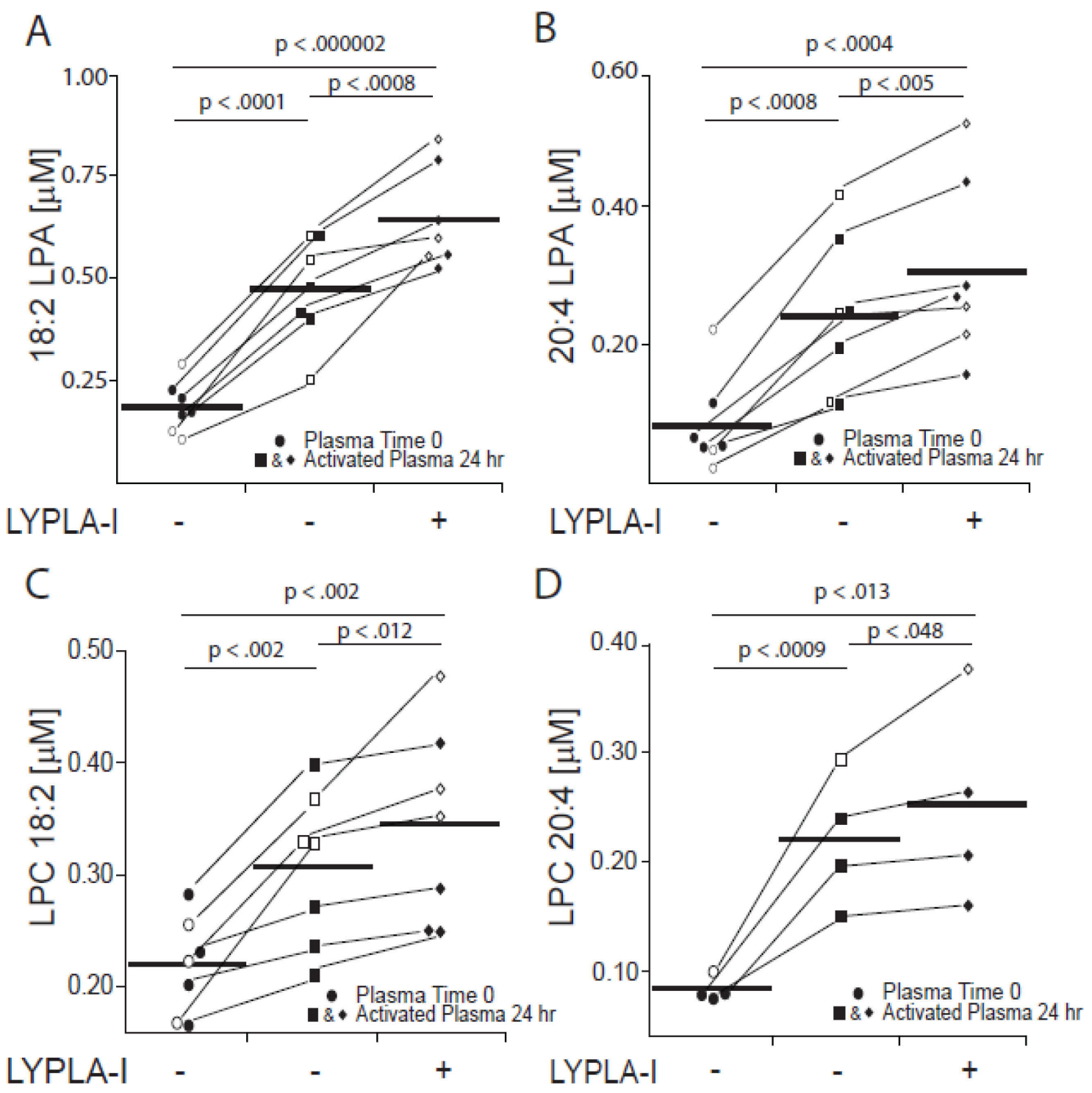

Figure 2.6 Human recombinant LYPLA-I/APT1 increases the amount of LPA produced. The addition of LYPLA-I/APT1 increases the amount of LPA 18:2 (panel A), LPA 20:4 (panel B), LPC 18:2 (panel C), and LPC 20:4 (panel D) produced in physiologically activated plasma. Physiologically activated plasma was incubated with or without human recombinant LYPLA-I/APT1 for 24 hours. LPA 18:2 and LPA 20:4 increased in 24 hours in comparison to the amount present in plasma immediately after blood draw. Production of LPA and LPC substantially increased with the addition of LYPLA-I/APT1 showing that LYPLA-I/APT1 plays a role in the production of LPA during blood coagulation. These results are from 3 female donors and 4 male donors (panel A, B \& C) or 1 female donor and 3 male donors (panel D). Open symbols represent female donors and closed symbols represent male donors $(* p<0.0524$ hour activated plasma with LYPLA-I vs. without LYPLA-I analyzed by paired t-test). 
to form $s n-1$ LPA. Since the $s n-2$ regioisomer of LPC is relatively unstable $\left(\mathrm{T}_{1 / 2} \sim 30 \mathrm{~min}\right.$ at $\mathrm{pH} 8.0$ ), especially during incubation at $37^{\circ} \mathrm{C}$ (Pluckthun and Dennis, 1982) (acyl migration generates a 9:1 excess of the $s n-1$ form), we were unable to use the natural substrate for ATX to experimentally determine substrate preference. In order to prevent acyl migration we used LPAF, an analogue of LPC in which the fatty acid is ether linked to the glycerol backbone. Using an Amplex Red, fluorescence-based choline release assay we determined the $\mathrm{K}_{\mathrm{m}}$ and $\mathrm{V}_{\max }$ of the $s n-1$ regioisomer to be $96 \pm 10 \mu \mathrm{M}$ and 0.11 $\pm 0.003 \mu \mathrm{M} \cdot \mathrm{min}^{-1}$, respectively. In contrast, the $\mathrm{K}_{\mathrm{m}}$ and $\mathrm{V}_{\max }$ of the $s n-2$ regioisomer were $51 \pm 4 \mu \mathrm{M}$ and $0.03 \pm 0.004 \mu \mathrm{M} \cdot \mathrm{min}^{-1}$, respectively (Figure 2.7 ). The $\mathrm{k}_{\text {cat }}$ value for the $s n$ 1 regioisomer was $11 \pm 0.03 \mathrm{~min}^{-1}$ whereas for the $s n-2$ regioisomer it was $3 \pm 0.14 \mathrm{~min}^{-1}$. $\mathrm{K}_{\mathrm{m}}$ and $\mathrm{k}_{\mathrm{cat}}$ values help to assess the efficiency of the enzymes against a given substrate: however, these values should not be used alone when considering the kinetic parameters of an enzyme. To better compare the enzyme efficiency for the two substrates the ratio $\mathrm{k}_{\mathrm{cat}} / \mathrm{K}_{\mathrm{m}}$ (specificity constant) can be used. This provides a measure of catalytic efficiency and allows for direct comparison of the efficiency of an enzyme towards different substrates. The $\mathrm{k}_{\mathrm{cat}} / \mathrm{K}_{\mathrm{m}}$ value for the $s n-1$ and $s n-2$ regioisomers of LPAF 18:1 were 0.12 $\pm 0.01 \mu \mathrm{M}^{-1} \cdot \mathrm{min}^{-1}$ and $0.05 \pm 0.01 \mu \mathrm{M}^{-1} \cdot \mathrm{min}^{-1}$ respectively (Table 2.3 ). Thus, the $\mathrm{K}_{\mathrm{cat}} / \mathrm{K}_{\mathrm{m}}$ of the $s n-1$ regioisomer was 2.3 times higher than that of the $s n-2$ regioisomer indicating that ATX catalyzes the $s n-1$ regioisomer of LPAF 18:1 more efficiently than the $s n-2$ regioisomer.

\subsection{DISCUSSION}

We have identified LYPLA-I/APT1 as an enzyme with PLA 1 activity that is released from human platelets during blood clotting that contributes to the generation of polyunsaturated species of LPA abundant in serum. Since the early reports of Schumacher et al. and Mauco et al. (Mauco et al., 1978; Schumacher et al., 1979) in the late seventies, it has been known that platelet activation and LPA production are coupled, however, the precise mechanism remained unknown (Eichholtz et al., 1993; Gaits et al., 1997; Sano et al., 2002; Aoki et al., 2008). Previously we have shown that only trace amounts of LPA are generated in activated platelets, far less than that could account for the rise in LPA concentration from the nanomolar range in plasma to the several micromolar level found in serum (Sano et al., 2002). The attention of the field has since been focused on the hypothesis that activated platelets release phospholipases, which generate a new pool of LPLs that are subsequently converted to LPA by ATX (Aoki et al., 2002b; Sano et al., 2002). Because more than eighty percent of LPA in serum is composed of the polyunsaturated 18:2 and 20:4 acyl species, we proposed that the LPL pool accessed by the constitutive ATX in plasma is likely to be generated by PLA 1 enzyme(s) derived from activated platelets (Sano et al., 2002). In pursuit of this hypothesis in the present study we report on the identification of one such PLA enzyme $_{1}$ previously known as LYPLA-I/APT1, which contributes to the increase in LPA

production during blood coagulation. Even though our results suggest that this $\mathrm{PLA}_{1}$ is a major contributor to the increase in LPA production, it may not be the only contributing phospholipase released by activated human platelets. 


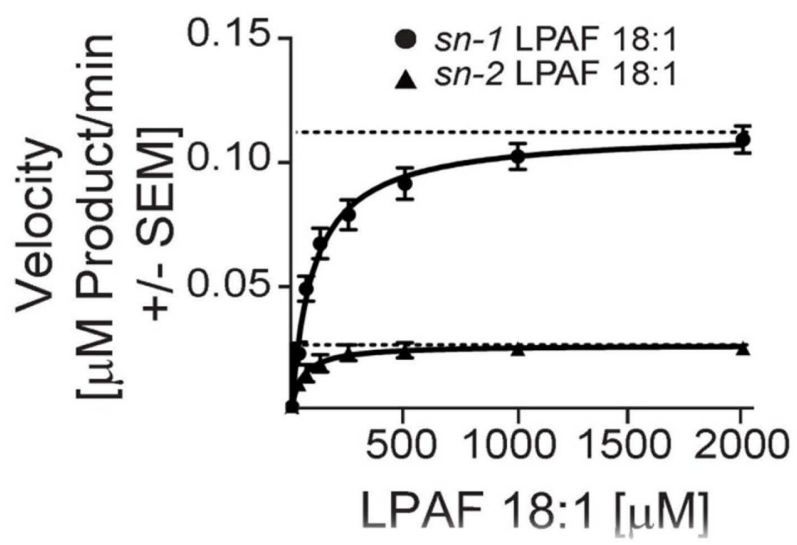

Figure 2.7 Comparison of the cleavage of $s n-1$ with $s n-2$ LPAF 18:1 by ATX. A linear segment of time $v s$. amount of product was plotted for each substrate concentration $(31.25 \mu \mathrm{M}-2 \mathrm{mM})$ to determine initial velocity. Substrate concentration $v s$. initial velocity was plotted. All absorbance values were converted to $\mu \mathrm{M}$ resorufin produced to report as actual product. Bars are the mean of 3 independent determinations \pm SEM. 
Table 2.3 Kinetic parameters for ATX-mediated hydrolysis of LPAF 18:1.

\begin{tabular}{ccccc}
\hline LysoPAF & $\mathrm{K}_{\mathrm{m}}(\mu \mathrm{M})$ & $\mathrm{V}_{\max }\left(\mu \mathrm{M} \cdot \min ^{-1}\right)$ & $\mathrm{K}_{\mathrm{cat}}\left(\min ^{-1}\right)$ & $\begin{array}{c}\mathrm{K}_{\mathrm{cat}} / \mathrm{K}_{\mathrm{m}}\left(\mu \mathrm{M}^{-}\right. \\
\left.1 \cdot \mathrm{min}^{-1}\right)\end{array}$ \\
\hline$s n-1$ & $96+/-10$ & $0.11+/-0.003$ & $11+/-0.03$ & $0.12+/-0.01$ \\
& $51+/-4$ & $0.025+/-0.004$ & $3.0+/-0.1$ & $0.050+/-0.01$ \\
\hline n=3, average values $+/-$ standard error.
\end{tabular}


Previous studies have used fluorescent phospholipids or $\left[{ }^{32} \mathrm{P}\right]$-orthophosphate for biosynthetic labeling of the substrates to monitor platelet-derived phospholipases (Sano et al., 2002). We developed LC-MS/MS techniques to monitor the sequential cleavage of PC/PS to LPC/LPS to LPA without the use of unnatural, fluorescently labeled substrates. Sano et al. previously showed that when fluorescently labeled PC, PE, or PS was incubated with supernatant from thrombin-stimulated platelets no LPA production could be detected. However, when plasma or serum was added LPA generation commenced suggesting that elements of the biochemical pathway were missing from the platelet supernatant (Sano et al., 2002). Using our newly developed method we were able to directly demonstrate that ATX addition to platelet supernatant significantly increases LPA production indicating that there is de novo generation of ATX substrates within the platelet supernatant. Using sn-2 NBD-labeled PC and PS, we found overwhelming hydrolytic activity generating NBD-LPC/LPS consistent with the abundant presence of $\mathrm{PLA}_{1}$ activity in the platelet supernatant. Under these conditions we found much less NBD-FA generation from either NBD-labeled phospholipid substrate, indicating that $\mathrm{PLA}_{2}$ activity was lower than corresponding PLA 1 activity toward these substrates. In the absence of exogenously added recombinant ATX, although very little, more LPA was generated from PS than from PC. This may indicate that some LPLD enzymes are present in the supernatant that prefer LPS over LPC or that trace amounts of contaminating ATX from plasma was present in the supernatant. It is also possible that the NBD-labeled lipids are poor substrates for ATX, but are good substrates for LYPLA-I. Lastly, it is known that LYPLA-I/APT1 is a multifunctional enzyme and cleaves LPC as a lysophospholipase as well as PC as a phospholipase. Thus, the lysophospholipase activity could have consumed LPC more readily than LPS, diminishing the former substrate from ATX, thereby decreasing the amount of LPA produced.

Pamuklar and colleagues (Pamuklar et al., 2009) examined the interaction of ATX with $\beta 3$ integrin expressed on platelets and proposed that this mechanism could localize and augment LPA production at the surface of platelets. We did not detect substantial LPA production by activated purified human platelets in the absence of added ATX (Figure 2.1). Thus, it appears that little ATX is associated with non-activated circulating human platelets and activation of $\beta 3$ integrins is required for capturing ATX to the platelet surface. Whether LPA receptors expressed in platelets activate $\beta 3$ integrins thereby promoting ATX binding remains to be demonstrated. Such feedforward mechanism amplifying LPA production at the platelet surface and aggregation via LPA receptors could play a role in thrombosis and hemostasis.

In the present study using three sequential chromatographic steps we were unable to purify the $\mathrm{PLA}_{1}$ activity to homogeneity. We pursued an affinity-labeling strategy using a fluorophosphonate probe, which selectively reacts with serine residues in the catalytic site of serine hydrolases to which most lipases belong (Leung et al., 2003). Using the FP-Biotin-labeled serine hydrolases isolated from the partially-purified PLA 1 fraction, we applied LC-MS/MS in combination with database searches to identify these enzymes. We searched for proteins that were known lipases among the FP-Biotin-labeled proteins. Most lipase domain members have characteristic surface loops ( $\beta 9$ loops) and a lid domain (Aoki et al., 2002a). These loops are part of the active site and help determine 
substrate recognition. These domains helped to identify our protein of interest. We also ignored all proteins that were too large to fit the size of the PLA $A_{1}$ estimated by gel filtration (25KDa and 50KDa - data not shown) and excluded any unknown peptide sequences. Using these exclusion criteria, we identified four proteins that were potential candidates for a PLA $A_{1}$. We further reasoned that if the $\mathrm{PLA}_{1}$ is released from platelets then it should be synthesized in platelets. Therefore, we looked for RNA transcripts of the four lipases in platelets. Using this criterion we were able to eliminate LCAT and PS$\mathrm{PLA}_{1}$, leaving MGLL and LYPLA-I/APT1 as the two remaining candidates.

We were also able to eliminate MGLL as a potential candidate protein because the recombinant enzyme lacked PLA 1 activity. We next cloned and expressed the human LYPLA-I/APT1 and unexpectedly found that the GST-tag interfered with enzymatic activity. We do not know whether the GST tag may have interfered with protein folding or may have affected the ability of the substrate to bind to the enzyme. Despite this interference, once the GST tag was removed, we determined that the recombinant LYPLA-I/APT1 had PLA 1 activity against NBD-labeled and natural PC or PS. Our attempts to determine the Km value of LYPLA-I/APT1 with PC or PS substrates were unsuccessful because the product of PLA 1 cleavage is also the substrate of the lysophospholipase activity of the enzyme. LYPLA-I/APT1 has been shown to cleave fatty acids esterified to either the $s n-1$ or the $s n-2$ carbon of LPC (Wang et al., 1997). However, we determined that LPA was not cleaved by LYPLA-I/APT1 indicating that this product escapes further modification by this multifunctional enzyme.

Another function of LYPLA-I/APT1 is the deacylation/depalmitoylation of G proteins, ghrelin, and other thioacylated protein substrates (Duncan and Gilman, 1998; 2002; Hirano et al., 2009; Satou et al., 2010). Deacylation/depalmitoylation contributes to the regulation of lipid modifications and reverses the process of thioacylation of proteins involved in signal transduction. It has been shown that the $\mathrm{K}_{\mathrm{m}}$ of the lysophospholipase activity is about 8-times higher than the $\mathrm{K}_{\mathrm{m}}$ value of the thioesterase activity of the enzyme. The $\mathrm{V}_{\max }$ is also about 17 times lower for the lysophospholipase activity than the thioesterase activity (Hirano et al., 2009). Based on these data it has been proposed that LYPLA-I/APT1 has a much higher thioesterase activity than lysophospholipase activity. However, in vivo the activity of this enzyme is likely to be affected by the availability and presentation of the different substrates.

In order to make a distinction between substrate preference for PC and LPC of LYPLA-I/APT1, we used NBD-PC substrate and followed the time course of NBD-LPC production generated by the $\mathrm{PLA}_{1}$ activity and NBD-FA production generated through lysophospholipase activity. We observed a considerable delay in the formation of NBDFA relative to NBD-LPC, the latter being continuously generated. For this reason, we suggest that LYPLA-I/APT1 functions preferentially as a PLA 1 and only after the buildup of LPL concentration presumably via acyl migration it begins to cleave this substrate as a lyso-PLA .

Without a knockout animal model or specific inhibitors of LYPLA-I/APT1 we were limited to study the effect of the enzyme on ex vivo LPA production in activated 
plasma. Following the addition of LYPLA-I/APT1 to heparinized plasma, we detected only a very small increase in polyunsaturated LPA production at $24 \mathrm{~h}$ suggesting that the enzyme can utilize physiological substrates. However, this increase was confounded because heparin inhibited the activity of ATX but not the PLA 1 activity of LYPLAI/APT1. LPA production in activated plasma began to increase after 3 hours and continued up to 24 hours (the last time point tested). Spiking LYPLA-I/APT1 into activated non-anticoagulated plasma increased LPA 18:2 and 20:4 production by 5- and 4-fold, respectively. This augmentation of LPA production indicates that LYPLA-I/APT1 recognizes and cleaves plasma phospholipids and contributes to the generation of LPA during blood coagulation. Production of LPA by this pathway is limited by the amount of LYPLA-I/APT1 released from platelets and the rate with which ATX generates LPA relative to the rate with which LYPLA-I/APT1 degrades LPL.

We considered that LYPLA-I/APT1 generates a new pool of sn-2 LPL, which can potentially undergo acyl migration before or after headgroup cleavage by ATX. The $s n-2$ regioisomer of LPC is relatively unstable and undergoes acyl migration to the sn-1 position at neutral $\mathrm{pH}$ at $37^{\circ} \mathrm{C}$. Due to the several minute-long half-life of the $s n-2$ regioisomer (Pluckthun and Dennis, 1982) we were unable to obtain biochemical proof whether the nascent LPA generated is of the $s n-2$ or $s n-1$ regioisomer because the extraction and HPLC separation of the regioisomers takes longer than 30 minutes. To obtain indirect insight into the role of acyl migration on ATX cleavage, we synthesized the $s n-2$ regioisomer of LPAF and compared its cleavage with the $s n-1$ regioisomer. ATX cleaved the $s n-1$ LPAF with a higher $\mathrm{k}_{\mathrm{cat}} / \mathrm{K}_{\mathrm{m}}$ than its $s n-2$ counterpart. Based on this finding it seems logical to propose that acyl migration occurs predominantly at the LPL stage of this biochemical pathway. However, only direct measurement of the nascent LPL and LPA regioisomers can help settle this question. An additional factor that must be taken into consideration is the short half-life of LPA in blood in vivo. LPA appears to be continuously produced and simultaneously broken down in blood on the minute scale (Albers et al., 2010). This might create a situation that may enrich the abundance of $s n-2$ regiosomer in blood relative to the $s n-1$ regioisomer because the LPA generated is broken down before or at a similar rate with which acyl migration occurs.

Based on the results of this study, we hypothesize that LPA production during blood coagulation occurs via the following steps: 1) Upon activation platelets release LYPLA-I/APT1.2) LYPLA-I/APT1 cleaves phospholipids to generate a new pool of sn2 LPL. 3) These newly generated sn-2 LPLs undergo acyl migration within minutes to produce a pool of sn-1 LPLs. 4) ATX or other lysophospholipase D enzymes cleave the sn-l LPLs to generate an upsurge of sn-l LPA enriched in polyunsaturated FA. This hypothesis needs further testing and the availability of LYPLA-I/APT1 knockout animals and rapid methods for the detection of LPA and LPA regioisomers will accelerate the progress toward a better understanding of LPA production in biological fluids. 


\subsection{SUPPLEMENTAL INFORMATION}

\section{Synthesis and characterization of $s n-2$ lyso-PAF 18:1.}

2-Oleyl-sn-glycero-3-phosphocholine (1) was synthesized. The synthetic scheme began with 3-O-(4-Methoxybenzyl)-sn-glycerol (2), which contains the appropriate stereochemistry for the subsequent target product and was synthesized as previously described (Perly et al., 1984; Rowland and Best, 2009). First, the primary alcohol of diol 2 was selectively protected through reaction with tert-butyldiphenyl chlorosilane to produce compound $\mathbf{3}$. Next, ether bond formation using oleyl triflate was performed to afford fully protected glycerol 4, followed by deprotection of the $p$-methoxybenzyl (PMB) group to provide the free alcohol of 5. Phosphoramidite chemistry was then used to install the choline phosphodiester of 7, at which time it was found that the cyanoethyl protecting group on the phosphate was deprotected in situ. When followed by mass spectrometry, this was found to happen during the process of purifying compound 7 . The yield for the 2-step production of 7 is somewhat low, likely due to the challenges associated with forming mixed phosphodiesters and the purification of the lyso-lipid product. Finally, the removal of the silyl protecting group of 7 yielded LPC analog 1. It is worth mentioning that a similar approach was also pursued that involved a glycerol precursor with opposite stereochemistry, initial removal of the silyl group, and deprotection of the PMB in the final step. However, this alternative route led significant challenges in purifying the final product, and was thus abandoned in favor of the route described above. LPC analog 1 has previously been reported in enantiomerically pure (Hirth et al., 1983) as well as racemic form (Huang et al., 2006) using different synthetic routes.

3-O-(4-Methoxybenzyl)-1-O-(tert-Butyldiphenylsilyl)-sn-glycerol (3) Diol 2 was synthesized from $S$-glycerol acetonide (purchased from AK Scientific, Inc.) according to a known procedure (Perly et al., 1984; Rowland and Best, 2009). Diol 2 (0.430g, $2.026 \mathrm{mmol})$ was then dissolved in dry $N, N$-dimethylformamide $(20 \mathrm{ml})$, to which was added tert-butyldiphenyl chlorosilane $(0.525 \mathrm{ml}, 2.026 \mathrm{mmol})$, followed by imidazole $(0.359 \mathrm{~g}, 5.270 \mathrm{mmol})$. The reaction mixture was next allowed to stir at room temperature overnight. The solvent was then concentrated under reduced pressure and the resulting residue was dissolved in chloroform $(100 \mathrm{ml})$ and washed with water $(2 \times 50 \mathrm{ml})$. The organic layer was then dried with magnesium sulfate and the solvent evaporated to yield the crude product. Purification via column chromatography with silica gel and gradient elution with $15-35 \%$ ethyl acetate/hexanes yielded 3 as a colorless oil $(0.73 \mathrm{~g}, 80 \%)$. The product matched previous characterizations (Greimel et al., 2008). ${ }^{1} \mathrm{H}$ NMR (300 MHz, $\left.\mathrm{CDCl}_{3}\right): \delta 7.62-7.65(\mathrm{~d}, J=9.0 \mathrm{~Hz}, 4 \mathrm{H}), 7.34-7.42(\mathrm{~m}, 6 \mathrm{H}), 7.20-7.25(\mathrm{~m}, 2 \mathrm{H}), 6.84-6.87$ $(\mathrm{d}, J=9.0 \mathrm{~Hz}, 2 \mathrm{H}), 4.45(\mathrm{~s}, 2 \mathrm{H}), 3.88-3.92(\mathrm{~m}, 1 \mathrm{H}), 3.79(\mathrm{~s}, 3 \mathrm{H}), 3.69-3.71(\mathrm{~d}, J=6.0 \mathrm{~Hz}$, 2H), 3.50-3.54 (m, 2H), $2.47(\mathrm{~d}, J=6.0 \mathrm{~Hz}, 1 \mathrm{H}), 1.06(\mathrm{~s}, 9 \mathrm{H})$; MALDI-HRMS [M+Na] calcd: 473.2119 , found: 473.2093 .

1-O-(tert-Butyldiphenylsilyl)-2-oleyl-3-O-(4-Methoxybenzyl)-sn-glycerol (4) The

procedure for synthesis of $\mathbf{4}$ was modified from similar ether-tail forming reactions (Jiang 
et al., 2006). Compound $\mathbf{3}(0.660 \mathrm{~g}, 1.465 \mathrm{mmol})$ was dissolved in dry dichloromethane $(40 \mathrm{ml})$, to which was added 1,8-Bis(dimethylamino)naphthalene (proton sponge, $1.10 \mathrm{~g}$, $5.15 \mathrm{mmol})$ and oleyl triflate $(2.900 \mathrm{~g}, 7.240 \mathrm{mmol})$, which was prepared from a known procedure (Heyes et al., 2002). The solution was next heated to reflux and allowed to stir overnight. The solvent was then removed under reduced pressure to yield the crude product $\mathbf{4}$, which was purified by column chromatography with silica gel and gradient elution with $5-10 \%$ acetone/hexanes to yield 4 as a yellowish oil $(0.714 \mathrm{~g}, 71 \%) .{ }^{1} \mathrm{H}$ NMR (300 MHz, $\left.\mathrm{CDCl}_{3}\right): \delta$ 7.66-7.75 (m, 4H), 7.32-7.40 (m, 6H), 7.22-7.30 (m, 2H), 6.83-6.91 (m, 2H), 5.35-5.41 (m, 2H), 4.47-4.52 (m, 2H), $3.79(\mathrm{~s}, 3 \mathrm{H}), 3.38-3.70(\mathrm{~m}$, $7 \mathrm{H}), 2.04(\mathrm{~m}, 4 \mathrm{H}), 1.58(\mathrm{~m}, 2 \mathrm{H}), 1.30-1.36(\mathrm{~m}, 22 \mathrm{H}), 1.03-1.06(\mathrm{~m}, 9 \mathrm{H}), 0.90-0.94(\mathrm{~m}$, $3 \mathrm{H}) ;{ }^{13} \mathrm{C}$ NMR $\left(100.6 \mathrm{MHz}, \mathrm{CDCl}_{3}\right): \delta 159.14,135.99,135.64,133.57,129.90,129.48$, $129.21,129.13,127.66,127.43,113.69,113.59,79.48,73.02,71.38,69.71,63.50,55.16$, $32.70,31.99,30.18,29.78,29.72,29.58,29.33,26.20,22.76,19.25,14.21$; MALDIHRMS [M+Na] $]^{+}$calcd: 723.4779 , found: 723.4759 .

1-O-(tert-Butyldiphenylsilyl)-2-oleyl-sn-glycerol (5) Compound 4 (0.325g, $0.463 \mathrm{mmol}$ ) was combined with 2,3-dichloro-5,6-dicyanobenzoquinone (DDQ, $0.315 \mathrm{~g}$, $1.389 \mathrm{mmol})$ in dichloromethane $(10 \mathrm{ml})$ and water $(1 \mathrm{ml})$. The reaction mixture was then stirred at rt. After $10 \mathrm{~h}$, saturated sodium bicarbonate $(100 \mathrm{ml})$ was added to quench the reaction, and the resulting solution was then extracted twice with chloroform $(2 \times 100 \mathrm{ml})$. The organic layers were then combined and dried with magnesium sulfate and the solvent removed by rotary evaporation to yield the crude product, which was carried on to the next step without further purification.

\section{1-O-(tert-Butyldiphenylsilyl)-2-oleoyl-sn-glycero-3-phosphocholine (7) Crude} compound 5 was combined with bis-( $N, N$-diisopropylamino) cyanoethyl phosphine (6, $0.205 \mathrm{~g}, 0.606 \mathrm{mmol})$, and $1 H$-tetrazole $(0.740 \mathrm{ml}$ of a $0.45 \mathrm{M}$ solution in acetonitrile, $0.333 \mathrm{mmol})$ in dichloromethane $(10 \mathrm{ml})$, and the solution was allowed to stir at $\mathrm{rt}$ for $1 \mathrm{~h}$. To this stirred solution, choline tosylate $(0.334 \mathrm{~g}, 1.212 \mathrm{mmol})$, and $1 H$-tetrazole $(2.690 \mathrm{ml}$ of a $0.45 \mathrm{M}$ solution in acetontrile, $1.212 \mathrm{mmol}$ ) were added, and the solution was allowed to stir at $\mathrm{rt}$ for another $12 \mathrm{~h}$, after which tert-butylhydroperoxide $(0.470 \mathrm{ml}, 4.848 \mathrm{mmol})$ was added. After $1 \mathrm{~h}$, the reaction was quenched by adding $50 \mathrm{ml}$ of saturated sodium thiosulfate aqueous solution. Next, the resulting solution was extracted with methanol/methylene chloride (v/v 1:4, 2 x 80ml), and the organic layers were combined and dried with magnesium sulfate. The solvent was then removed under reduced pressure, and the resulting residue was purified by column chromatography with silica gel through gradient elution of 5-30\% methanol/dichloromethane to yield 7 as a colorless oil $\left(0.060 \mathrm{~g}, 17 \%\right.$ yield over 2 steps). ${ }^{1} \mathrm{H}$ NMR $\left(300 \mathrm{MHz}, \mathrm{CDCl}_{3}\right): \delta 7.65-7.69(\mathrm{~m}, 4 \mathrm{H})$, 7.26-7.38 (m, 6H), 5.32-5.35 (m, 2H), 4.14-4.18 (m, 2H), 3.89-3.91 (m, 2H), 3.49-3.74 (m, 5H), 3.28-3.30 (m, 2H), $3.22(\mathrm{~s}, 9 \mathrm{H}), 1.99-2.01(\mathrm{~m}, 4 \mathrm{H}), 1.47-1.49$ (m, 2H), 1.19$1.23(\mathrm{~m}, 22 \mathrm{H}), 1.02(\mathrm{~s}, 9 \mathrm{H}), 0.86(\mathrm{t}, J=6.0 \mathrm{~Hz}, 3 \mathrm{H}) ;{ }^{31} \mathrm{P}$ NMR: $\delta-0.59$; MALDI-HRMS [M-H] ${ }^{+}$calcd: 746.4939 , found: 746.4946 .

2-Oleyl-sn-glycero-3-phosphocholine (1) Compound $7(0.060 \mathrm{~g}, 0.080 \mathrm{mmol})$ and tetrabutylammonium fluoride trihydrate (TBAF, $0.126 \mathrm{~g}, 0.40 \mathrm{mmol}$ ) were dissolved in tetrahydrofuran $(10 \mathrm{ml})$, and the reaction was allowed to stir at room temperature 
overnight, at which point the solvent was removed under reduced pressure. Purification of the resulting residue by column chromatography with $3 \mathrm{~g}$ of silica gel and a gradient eluant of $10-50 \%$ methanol/chloroform yielded 7 , but also contained TBAF as a contaminant. This mixture was then dissolved in water and stirred with Chelex-100 resin, sodium form, for $3 \mathrm{~h}$. The solution was then loaded directly onto a $\mathrm{C} 18$ reverse phase column and eluted with a gradient of water/methanol mixtures to yield $\mathbf{7}$ as an off-white paste $(0.025 \mathrm{~g}, 62 \%)$. The product matched previous characterizations.(Hirth et al., 1983; Huang et al., 2006) ${ }^{1} \mathrm{H}$ NMR (300 MHz, $\mathrm{CD}_{3} \mathrm{OD} / \mathrm{CDCl}_{3}$, v/v 1:2): $\delta 5.33-5.36(\mathrm{~m}, 2 \mathrm{H})$, 4.4-4.28 (m, 2H), $4.14(\mathrm{~m}, 1 \mathrm{H}), 3.96(\mathrm{t}, J=6.0 \mathrm{~Hz}, 2 \mathrm{H}), 3.49-3.74(\mathrm{~m}, 5 \mathrm{H}), 3.34-3.36(\mathrm{~m}$, $2 \mathrm{H}), 3.21(\mathrm{~s}, 9 \mathrm{H}), 1.99-2.04(\mathrm{~m}, 4 \mathrm{H}), 1.52-1.59(\mathrm{~m}, 2 \mathrm{H}), 1.25-1.32(\mathrm{~m}, 22 \mathrm{H}), 0.86(\mathrm{t}$, $J=6.0 \mathrm{~Hz}, 3 \mathrm{H}) ;{ }^{31}$ P NMR: $\delta$ 4.01; MALDI-HRMS [M-H] ${ }^{+}$calcd: 508.3762 , found: 508.3768 .

Column chromatography was performed using $230-400$ mesh silica gel purchased from Sorbent Technologies (Atlanta, GA). NMR spectra were obtained using a Varian Mercury 300 spectrometer. Mass spectra were obtained with a Voyager DE MALDI-TOF spectrometer. Synthesis of 2-Oleyl-sn-glycero-3-phosphocholine (1) is shown in Scheme 2.1. 

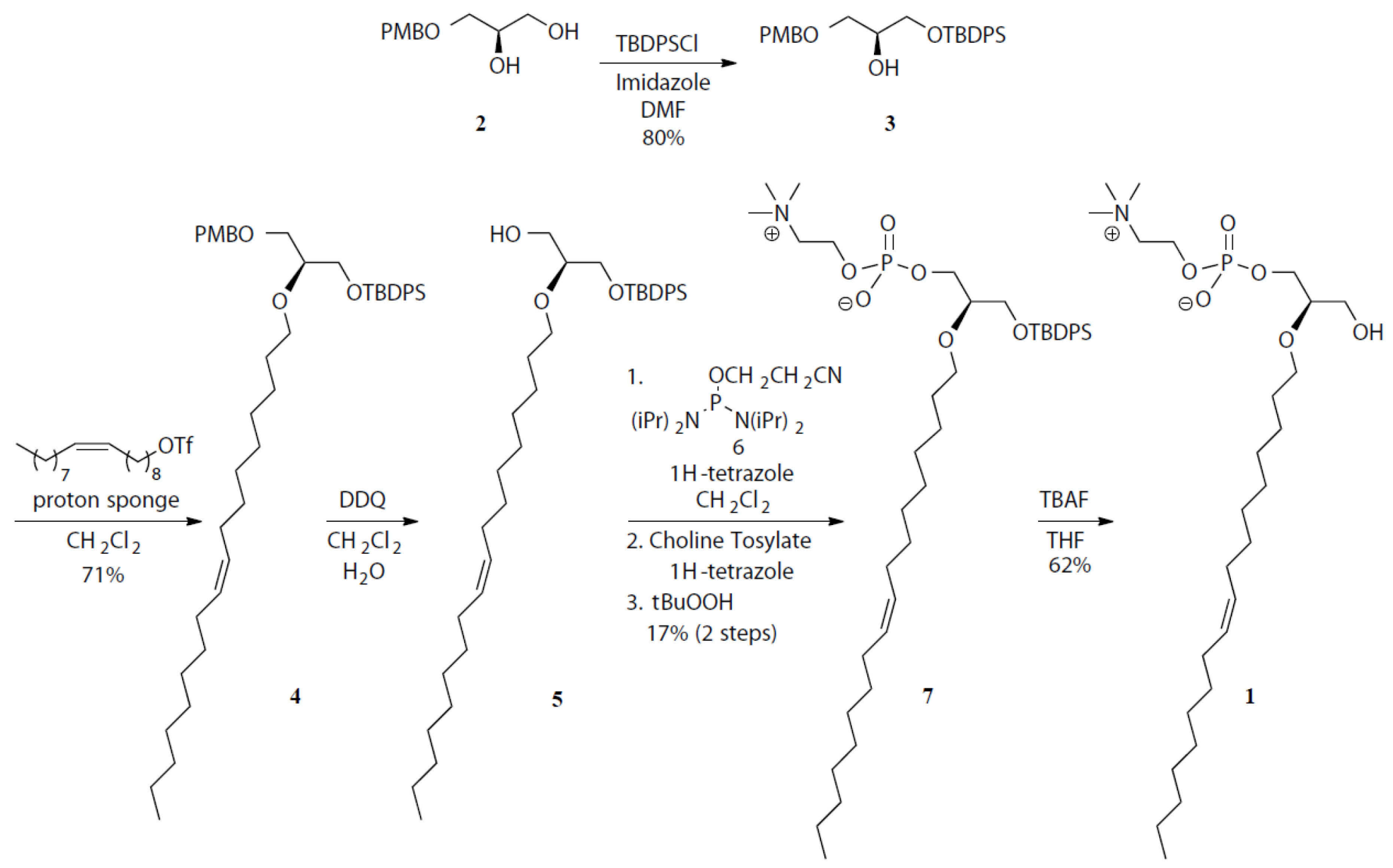

Scheme 2.1 Synthesis of 2-oleyl-sn-glycero-3-phosphocholine. 


\section{CHAPTER 3. QUANTIFICATION OF $S N$-1 AND $S N$-2 REGIOISOMERS OF LPA AND LPC}

\subsection{INTRODUCTION}

We hypothesized that the production of $s n-1$ LPA during blood coagulation proceeds through the following steps: 1) Secretion of PLA from activated platelets. 2) Generation of $s n$-2 LPLs by PLA 1.3 ) Acyl migration of $s n-2$ LPLs to yield the $s n-1$ regioisomer of LPLs. 4. Cleavage of $s n-1$ lysophospholipids by LPLD to yield $s n-1$ LPA. The predominance of 18:2 and 20:4 LPA species in serum indicate that PLA $A_{1}$ cleavage must be involved in this biochemical pathway because these fatty acids are only present in the $s n-2$ position of phospholipids. In order to understand LPA production in biological fluids we sought to develop a method for the separation and quantification of the $s n-1$ and $s n-2$ regioisomers of LPC and LPA. Using such a method one would be able to analyze human blood samples at various time points throughout the coagulation process and accurately determine a time course of the production of $s n-2$ and subsequently $s n-1$ lysophospholipids. We have developed an HPLC method coupled with MS/MS that separated the regioisomers of both LPC and LPA. However, the duration of the extraction and separation of the regioisomers $(\sim 40 \mathrm{~min})$ was longer than the very short half-life ( $\sim 10 \mathrm{~min})$ of the $s n-2$ regioisomer in biological samples (Pluckthun and Dennis, 1982). Consequently, were unable to reliably resolve any changes in the composition of the $s n-1$ and $s n-2$ regioisomers in human plasma or blood samples using this method.

\subsection{METHOD DEVELOPMENT}

\subsubsection{Production of the sn-2 Regioisomer of LPC and LPA}

sn-2 LPA 18:2 standard was synthesized from dilinoleoyl-phosphatidic acid (18:2 PA) using Rhizomucor miehei lipase specific for fatty acid esters in positions 1 and 3 on the glycerol backbone (Sigma-Aldrich, St. Louis, MO). $400 \mu \mathrm{g}$ PA 18:2 was incubated at $37^{\circ} \mathrm{C}$ for $1 \mathrm{~h}$ in $100 \mu 1$ reaction buffer $(10 \mathrm{mM}$ TRIS, $\mathrm{pH} 7.8,150 \mathrm{mM} \mathrm{NaCl}$, and $2 \mathrm{mM}$ $\mathrm{CaCl}_{2}$ final concentration) with $500 \mu 1$ lipase (10 units) and an equal volume of diethyl ether. The aqueous phase was then transferred to a new glass tube and $200 \mu 1$ watersaturated butanol was added. The sample was vortexed and centrifuged for $1 \mathrm{~min}$ at 13000 $\mathrm{x} g$,and the butanol layer was isolated and dried under a stream of argon gas.

sn-2 LPC 18:1 was synthesized from PC 16:0-18:1 using Rhizopus arrhizus miehei lipase. $400 \mu \mathrm{g} \mathrm{PC} 18: 1$ was incubated at $37^{\circ} \mathrm{C}$ for $1 \mathrm{~h}$ in $100 \mu 1$ reaction buffer (10mM TRIS, $\mathrm{pH} 7.8,10 \mathrm{mM}$ TritonX-100 final concentration) with $10 \mu \mathrm{g}$ lipase $(0.1$ units). The product was extracted using the same procedure described above for $s n-2$ LPA. 


\subsubsection{LC-MS/MS Method Development for Separation of the $s n-1$ and $s n-2$ Regioisomers of LPA}

We used a Tosoh TSK-ODS-100Z column (250mm x $2 \mathrm{~mm}$; silica with 5- $\mu \mathrm{m}$ particle size) HPLC column to separate $s n-1$ and $s n-2$ regioisomers of LPA. The HPLC column was connected to a Shimadazu LC-10ADvp pump (Columbia, MD) and interfaced to an Applied Biosystems Sciex (Foster City, CA) API 4000 tandem mass spectrometer equipped with a Turboionspray ${ }^{\mathrm{TM}}$ interface. The typical ion source parameters used were: Capillary $3.5 \mathrm{kV}$, declustering potential (DP) $32 \mathrm{~V}$, focusing potential (FP) $130 \mathrm{~V}$, entrance potential (EP) $-12 \mathrm{~V}$, collision energy (CE) $29 \mathrm{eV}$, collision cell exit potential (CXP) $10 \mathrm{~V}$, deflector $-348 \mathrm{~V}$, channel electron multiplier $(\mathrm{CEM}) 2200 \mathrm{~V}$, and source temperature $325^{\circ} \mathrm{C}$. The data was processed by Analyst software, version 1.3. Various species of LPA were analyzed by multiple reaction monitoring (MRM) in negative ion mode with $\mathrm{Q}_{3}$ (product ion) set at $\mathrm{m} / \mathrm{z} 153$ (glycerophosphate moiety). LPC species were analyzed in MRM positive ion mode with $\mathrm{Q}_{3}$ set at $m / z 184$ (glycerophosphocholine). $\mathrm{Q}_{1}$ was set for the deprotonated molecular ion for all lysophospholipids (Tokumura, 2009).

Since commercially available $s n-1$ LPA contains some $s n-2$ regioisomers, we started method development by separating $s n-1$ and $s n-2$ regioisomers present in $5 n g$ LPA 20:0 and 18:1 purchased from Avanti Polar Lipids (Alabaster, AL). Our goal was to obtain baseline separation for multiple LPA species. Initially we used a $150 \mathrm{~mm}$ Tosoh TSK-ODS-100Z column ( $2 \mathrm{~mm}$ diameter; 5 - $\mu \mathrm{m}$ particle size) and methanol/water $(95 / 5$, $\mathrm{v} / \mathrm{v}$ ) containing $5 \mathrm{mM}$ ammonium formate as the mobile phase with an isocratic flow rate of $0.22 \mathrm{ml} / \mathrm{min}$. LPA 20:0 was reconstituted in the mobile phase for injection. The separation of the regioismers of LPA 20:0 was incomplete (Figure 3.1A). The $s n-1$ peak retention time was $5.6 \mathrm{~min}$ and the $s n-2$ peak retention time was $5.3 \mathrm{~min}$. To improve the separation, LPA was reconstituted in acetonitrile/methanol/isopropanol/water (1/1/1/1, $\mathrm{v} / \mathrm{v})$ for injection. The separation improved slightly but baseline separation could not be achieved (Figure 3.1B). From this point on all samples were injected in acetonitrile/methanol/isopropanol/water (1/1/1/1, v/v) solvent.

Next, we adjusted the concentration of water in the mobile phase because increasing water concentration slows elution time and improved the separation of the regioisomers. We increased water to $7.5 \% \mathrm{~V} / \mathrm{V}$ that improved peak separation of the LPA 20:0 sn-1 and $s n-2$ regioisomers to $0.7 \mathrm{~min}$ (Figure 3.1C). To further increase separation we changed the mobile phase to methanol/water $(90 / 10, \mathrm{v} / \mathrm{v})$ containing $5 \mathrm{mM}$ ammonium formate. The peak separation of the LPA 20:0 regioisomers increased to $1.28 \mathrm{~min}$, but the separation of the LPA 18:1 regioisomers remained $0.60 \mathrm{~min}$ and poor (Figure 3.2). To increase the separation of all major acyl species we adjusted the column temperature from $40{ }^{\circ} \mathrm{C}$ to room temperature, which further improved the separation (data not shown). 


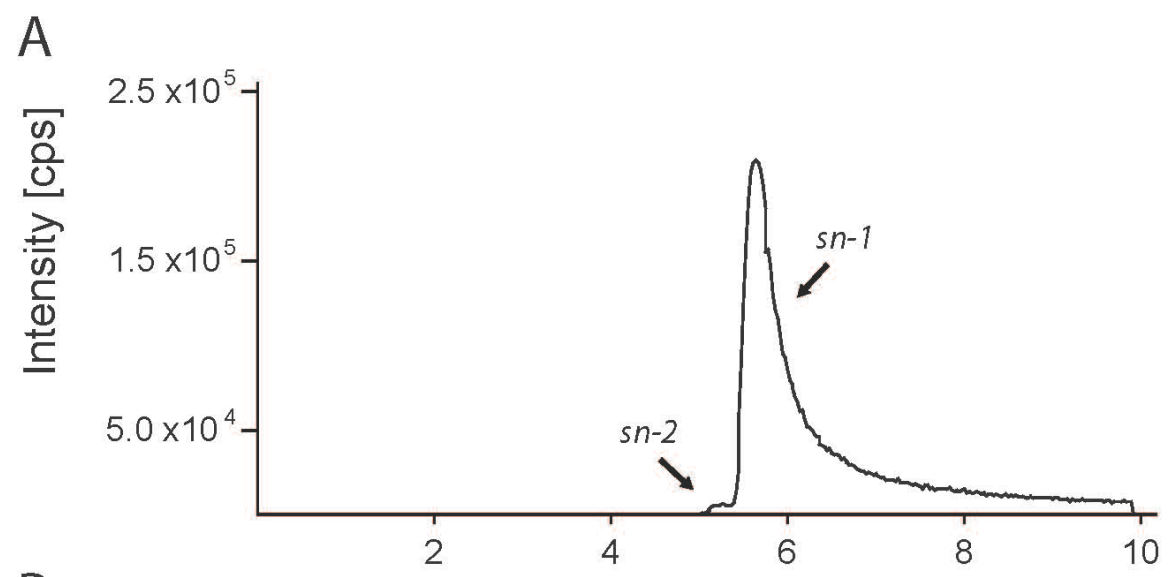

B minutes
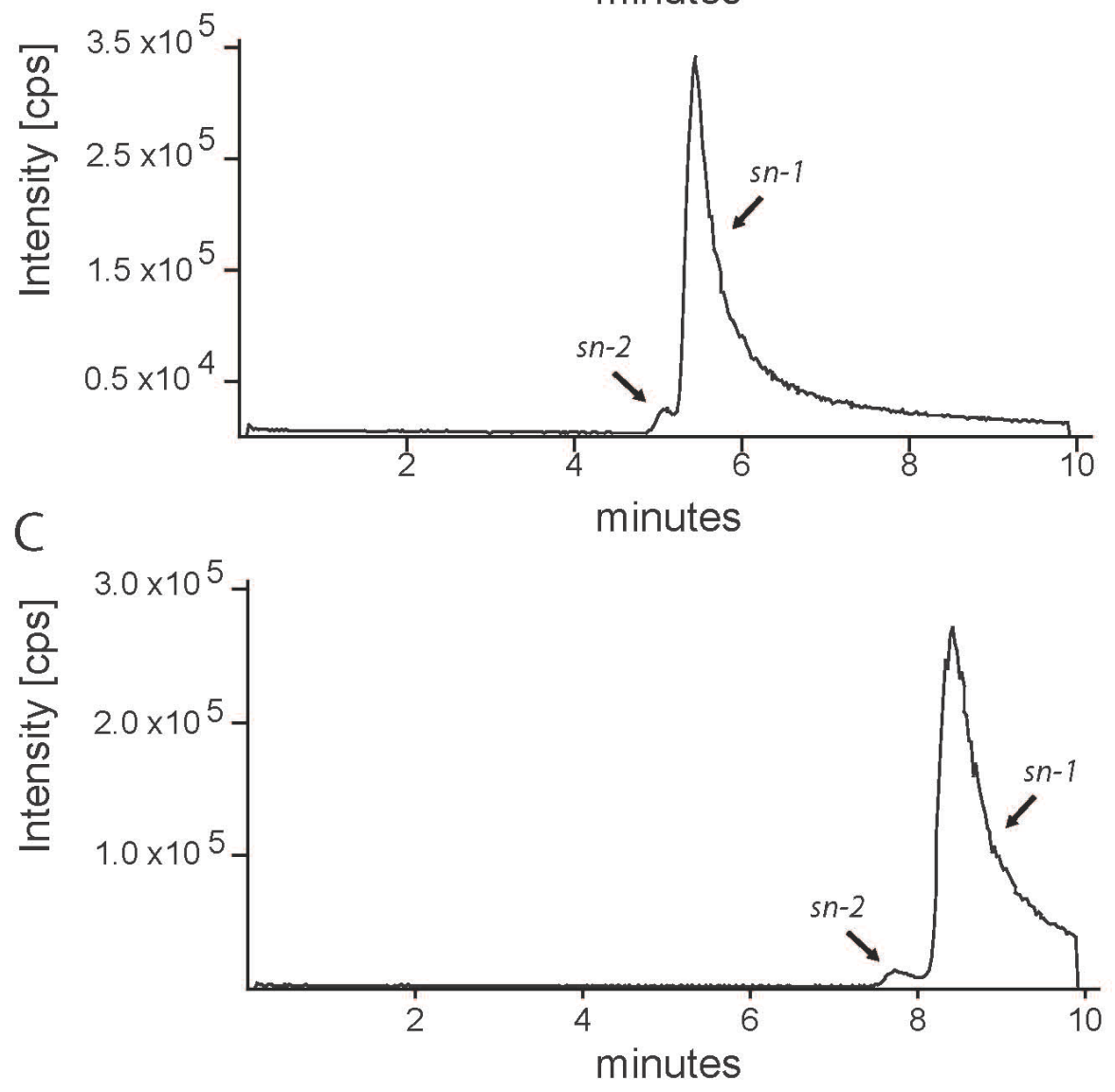

Figure 3.1 HPLC-MS/MS chromatogram of LPA 20:0 regioisomers under varying conditions. LPA 20:0 injected in methanol/water (95/5, V/V), 5mM ammonium formate solvent and mobile phase (panel A). LPA 20:0 injected in acetonitrile/methanol /isopropanol /water (1/1/1/1, V/V/V/V) solvent and methanol/water $(95 / 5, \mathrm{~V} / \mathrm{V}), 5 \mathrm{mM}$ ammonium formate mobile phase (panel B). LPA 20:0 injected in acetonitrile/methanol/ isopropanol/water (1/1/1/1, V/V/V/V) solvent and methanol/water $(92.5 / 7.5, \mathrm{~V} / \mathrm{V}), 5 \mathrm{mM}$ ammonium formate mobile phase (panel C). 


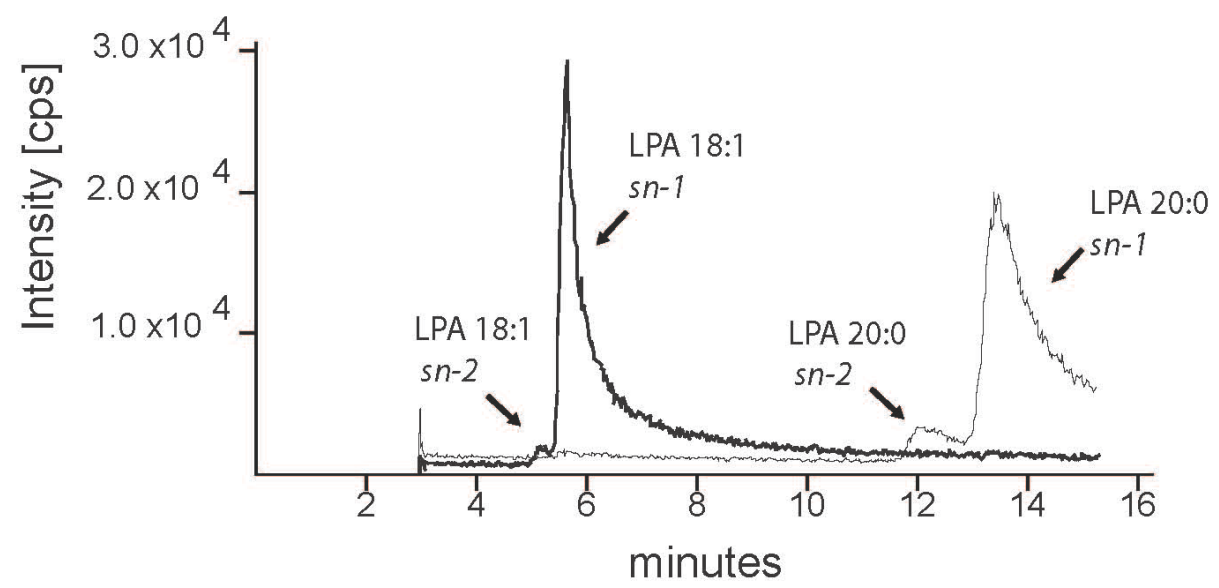

Figure 3.2 HPLC-MS/MS chromatogram of LPA 18:1 and 20:0 regioisomers. LPA 18:1 and 20:0 injected in acetonitrile/methanol/isopropanol/water (1/1/1/1, V/V/V/V) solvent and methanol/water $(90 / 10, \mathrm{~V} / \mathrm{V}), 5 \mathrm{mM}$ ammonium formate mobile phase. 
To validate the method for the most abundant polyunsaturated LPA species we synthesized LPA 18:2 regioisomers and injected nominally equal amounts of the sn-1 and $s n-2$ regioisomers. In the commercially available LPA 18:2 (Avanti, Alabaster, AL) the peak retention times were 8.3 and at $9.2 \mathrm{~min}$ for the $s n-2$ and $s n-1$ regioisomers, respectively (Figure 3.3A). The synthetic $s n-2$ LPA when injected alone showed a peak retention time at $8.4 \mathrm{~min}$ (Figure 3.3B). The mixture of the two regioisomers showed a peak retention time of $8.1 \mathrm{~min}$ for the $s n-2$ and $9.2 \mathrm{~min}$ for the $s n-1$ providing validation of the identity of the peaks detected in the commercial LPA 18:2 preparation (Figure $3.3 \mathrm{C}$ ). Because of the large tail of the $s n-2$ peak, small amounts of $s n-1$ LPA could not be resolved. Because of this we decided to further improve the separation of the regioisomers by increasing the water concentration to $20 \%$ and found that this resulted in a separation of the two peaks by 3.4 min (Figure 3.4). The retention times of the various LPA and LPC species under varying conditions are summarized in Table 3.1.

\subsubsection{Stability of the sn-2 Regioisomers of LPA and LPC}

Based on studies conducted with LPC, it has been widely accepted that the sn-2 regioisomers of lysophospholipids are highly unstable and that acyl migration towards a 9:1 equilibrium ratio of $s n-1$ to $s n-2$ occurs rapidly in aqueous buffers in a $\mathrm{pH}$ dependent manner (Pluckthun and Dennis 1982). Pluckthun and Dennis showed that the rate of acyl migration increases as $\mathrm{pH}$ increases. They also showed that acyl migration is reduced at $\mathrm{pH} 4.0$ to 5.0 but again increases as $\mathrm{pH}$ decreases from 4.0 to 1.0. Pluckthun and Dennis used ${ }^{31} \mathrm{P}$ NMR to show that upon synthesis of $s n-2$ LPC 16:0 acyl migration begins to take place immediately and within 60 minutes more than $60 \%$ of the $s n-2$ LPC 16:0 has migrated to the $s n-1$ position (Pluckthun and Dennis 1982).In order to gain confidence in our method of quantification of the $s n-1$ and $s n-2$ regioisomers of LPC and LPA, it was imperative that we determine the stability of the $s n-2$ regioisomer under the conditions used in our method. To achieve this, sn-2 LPA 18:2 was synthesized as described above and divided into two samples. The first sample was reconstituted in isopropanol/water/methanol/acetonitrile $(1 / 1 / 1 / 1, \mathrm{~V} / \mathrm{V} / \mathrm{V} / \mathrm{V})$ and immediately analyzed by LC-MS/MS with a mobile phase of methanol/water (90/10, v/v) $5 \mathrm{mM}$ ammonium formate (Time 0, Figure 3.5A). This sample was then left at room temperature and reanalyzed by LC-MS/MS at 1 hour and 24 hours later (1 hour at pH 4.0, Figure 3.5B; 24 hour at $\mathrm{pH} 4.0$, Figure $3.5 \mathrm{C}$ ). It was determined that the $s n-2$ regioisomer was stable at $\mathrm{pH} 4.0$ for at least 24 hours of incubation and no migration occurred throughout the time and conditions of the mass spec method for analysis. We also tested the stability of the $s n-2$ regioisomer of LPC 18:1. sn-2 18:1 LPC was prepared from 16:0-18:1 PC as previously described. The sample was reconstituted with $20 \mu 1$ isopropanol/water/methanol/acetonitrile $(1 / 1 / 1 / 1, \mathrm{~V} / \mathrm{V} / \mathrm{V} / \mathrm{V})$ and immediately analyzed using LC-MS/MS (Figure 3.6A). The sample was left at room temperature for 24 hours and reanalyzed (Figure 3.6B). sn-1 and $s n-2$ 18:1 LPC was also analyzed to validate retention times (Figure 3.6C). Based on these experiments we can conclude that the $s n-2$ regioisomer of LPC 18:1 is stable under the conditions used for analysis. 

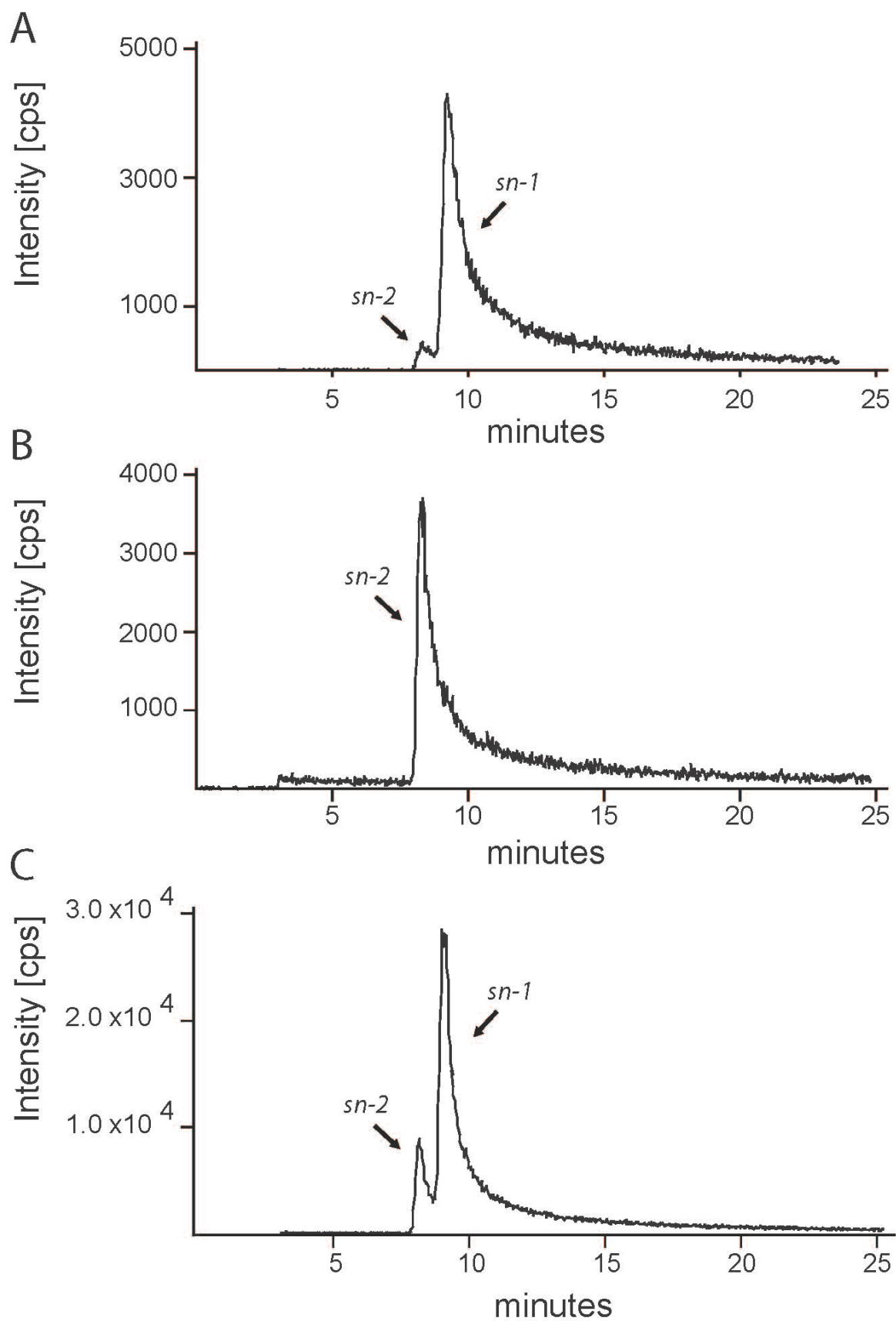

Figure 3.3 HPLC-MS/MS chromatogram of LPA 18:2 regioisomers. sn-l LPA 18:2 (panel A), sn-2 LPA 18:2 (panel B), and sn-1 and sn-2 LPA 18:2 (panel C) injected in acetonitrile/methanol/isopropanol/water $(1 / 1 / 1 / 1, \mathrm{~V} / \mathrm{V} / \mathrm{V} / \mathrm{V})$ solvent and methanol/water $(90 / 10, \mathrm{~V} / \mathrm{V}), 5 \mathrm{mM}$ ammonium formate mobile phase. 


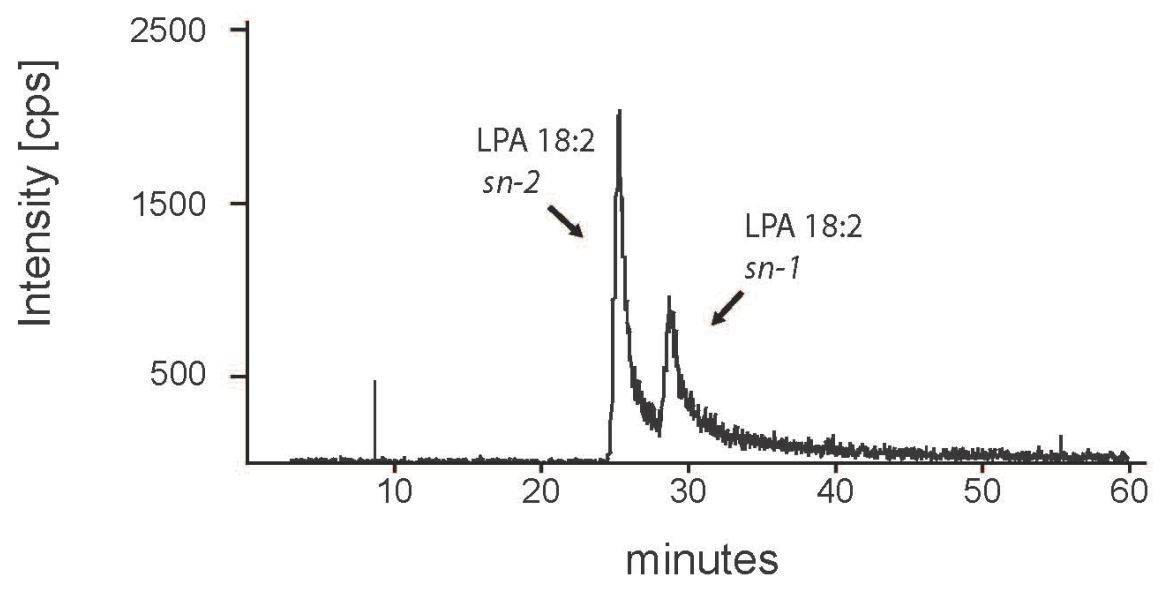

Figure 3.4 HPLC-MS/MS chromatogram of separation of LPA 18:2 regioisomers. $s n-1$ and $s n$-2 LPA 18:2 injected in acetonitrile/methanol/isopropanol/water (1/1/1/1, $\mathrm{V} / \mathrm{V} / \mathrm{V} / \mathrm{V})$ solvent and methanol/water $(80 / 20, \mathrm{~V} / \mathrm{V}), 5 \mathrm{mM}$ ammonium formate mobile phase. 
Table 3.1 Retention times of LPA and LPC species under varying conditions.

\begin{tabular}{|c|c|c|c|c|c|}
\hline $\begin{array}{c}\text { LPA/LPC } \\
\text { species }\end{array}$ & Solvent & $\begin{array}{c}\text { Ratio of } \\
\text { methanol/water } \\
(\mathrm{V} / \mathrm{V}) \text { in } \\
\text { Mobile Phase* }\end{array}$ & $\begin{array}{c}s n-1 \\
\text { retention } \\
\text { time } \\
(\mathrm{min})\end{array}$ & $\begin{array}{c}s n-2 \\
\text { retention } \\
\text { time } \\
(\mathrm{min})\end{array}$ & $\begin{array}{c}\text { Peak } \\
\text { separation } \\
(\text { min })\end{array}$ \\
\hline LPA 20:0 & $\begin{array}{l}\text { Methanol/water } 95 / 5 \\
(\mathrm{~V} / \mathrm{V}) 5 \mathrm{mM} \\
\text { ammonium formate }\end{array}$ & $95 / 5$ & 5.6 & 5.3 & 0.3 \\
\hline LPA 20:0 & $\begin{array}{c}\text { acetonitrile/methanol/ } \\
\text { isopropanol/water } \\
(1 / 1 / 1 / 1, \mathrm{v} / \mathrm{v})\end{array}$ & $95 / 5$ & 5.5 & 5.1 & 0.4 \\
\hline LPA 20:0 & $\begin{array}{c}\text { acetonitrile/methanol/ } \\
\text { isopropanol/water } \\
(1 / 1 / 1 / 1, \mathrm{v} / \mathrm{v})\end{array}$ & $92.5 / 7.5$ & 8.4 & 7.7 & 0.7 \\
\hline LPA 20:0 & $\begin{array}{c}\text { acetonitrile/methanol/ } \\
\text { isopropanol/water } \\
(1 / 1 / 1 / 1, \mathrm{v} / \mathrm{v})\end{array}$ & $90 / 10$ & 13.4 & 12.1 & 1.3 \\
\hline LPA $18: 2$ & $\begin{array}{c}\text { acetonitrile/methanol/ } \\
\text { isopropanol/water } \\
(1 / 1 / 1 / 1, \mathrm{v} / \mathrm{v})\end{array}$ & $90 / 10$ & 9.2 & 8.3 & 0.9 \\
\hline LPA $18: 2$ & $\begin{array}{c}\text { acetonitrile/methanol/ } \\
\text { isopropanol/water } \\
(1 / 1 / 1 / 1, \mathrm{v} / \mathrm{v})\end{array}$ & $80 / 20$ & 28.7 & 25.3 & 3.4 \\
\hline LPC 18:1 & $\begin{array}{c}\text { acetonitrile/methanol/ } \\
\text { isopropanol/water } \\
(1 / 1 / 1 / 1, \mathrm{v} / \mathrm{v})\end{array}$ & $90 / 10$ & 39.2 & 33.3 & 5.9 \\
\hline LPC 18:1 & $\begin{array}{c}\text { acetonitrile/methanol/ } \\
\text { isopropanol/water } \\
(1 / 1 / 1 / 1, \mathrm{v} / \mathrm{v})\end{array}$ & $80 / 20$ & 61.1 & 51.1 & 10.0 \\
\hline
\end{tabular}

*Mobile phase includes $5 \mathrm{mM}$ ammonium formate. 

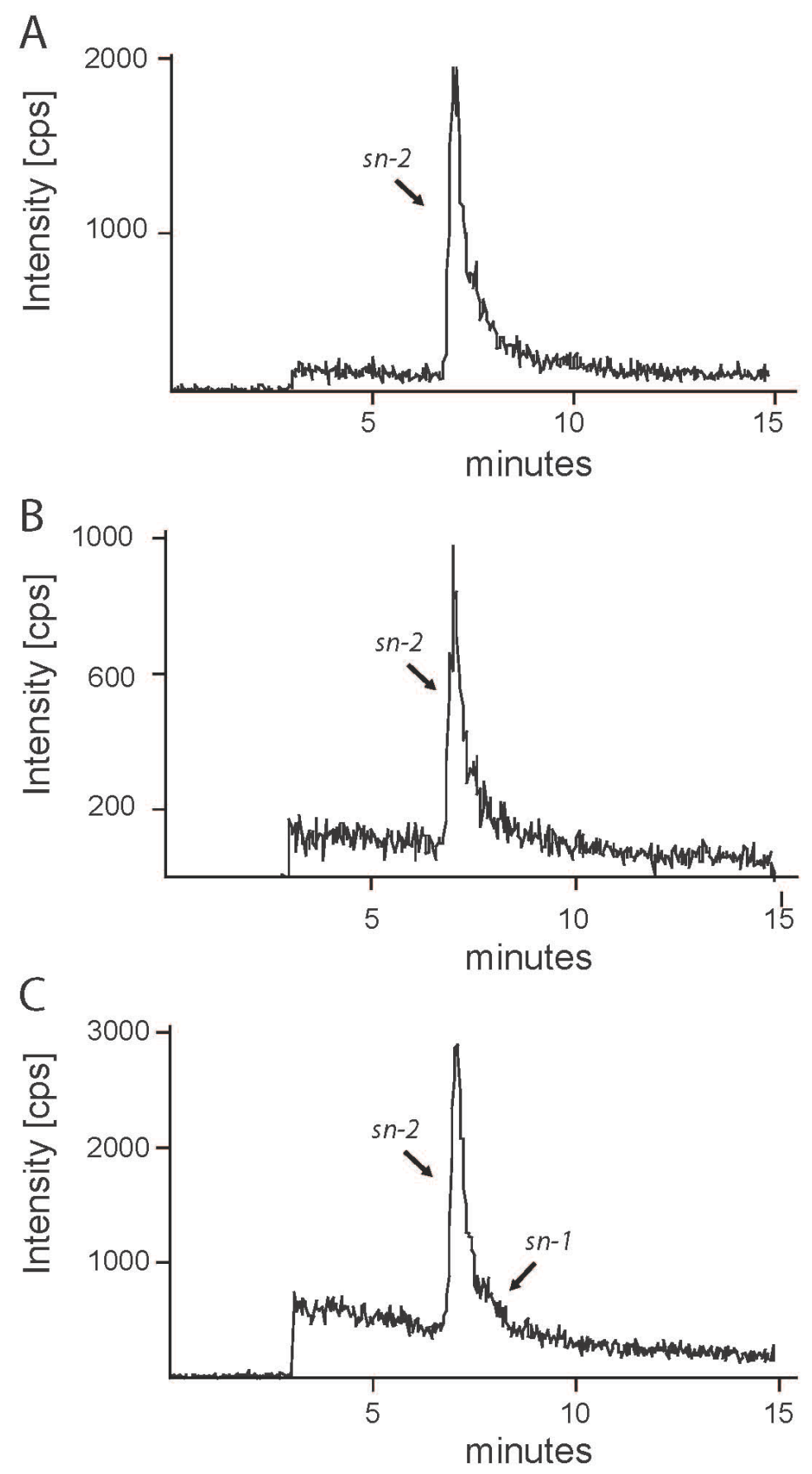

Figure 3.5 HPLC-MS/MS chromatogram of $s n-2$ LPA 18:2 at varying time points post synthesis. sn-2 LPA 18:2 injected in acetonitrile/methanol/isopropanol/water $(1 / 1 / 1 / 1, \mathrm{~V} / \mathrm{V} / \mathrm{V} / \mathrm{V})$ solvent and methanol/water $(90 / 10, \mathrm{~V} / \mathrm{V}), 5 \mathrm{mM}$ ammonium formate mobile phase at time 0 (panel A), 1 hour at $\mathrm{pH} 4.0$ (panel B), and 24 hours at $\mathrm{pH} 4.0$ (panel C). 

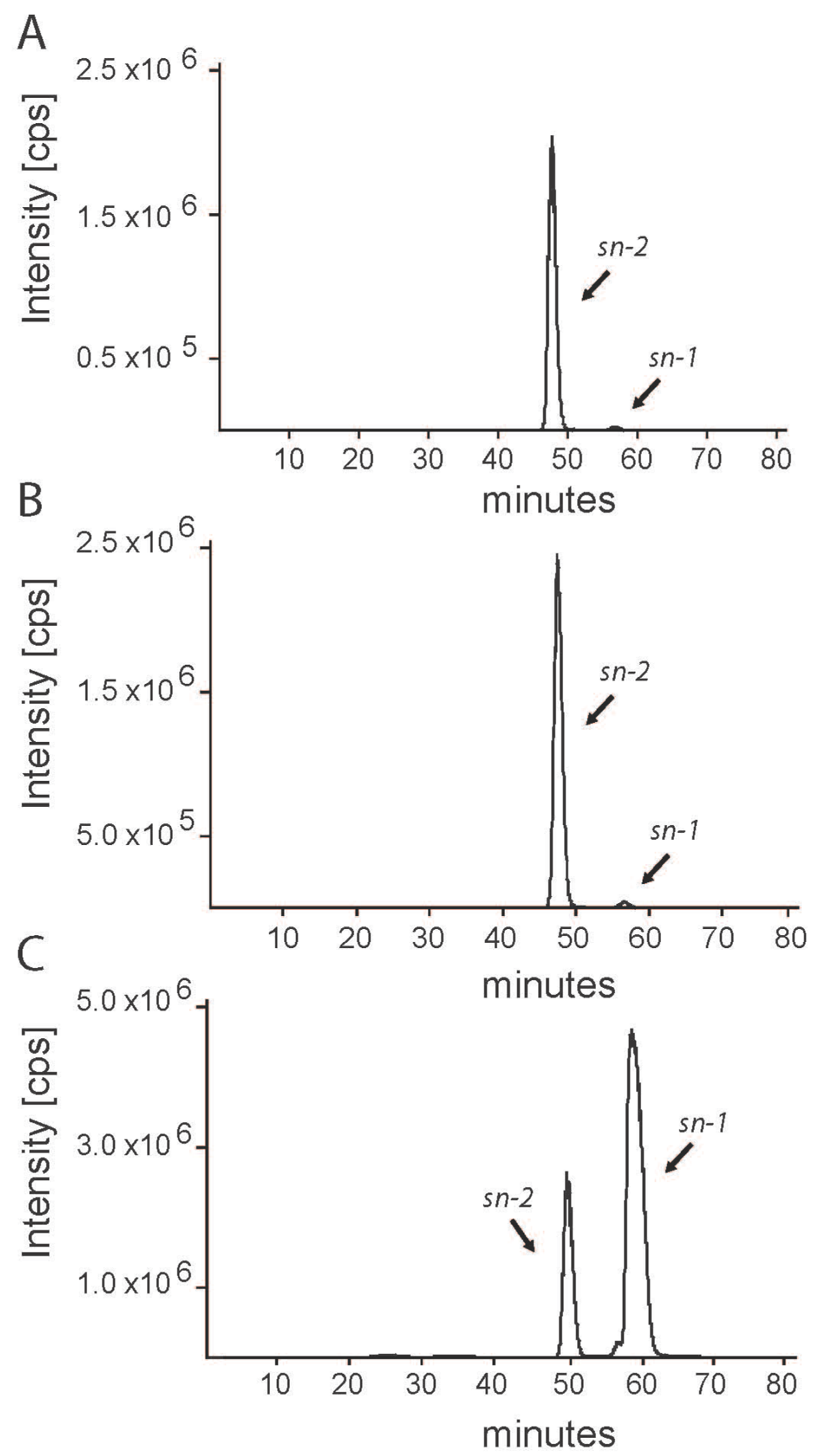

Figure 3.6 HPLC-MS/MS chromatogram of sn-2 LPC 18:1 at varying time points post synthesis. $s n$-2 LPC 18:1 injected in acetonitrile/methanol/isopropanol/water $(1 / 1 / 1 / 1, \mathrm{~V} / \mathrm{V} / \mathrm{V} / \mathrm{V})$ solvent and methanol/water $(80 / 20, \mathrm{~V} / \mathrm{V}), 5 \mathrm{mM}$ ammonium formate mobile phase at time 0 (panel A), 24 hours at $\mathrm{pH} 4.0$ (panel B), time 0 sn-1 and sn-2 LPC 18:1 (panel C). 


\subsubsection{Application}

In order to quantify the various regioisomers at different time points in human serum, $5 \mathrm{ml}$ blood was drawn into a heparinized or non-treated Vacutainer tubes. Blood was centrifuged at $14000 \mathrm{x}$ g for $1 \mathrm{~min}$ and the PRP was transferred to a new tube. The PRP from the tube with no additive was allowed to clot to generate serum. $1 \mathrm{ml}$ aliquots of plasma and serum incubated for 1 hour and 24 hours at $37^{\circ} \mathrm{C}$ were spiked with $50 \mathrm{ng}$ LPA 17:0 internal standard. LPA and LPC were extracted as described by Bollinger, et al. (Bollinger, Ii et al. 2010). High yield extraction of lipids from biological samples is difficult. Bollinger et al. have recently developed a method of extraction that has been shown to be cleaner and higher yield than previous methods. Regioisomers of LPA 18:2 and LPC 18:1 and 18:2 were analyzed using the appropriate $\mathrm{m} / \mathrm{z}$ ratios of the regioisomers at the proper retention times. To minimize run time a mobile phase of methanol/water $(90 / 10, \mathrm{v} / \mathrm{v}) 5 \mathrm{mM}$ ammonium formate was used for analysis of LPC species. The ratio of $s n-1$ to $s n-2$ LPC 18:1 and 18:2 was 9:1 in all plasma and serum samples (Figure 3.7A, B, and C). We expected this ratio in plasma however; we expected an immediate but short lived spike in the $s n-2$ regioisomers in serum incubated for 1 hour. The same 9:1 ratio was found for the $s n-1$ and $s n-2$ regioisomers of LPA 18:2 in all samples (Figure 3.8A, B, and C).

\subsubsection{Conclusions}

We have developed a HPLC/MS/MS method for the detection and quantification of LPA and LPC sn- 1 and sn-2 regioisomers. Using this method we will be able to further progress toward a more complete analysis of LPA production in biological fluids. We were unable to observe a change in the composition of the regioisomers in human plasma or serum using the extraction method described by Bollinger et al. (Bollinger, Ii et al. 2010). Even though this method was designed to limit the acidification of the sample, it is possible that the extraction method encouraged acyl migration towards equilibrium with the minimal acidic nature of the extraction. This extraction method is also quite long $(\sim 1$ hour to complete) which may have allowed time for acyl migration. In order to observe the $s n-2$ regioisomer production and migration a much more rapid method of lipid extraction from biological samples must be developed in which the samples are at a constant $\mathrm{pH}$ range of 4.0 to 5.0 to minimize any $\mathrm{pH}$ dependent acyl migration.

Using this method in conjunction with a rapid lipid extraction into a slightly acidic solvent ( $\mathrm{pH} 4.0-5.0)$, one can potentially analyze the composition of all species of $s n-1$ and $s n-2$ LPC and LPA at different time points during blood coagulation and determine changes in the regioisomeric composition of LPA production. The evaluation of this mechanism is fundamental to understanding the role the different regioisomers of lysophospholipids play in regulation of enzymatic activity, ligand binding, and receptor activation. These studies will require the development of a rapid lipid extraction method preferentially shorter than the time it takes for acyl migration. Development of such method will be subject of future investigations that are beyond the scope of the present thesis. 

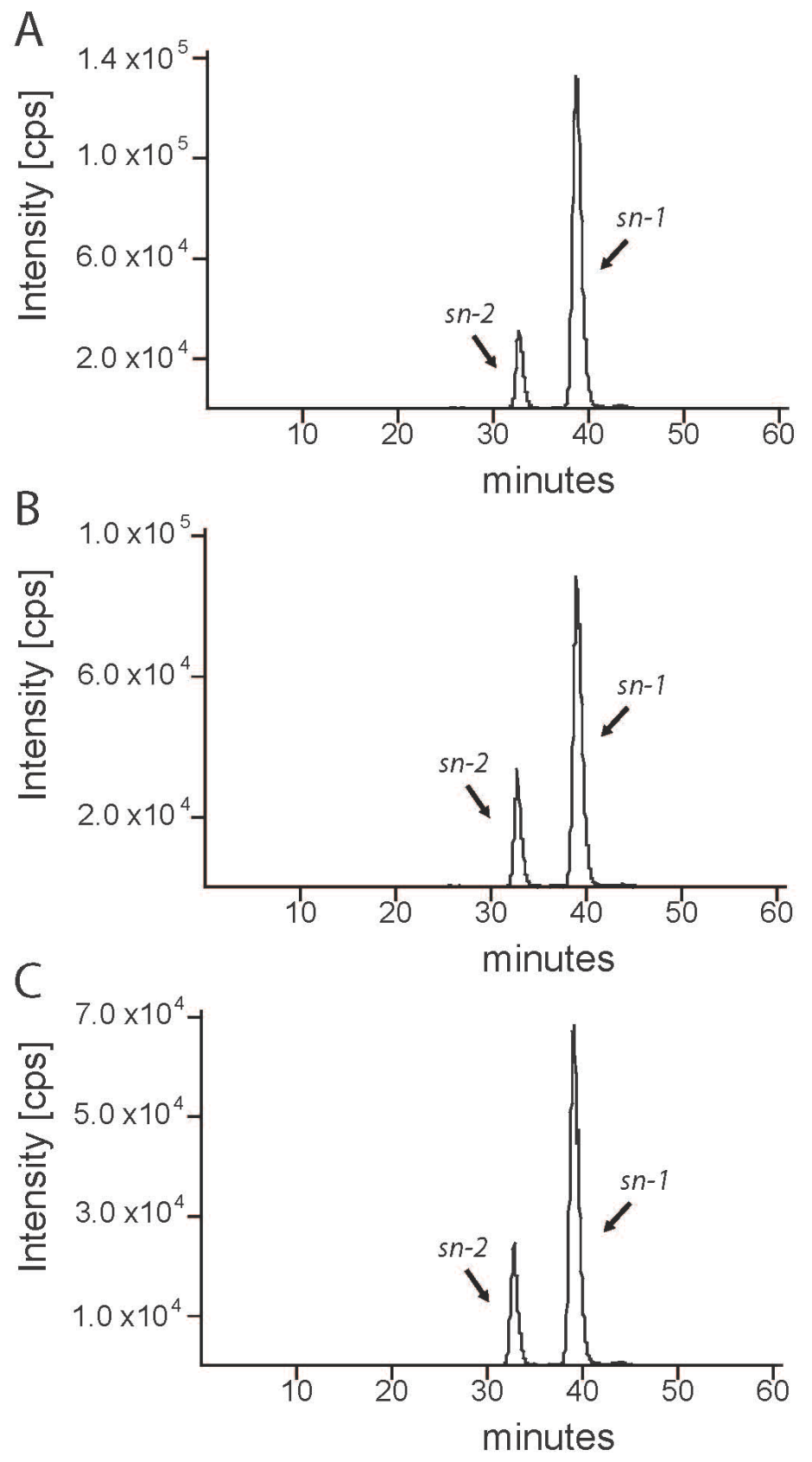

Figure 3.7 HPLC-MS/MS chromatogram of LPC 18:1 at varying time points in plasma and serum. Lipid extractions from plasma at time 0 (panel A), serum at 1 hour (panel B), and serum at 24 hours (panel C) were injected in acetonitrile/methanol/isopropanol/water (1/1/1/1, V/V/V/V) solvent and methanol/water $(90 / 10, \mathrm{~V} / \mathrm{V}), 5 \mathrm{mM}$ ammonium formate mobile phase. The ratio of the $s n-1$ to $s n-2$ regioisomers was 9:1 for all three time points. 

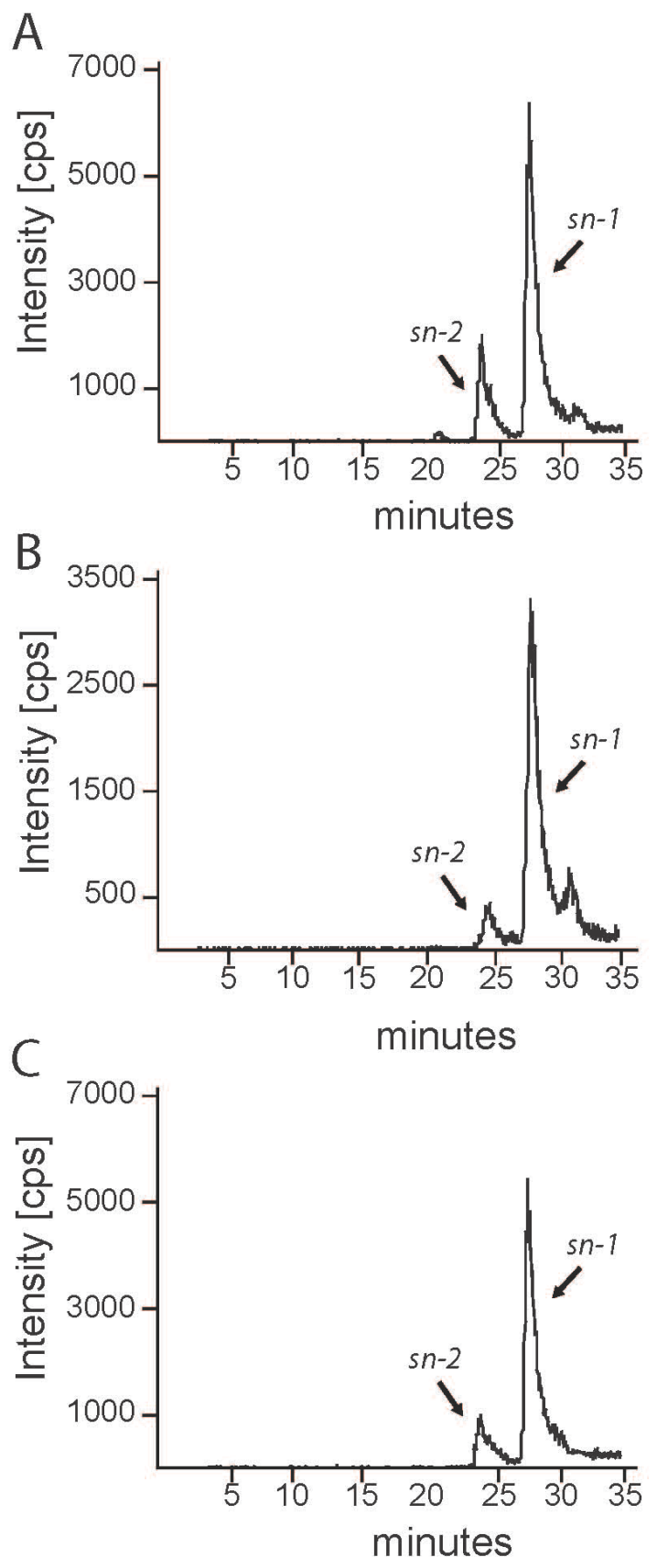

Figure 3.8 HPLC-MS/MS chromatogram of LPA 18:2 at varying time points in plasma and serum. Lipid extractions from plasma at time 0 (panel A), serum at 1 hour (panel B), and serum at 24 hours (panel C) were injected in acetonitrile/methanol/isopropanol/water (1/1/1/1, V/V/V/V) solvent and methanol/water $(80 / 20, \mathrm{~V} / \mathrm{V}), 5 \mathrm{mM}$ ammonium formate mobile phase. 


\section{LIST OF REFERENCES}

Ackermann EJ, Kempner ES, Dennis EA (Ca[2+]-independent cytosolic phospholipase A2 from macrophage-like P388D1 cells. Isolation and characterization. J Biol Chem 269:9227-9233.1994).

Aguado B, Campbell RD (Characterization of a human lysophosphatidic acid acyltransferase that is encoded by a gene located in the class III region of the human major histocompatibility complex. J Biol Chem 273:4096-4105.1998).

Albers HM, Dong A, van Meeteren LA, Egan DA, Sunkara M, van Tilburg EW, Schuurman K, van Tellingen O, Morris AJ, Smyth SS, Moolenaar WH, Ovaa H (Boronic acid-based inhibitor of autotaxin reveals rapid turnover of LPA in the circulation. Proc Natl Acad Sci U S A 107:7257-7262.2010).

An S, Bleu T, Zheng Y, Goetzl EJ (Recombinant human G protein-coupled lysophosphatidic acid receptors mediate intracellular calcium mobilization. Mol Pharmacol 54:881-888.1998).

An S, Dickens MA, Bleu T, Hallmark OG, Goetzl EJ (Molecular cloning of the human Edg2 protein and its identification as a functional cellular receptor for lysophosphatidic acid. Biochem Biophys Res Commun 231:619-622.1997).

Aoki J (Mechanisms of lysophosphatidic acid production. Semin Cell Dev Biol 15:477489.2004).

Aoki J, Inoue A, Okudaira S (Two pathways for lysophosphatidic acid production. Biochimica Biophysica Acta 1781:513-518.2008).

Aoki J, Nagai Y, Hosono H, Inoue K, Arai H (Structure and function of phosphatidylserine-specific phospholipase A1. Biochimica Biophysica Acta 1582:26-32.2002a).

Aoki J, Taira A, Takanezawa Y, Kishi Y, Hama K, Kishimoto T, Mizuno K, Saku K, Taguchi R, Arai H (Serum lysophosphatidic acid is produced through diverse phospholipase pathways. J Biol Chem 277:48737-48744.2002b).

Atsumi G, Tajima M, Hadano A, Nakatani Y, Murakami M, Kudo I (Fas-induced arachidonic acid release is mediated by $\mathrm{Ca} 2+$-independent phospholipase $\mathrm{A} 2$ but not cytosolic phospholipase A2, which undergoes proteolytic inactivation. J Biol Chem 273:13870-13877.1998).

Bacha AB, Gargouri Y, Bezzine S, Mejdoub H (Purification and biochemical characterization of phospholipase A2 from dromedary pancreas. Biochimica Biophysica Acta 1760:1202-1209.2006). 
Baker DL, Desiderio DM, Miller DD, Tolley B, Tigyi GJ (Direct quantitative analysis of lysophosphatidic acid molecular species by stable isotope dilution electrospray ionization liquid chromatography-mass spectrometry. Anal Biochem 292:287295.2001).

Baker DL, Morrison P, Miller B, Riely CA, Tolley B, Westermann AM, Bonfrer JM, Bais E, Moolenaar WH, Tigyi G (Plasma lysophosphatidic acid concentration and ovarian cancer. JAMA 287:3081-3082.2002).

Baker RR, Chang H (A metabolic path for the degradation of lysophosphatidic acid, an inhibitor of lysophosphatidylcholine lysophospholipase, in neuronal nuclei of cerebral cortex. Biochimica Biophysica Acta 1483:58-68.2000).

Balsinde J, Dennis EA (Distinct roles in signal transduction for each of the phospholipase A2 enzymes present in P388D1 macrophages. J Biol Chem 271:6758-6765.1996).

Balsinde J, Dennis EA (Function and inhibition of intracellular calcium-independent phospholipase A2. J Biol Chem 272:16069-16072.1997).

Bandoh K, Aoki J, Hosono H, Kobayashi S, Kobayashi T, Murakami-Murofushi K, Tsujimoto M, Arai H, Inoue K (Molecular cloning and characterization of a novel human G-protein-coupled receptor, EDG7, for lysophosphatidic acid. J Biol Chem 274:27776-27785.1999).

Bandoh K, Aoki J, Taira A, Tsujimoto M, Arai H, Inoue K (Lysophosphatidic acid [LPA] receptors of the EDG family are differentially activated by LPA species. Structure-activity relationship of cloned LPA receptors. FEBS Lett 478:159165.2000a).

Bandoh K, Aoki J, Taira A, Tsujimoto M, Arai H, Inoue K (Lysophosphatidic acid [LPA] receptors of the EDG family are differentially activated by LPA species. Structure-activity relationship of cloned LPA receptors. FEBS Lett 478:159165.2000b).

Bektas M, Payne SG, Liu H, Goparaju S, Milstien S, Spiegel S (A novel acylglycerol kinase that produces lysophosphatidic acid modulates cross talk with EGFR in prostate cancer cells. J Cell Biol 169:801-811.2005).

Billah MM, Lapetina EG, Cuatrecasas P (Phospholipase A2 and phospholipase C activities of platelets. Differential substrate specificity, $\mathrm{Ca} 2+$ requirement, $\mathrm{pH}$ dependence, and cellular localization. J Biol Chem 255:10227-10231.1980).

Billah MM, Lapetina EG, Cuatrecasas P (Phospholipase A2 activity specific for phosphatidic acid. A possible mechanism for the production of arachidonic acid in platelets. J Biol Chem 256:5399-5403.1981). 
Brindley DN, Waggoner DW (Mammalian lipid phosphate phosphohydrolases. J Biol Chem 273:24281-24284.1998).

Carnevale KA, Cathcart MK (Calcium-independent phospholipase A[2] is required for human monocyte chemotaxis to monocyte chemoattractant protein 1. J Immunol 167:3414-3421.2001).

Choi JW, Lee CW, Chun J (Biological roles of lysophospholipid receptors revealed by genetic null mice: an update. Biochimica et Biophysica Acta 1781:531-539.2008).

Clark JD, Schievella AR, Nalefski EA, Lin LL (Cytosolic phospholipase A2. J Lipid Mediat Cell Signal 12:83-117.1995).

Contos JJ, Chun J (Complete cDNA sequence, genomic structure, and chromosomal localization of the LPA receptor gene, lpA1/vzg-1/Gpcr26. Genomics 51:364378.1998).

Cummings R, Parinandi N, Wang L, Usatyuk P, Natarajan V (Phospholipase $\mathrm{D} /$ phosphatidic acid signal transduction: role and physiological significance in lung. Mol Cell Biochem 234-235:99-109.2002).

Das AK, Hajra AK (Estimation of acyldihydroxyacetone phosphate and lysophosphatidate in animal tissues. Biochimica Biophysica Acta 796:178189.1984).

de Jong JG, van den Bosch H, Rijken D, van Deenen LL (Studies on lysophospholipases. 3 . The complete purification of two proteins with lysophospholipase activity from beef liver. Biochimica Biophysica Acta 369:50-63.1974).

Deng W, Balazs L, Wang DA, Van Middlesworth L, Tigyi G, Johnson LR (Lysophosphatidic acid protects and rescues intestinal epithelial cells from radiation- and chemotherapy-induced apoptosis. Gastroenterology 123:206216.2002).

Deng W, Wang DA, Gosmanova E, Johnson LR, Tigyi G (LPA protects intestinal epithelial cells from apoptosis by inhibiting the mitochondrial pathway. Am J Physiol Gastrointest Liver Physiol 284:G821-829.2003).

Dimova I, Raitcheva S, Dimitrov R, Doganov N, Toncheva D (Correlations between cmyc gene copy-number and clinicopathological parameters of ovarian tumours. Eur J Cancer 42:674-679.2006).

Duncan JA, Gilman AG (A cytoplasmic acyl-protein thioesterase that removes palmitate from $\mathrm{G}$ protein alpha subunits and p21[RAS]. J Biol Chem 273:1583015837.1998). 
Duncan JA, Gilman AG (Characterization of Saccharomyces cerevisiae acyl-protein thioesterase 1, the enzyme responsible for $\mathrm{G}$ protein alpha subunit deacylation in vivo. J Biol Chem 277:31740-31752.2002).

Durgam GG, Virag T, Walker MD, Tsukahara R, Yasuda S, Liliom K, van Meeteren LA, Moolenaar WH, Wilke N, Siess W, Tigyi G, Miller DD (Synthesis, structureactivity relationships, and biological evaluation of fatty alcohol phosphates as lysophosphatidic acid receptor ligands, activators of PPARgamma, and inhibitors of autotaxin. J Med Chem 48:4919-4930.2005).

E S, Lai YJ, Tsukahara R, Chen CS, Fujiwara Y, Yue J, Yu JH, Guo H, Kihara A, Tigyi G, Lin FT (Lysophosphatidic acid 2 receptor-mediated supramolecular complex formation regulates its antiapoptotic effect. J Biol Chem 284:14558-14571.2009).

Eichholtz T, Jalink K, Fahrenfort I, Moolenaar WH (The bioactive phospholipid lysophosphatidic acid is released from activated platelets. Biochem J 291 ( Pt 3):677-680.1993).

Elstner E, Muller C, Koshizuka K, Williamson EA, Park D, Asou H, Shintaku P, Said JW, Heber D, Koeffler HP (Ligands for peroxisome proliferator-activated receptorgamma and retinoic acid receptor inhibit growth and induce apoptosis of human breast cancer cells in vitro and in BNX mice. Proc Natl Acad Sci U S A 95:8806-8811.1998).

Evans RM (The nuclear receptor superfamily: a rosetta stone for physiology. Mol Endocrinol 19:1429-1438.2005).

Fourcade O, Simon MF, Viode C, Rugani N, Leballe F, Ragab A, Fournie B, Sarda L, Chap H (Secretory phospholipase A2 generates the novel lipid mediator lysophosphatidic acid in membrane microvesicles shed from activated cells. Cell 80:919-927.1995).

Fujiwara Y, Sardar V, Tokumura A, Baker D, Murakami-Murofushi K, Parrill A, Tigyi G (Identification of residues responsible for ligand recognition and regioisomeric selectivity of lysophosphatidic acid receptors expressed in mammalian cells. J Biol Chem 280:35038-35050.2005).

Fukushima N, Kimura Y, Chun J (A single receptor encoded by vzg-1/lpA1/edg-2 couples to $\mathrm{G}$ proteins and mediates multiple cellular responses to lysophosphatidic acid. Proc Natl Acad Sci U S A 95:6151-6156.1998).

Gaits F, Fourcade O, Le Balle F, Gueguen G, Gaige B, Gassama-Diagne A, Fauvel J, Salles JP, Mauco G, Simon MF, Chap H (Lysophosphatidic acid as a phospholipid mediator: pathways of synthesis. FEBS Lett 410:54-58.1997). 
Garsetti DE, Ozgur LE, Steiner MR, Egan RW, Clark MA (Isolation and characterization of three lysophospholipases from the murine macrophage cell line WEHI 265.1. Biochimica Biophysica Acta 1165:229-238.1992).

Gendaszewska-Darmach E (Lysophosphatidic acids, cyclic phosphatidic acids and autotaxin as promising targets in therapies of cancer and other diseases. Acta Biochim Pol 55:227-240.2008).

Goetzl EJ, Dolezalova H, Kong Y, Hu YL, Jaffe RB, Kalli KR, Conover CA (Distinctive expression and functions of the type 4 endothelial differentiation gene-encoded $\mathrm{G}$ protein-coupled receptor for lysophosphatidic acid in ovarian cancer. Cancer Res 59:5370-5375.1999a).

Goetzl EJ, Kong Y, Mei B (Lysophosphatidic acid and sphingosine 1-phosphate protection of T cells from apoptosis in association with suppression of Bax. J Immunol 162:2049-2056.1999b).

Greimel P, Lapeyre M, Nagatsuka Y, Hirabayashi Y, Ito Y (Syntheses of phosphatidylbeta-D-glucoside analogues to probe antigen selectivity of monoclonal antibody 'DIM21'. Bioorg Med Chem 16:7210-7217.2008).

Gross RW, Sobel BE (Rabbit myocardial cytosolic lysophospholipase. Purification, characterization, and competitive inhibition by L-palmitoyl carnitine. J Biol Chem 258:5221-5226.1983).

Hecht JH, Weiner JA, Post SR, Chun J (Ventricular zone gene-1 [vzg-1] encodes a lysophosphatidic acid receptor expressed in neurogenic regions of the developing cerebral cortex. J Cell Biol 135:1071-1083.1996).

Heyes JA, Niculescu-Duvaz D, Cooper RG, Springer CJ (Synthesis of novel cationic lipids: Effect of structural modification on the efficiency of gene transfer. J Med Chem 45:99-114.2002).

Higashi S, Kobayashi T, Kudo I, Inoue K (Purification and characterization of lysophospholipase released from rat platelets. J Biol Chem 103:442-447.1988).

Higgs HN, Glomset JA (Purification and properties of a phosphatidic acid-preferring phospholipase A1 from bovine testis. Examination of the molecular basis of its activation. J Biol Chem 271:10874-10883.1996).

Hirano T, Kishi M, Sugimoto H, Taguchi R, Obinata H, Ohshima N, Tatei K, Izumi T (Thioesterase activity and subcellular localization of acylprotein thioesterase 1/lysophospholipase 1. Biochimica Biophysica Acta 1791:797-805.2009). 
Hirth G, Saroka H, Bannwarth W, Barner R (Synthesis of glyceryletherphosphatides, .2. preparation of 2-O-acetyl-1-O-[Z]-9-octadecenyl-sn-glyceryl-3-phosphorylcholin [oleyl-PAF], of its enantiomer and some analogous, unsaturated-compounds. Helv Chim Acta 66:1210-1240.1983).

Hosogaya S, Yatomi Y, Nakamura K, Ohkawa R, Okubo S, Yokota H, Ohta M, Yamazaki H, Koike T, Ozaki Y (Measurement of plasma lysophosphatidic acid concentration in healthy subjects: strong correlation with lysophospholipase D activity. Ann Clin Biochem 45:364-368.2008).

Hu YL, Tee MK, Goetzl EJ, Auersperg N, Mills GB, Ferrara N, Jaffe RB (Lysophosphatidic acid induction of vascular endothelial growth factor expression in human ovarian cancer cells. J Natl Cancer Inst 93:762-768.2001).

Huang MC, Lee HY, Yeh CC, Kong Y, Zaloudek CJ, Goetzl EJ (Induction of protein growth factor systems in the ovaries of transgenic mice overexpressing human type 2 lysophosphatidic acid G protein-coupled receptor [LPA2]. Oncogene 23:122-129.2004).

Huang ZH, Guo X, Li WJ, MacKay JA, Szoka FC (Acid-triggered transformation of diortho ester phosphocholine liposome. J Am Chem Soc 128:60-61.2006).

Im DS, Heise CE, Harding MA, George SR, O'Dowd BF, Theodorescu D, Lynch KR (Molecular cloning and characterization of a lysophosphatidic acid receptor, Edg7, expressed in prostate. Mol Pharmacol 57:753-759.2000).

Inoue M, Okuyama $\mathrm{H}$ (Phospholipase $\mathrm{A} 1$ acting on phosphatidic acid in porcine platelet membranes. J Biol Chem 259:5083-5086.1984).

Ishii S, Noguchi K, Yanagida K (Non-Edg family lysophosphatidic acid [LPA] receptors. Prosta \& Other Lipid Med 89:57-65.2009).

Jiang GW, Xu Y, Prestwich GD (Practical enantiospecific syntheses of lysobisphosphatidic acid and its analogues. J Org Chem 71:934-939.2006).

Kai M, Wada I, Imai S, Sakane F, Kanoh H (Cloning and characterization of two human isozymes of $\mathrm{Mg} 2+$-independent phosphatidic acid phosphatase. J Biol Chem 272:24572-24578.1997).

Koeberle A, Shindou H, Harayama T, Shimizu T (Role of lysophosphatidic acid acyltransferase 3 for the supply of highly polyunsaturated fatty acids in TM4 Sertoli cells. FASEB J.2010). 
Kotarsky K, Boketoft A, Bristulf J, Nilsson NE, Norberg A, Hansson S, Owman C, Sillard R, Leeb-Lundberg LM, Olde B (Lysophosphatidic acid binds to and activates GPR92, a G protein-coupled receptor highly expressed in gastrointestinal lymphocytes. J Pharmacol Exp Ther 318:619-628.2006).

Kramer RM, Sharp JD (Structure, function and regulation of Ca2+-sensitive cytosolic phospholipase A2 [cPLA2]. FEBS Lett 410:49-53.1997).

Kume K, Shimizu T (cDNA cloning and expression of murine 1-acyl-sn-glycerol-3phosphate acyltransferase. Biochem Biophys Res Commun 237:663-666.1997).

Larsson PK, Claesson HE, Kennedy BP (Multiple splice variants of the human calciumindependent phospholipase A2 and their effect on enzyme activity. J Biol Chem 273:207-214.1998).

Lee CW, Rivera R, Dubin AE, Chun J (LPA[4]/GPR23 is a lysophosphatidic acid [LPA] receptor utilizing G[s]-, G[q]/G[i]-mediated calcium signaling and $\mathrm{G}[12 / 13]$ mediated Rho activation. J Biol Chem 282:4310-4317.2007).

Lee CW, Rivera R, Gardell S, Dubin AE, Chun J (GPR92 as a new G12/13- and Gqcoupled lysophosphatidic acid receptor that increases cAMP, LPA5. J Biol Chem 281:23589-23597.2006).

Lee HY, Bae GU, Jung ID, Lee JS, Kim YK, Noh SH, Stracke ML, Park CG, Lee HW, Han JW (Autotaxin promotes motility via G protein-coupled phosphoinositide 3kinase gamma in human melanoma cells. FEBS Lett 515:137-140.2002).

Lehmann JM, Moore LB, Smith-Oliver TA, Wilkison WO, Willson TM, Kliewer SA (An antidiabetic thiazolidinedione is a high affinity ligand for peroxisome proliferatoractivated receptor gamma [PPAR gamma]. J Biol Chem 270:12953-12956.1995).

Leslie CC (Properties and regulation of cytosolic phospholipase A2. J Biol Chem 272:16709-16712.1997).

Leung D, Hardouin C, Boger DL, Cravatt BF (Discovering potent and selective reversible inhibitors of enzymes in complex proteomes. Nat Biotechnol 21:687691.2003).

Leung DW (The structure and functions of human lysophosphatidic acid acyltransferases. Front Biosci 6:D944-953.2001).

Leung DW, Tompkins CK, White T (Molecular cloning of two alternatively spliced forms of human phosphatidic acid phosphatase cDNAs that are differentially expressed in normal and tumor cells. DNA Cell Biol 17:377-385.1998). 
Li AC, Brown KK, Silvestre MJ, Willson TM, Palinski W, Glass CK (Peroxisome proliferator-activated receptor gamma ligands inhibit development of atherosclerosis in LDL receptor-deficient mice. J Clin Invest 106:523-531.2000).

Libby P (Inflammation in atherosclerosis. Nature 420:868-874.2002).

Lin FT, Lai YJ, Makarova N, Tigyi G, Lin WC (The lysophosphatidic acid 2 receptor mediates down-regulation of Siva-1 to promote cell survival. J Biol Chem 282:37759-37769.2007).

Lio YC, Dennis EA (Interfacial activation, lysophospholipase and transacylase activity of group VI Ca2+-independent phospholipase A2. Biochimica Biophysica Acta 1392:320-332.1998).

Liu Y, Patricelli MP, Cravatt BF (Activity-based protein profiling: the serine hydrolases. Proc Natl Acad Sci USA 96:14694-14699.1999).

Loo RW, Conde-Frieboes K, Reynolds LJ, Dennis EA (Activation, inhibition, and regiospecificity of the lysophospholipase activity of the $85-\mathrm{kDa}$ group IV cytosolic phospholipase A2. J Biol Chem 272:19214-19219.1997).

Mauco G, Chap H, Simon MF, Douste-Blazy L (Phosphatidic and lysophosphatidic acid production in phospholipase $\mathrm{C}$-and thrombin-treated platelets. Possible involvement of a platelet lipase. Biochimie 60:653-661.1978).

Mills GB, Moolenaar WH (The emerging role of lysophosphatidic acid in cancer. Nat Rev Cancer 3:582-591.2003).

Mishra RS, Carnevale KA, Cathcart MK (iPLA2beta: front and center in human monocyte chemotaxis to MCP-1. J Exp Med 205:347-359.2008).

Mueller E, Sarraf P, Tontonoz P, Evans RM, Martin KJ, Zhang M, Fletcher C, Singer S, Spiegelman BM (Terminal differentiation of human breast cancer through PPAR gamma. Mol Cell 1:465-470.1998).

Murakami M, Kudo I (Secretory phospholipase A2. Biol Pharm Bull 27:11581164.2004).

Murakami M, Shiraishi A, Tabata K, Fujita N (Identification of the orphan GPCR, P2Y(10) receptor as the sphingosine-1-phosphate and lysophosphatidic acid receptor. Biochem Biophys Res Commun 371:707-712.2008).

Mutoh T, Chun J (Lysophospholipid activation of G protein-coupled receptors. Subcell Biochem 49:269-297.2008). 
Nagai Y, Aoki J, Sato T, Amano K, Matsuda Y, Arai H, Inoue K (An alternative splicing form of phosphatidylserine-specific phospholipase A1 that exhibits lysophosphatidylserine-specific lysophospholipase activity in humans. J Biol Chem 274:11053-11059.1999).

Nam SW, Clair T, Campo CK, Lee HY, Liotta LA, Stracke ML (Autotaxin (ATX), a potent tumor motogen, augments invasive and metastatic potential of rastransformed cells. Oncogene 19:241-247.2000).

Nam SW, Clair T, Kim YS, McMarlin A, Schiffmann E, Liotta LA, Stracke ML (Autotaxin (NPP-2), a metastasis-enhancing motogen, is an angiogenic factor. Cancer Res 61:6938-6944.2001).

Noguchi K, Herr D, Mutoh T, Chun J (Lysophosphatidic acid (LPA) and its receptors. Curr Opin Pharmacol 9:15-23.2009).

Noguchi K, Ishii S, Shimizu T (Identification of p2y9/GPR23 as a novel G proteincoupled receptor for lysophosphatidic acid, structurally distant from the Edg family. J Biol Chem 278:25600-25606.2003).

Osborne N, Stainier DY (Lipid receptors in cardiovascular development. Annu Rev Physiol 65:23-43.2003).

Pages C, Simon MF, Valet P, Saulnier-Blache JS (Lysophosphatidic acid synthesis and release. Prosta \& Other Lipid Med 64:1-10.2001).

Pamuklar Z, Federico L, Liu S, Umezu-Goto M, Dong A, Panchatcharam M, Fulerson Z, Berdyshev E, Natarajan V, Fang X, van Meeteren LA, Moolenaar WH, Mills GB, Morris AJ, Smyth SS (Autotaxin/lysopholipase D and lysophosphatidic acid regulate murine hemostasis and thrombosis. J Biol Chem 284:7385-7394.2009).

Pasternack SM, von Kugelgen I, Aboud KA, Lee YA, Ruschendorf F, Voss K, Hillmer AM, Molderings GJ, Franz T, Ramirez A, Nurnberg P, Nothen MM, Betz RC (G protein-coupled receptor P2Y5 and its ligand LPA are involved in maintenance of human hair growth. Nat Genet 40:329-334.2008).

Patricelli MP, Lovato MA, Cravatt BF (Chemical and mutagenic investigations of fatty acid amide hydrolase: evidence for a family of serine hydrolases with distinct catalytic properties. Biochem 38:9804-9812.1999).

Perly B, Dufourc EJ, Jarrell HC (Facile and high yielding syntheses of phosphatidylcholines and phosphatidylethanolamines containing H-2-labeled acyl chains. J Labelled Compd Radiopharm 21:1-13.1984). 
Peyruchaud O (Novel implications for lysophospholipids, lysophosphatidic acid and sphingosine 1-phosphate, as drug targets in cancer. Anticancer Agents Med Chem 9:381-391.2009).

Pieringer RA, Hokin LE (Biosynthesis of lysophosphatdic acid from monoglyceride and adenosine triphosphate. J Biol Chem 237:653-658.1962).

Pluckthun A, Dennis EA (Acyl and phosphoryl migration in lysophospholipids: importance in phospholipid synthesis and phospholipase specificity. Biochem 21:1743-1750.1982).

Pouliot M, McDonald PP, Krump E, Mancini JA, McColl SR, Weech PK, Borgeat P (Colocalization of cytosolic phospholipase A2, 5-lipoxygenase, and 5lipoxygenase-activating protein at the nuclear membrane of A23187-stimulated human neutrophils. Eur J Biol Chem 238:250-258.1996).

Ptaszynska MM, Pendrak ML, Bandle RW, Stracke ML, Roberts DD (Positive feedback between vascular endothelial growth factor-A and autotaxin in ovarian cancer cells. Mol Cancer Res 6:352-363.2008).

Radeff-Huang J, Seasholtz TM, Matteo RG, Brown JH (G protein mediated signaling pathways in lysophospholipid induced cell proliferation and survival. J Cell Biochem 92:949-966.2004).

Ricote M, Glass CK (PPARs and molecular mechanisms of transrepression. Biochimica Biophysica Acta 1771:926-935.2007).

Rivera R, Chun J (Biological effects of lysophospholipids. Rev Physiol Biochem Pharmacol 160:25-46.2008).

Roberts R, Sciorra VA, Morris AJ (Human type 2 phosphatidic acid phosphohydrolases. Substrate specificity of the type $2 a, 2 b$, and $2 c$ enzymes and cell surface activity of the 2a isoform. J Biol Chem 273:22059-22067.1998).

Rowland MM, Best MD (Modular synthesis of bis(monoacylglycero)phosphate for convenient access to analogues bearing hydrocarbon and perdeuterated acyl chains of varying length. Tetrahedron 65:6844-6849.2009).

Sano T, Baker D, Virag T, Wada A, Yatomi Y, Kobayashi T, Igarashi Y, Tigyi G (Multiple mechanisms linked to platelet activation result in lysophosphatidic acid and sphingosine 1-phosphate generation in blood. J Biol Chem 277:2119721206.2002).

Sarraf P, Mueller E, Jones D, King FJ, DeAngelo DJ, Partridge JB, Holden SA, Chen LB, Singer S, Fletcher C, Spiegelman BM (Differentiation and reversal of malignant changes in colon cancer through PPARgamma. Nat Med 4:1046-1052.1998). 
Sato T, Aoki J, Nagai Y, Dohmae N, Takio K, Doi T, Arai H, Inoue K (Serine phospholipid-specific phospholipase A that is secreted from activated platelets. A new member of the lipase family. J Biol Chem 272:2192-2198.1997).

Satou M, Nishi Y, Yoh J, Hattori Y, Sugimoto H (Identification and characterization of acyl-protein thioesterase 1/lysophospholipase I as a ghrelin deacylation/lysophospholipid hydrolyzing enzyme in fetal bovine serum and conditioned medium. Endocrinology 151:4765-4775.2010).

Schaloske RH, Dennis EA (The phospholipase A2 superfamily and its group numbering system. Biochimica Biophysica Acta 1761:1246-1259.2006).

Schievella AR, Regier MK, Smith WL, Lin LL (Calcium-mediated translocation of cytosolic phospholipase A2 to the nuclear envelope and endoplasmic reticulum. J Biol Chem 270:30749-30754.1995).

Schumacher KA, Classen HG, Spath M (Platelet aggregation evoked in vitro and in vivo by phosphatidic acids and lysoderivatives: identity with substances in aged serum (DAS). Thromb Haemost 42:631-640.1979).

Shimomura Y, Wajid M, Ishii Y, Shapiro L, Petukhova L, Gordon D, Christiano AM (Disruption of P2RY5, an orphan G protein-coupled receptor, underlies autosomal recessive woolly hair. Nat Genet 40:335-339.2008).

Siess W, Tigyi G (Thrombogenic and atherogenic activities of lysophosphatidic acid. J Cell Biochem 92:1086-1094.2004).

Siess W, Zangl KJ, Essler M, Bauer M, Brandl R, Corrinth C, Bittman R, Tigyi G, Aepfelbacher M (Lysophosphatidic acid mediates the rapid activation of platelets and endothelial cells by mildly oxidized low density lipoprotein and accumulates in human atherosclerotic lesions. Proc Natl Acad Sci U S A 96:6931-6936.1999).

Smart BP, Pan YH, Weeks AK, Bollinger JG, Bahnson BJ, Gelb MH (Inhibition of the complete set of mammalian secreted phospholipases $\mathrm{A}[2]$ by indole analogues: a structure-guided study. Bioorg Med Chem 12:1737-1749.2004).

Smith JB, Silver MJ, Webster GR (Phospholipase A-1 of human blood platelets. Biochem J 131:615-618.1973).

So J, Navari J, Wang FQ, Fishman DA (Lysophosphatidic acid enhances epithelial ovarian carcinoma invasion through the increased expression of interleukin-8. Gynecol Oncol 95:314-322.2004).

So J, Wang FQ, Navari J, Schreher J, Fishman DA (LPA-induced epithelial ovarian cancer [EOC] in vitro invasion and migration are mediated by VEGF receptor-2 [VEGF-R2]. Gynecol Oncol 97:870-878.2005). 
Sonoda H, Aoki J, Hiramatsu T, Ishida M, Bandoh K, Nagai Y, Taguchi R, Inoue K, Arai $\mathrm{H}$ (A novel phosphatidic acid-selective phospholipase A1 that produces lysophosphatidic acid. J Biol Chem 277:34254-34263.2002).

Steinberg D (Atherogenesis in perspective: hypercholesterolemia and inflammation as partners in crime. Nat Med 8:1211-1217.2002).

Stracke ML, Clair T, Liotta LA (Autotaxin, tumor motility-stimulating exophosphodiesterase. Adv Enzyme Regul 37:135-144.1997).

Sugimoto H, Hayashi H, Yamashita S (Purification, cDNA cloning, and regulation of lysophospholipase from rat liver. J Biol Chem 271:7705-7711.1996).

Sunaga H, Sugimoto H, Nagamachi Y, Yamashita S (Purification and properties of lysophospholipase isoenzymes from pig gastric mucosa. Biochem J 308 ( Pt 2):551-557.1995).

Sutphen R, Xu Y, Wilbanks GD, Fiorica J, Grendys EC, Jr., LaPolla JP, Arango H, Hoffman MS, Martino M, Wakeley K, Griffin D, Blanco RW, Cantor AB, Xiao YJ, Krischer JP (Lysophospholipids are potential biomarkers of ovarian cancer. Cancer Epidemiol Biomarkers Prev 13:1185-1191.2004).

Tabata K, Baba K, Shiraishi A, Ito M, Fujita N (The orphan GPCR GPR87 was deorphanized and shown to be a lysophosphatidic acid receptor. Biochem Biophys Res Commun 363:861-866.2007).

Tanaka M, Okudaira S, Kishi Y, Ohkawa R, Iseki S, Ota M, Noji S, Yatomi Y, Aoki J, Arai $\mathrm{H}$ (Autotaxin stabilizes blood vessels and is required for embryonic vasculature by producing lysophosphatidic acid. J Biol Chem 281:2582225830.2006).

Thompson FJ, Clark MA (Purification of a lysophosphatidic acid-hydrolysing lysophospholipase from rat brain. Biochem J 300 ( Pt 2):457-461.1994).

Tice DA, Szeto W, Soloviev I, Rubinfeld B, Fong SE, Dugger DL, Winer J, Williams PM, Wieand D, Smith V, Schwall RH, Pennica D, Polakis P (Synergistic induction of tumor antigens by Wnt-1 signaling and retinoic acid revealed by gene expression profiling. J Biol Chem 277:14329-14335.2002).

Tigyi G (Aiming drug discovery at lysophosphatidic acid targets. British J of Pharm $161: 241-270.2010)$.

Tigyi G, Parrill AL (Molecular mechanisms of lysophosphatidic acid action. Prog Lipid Res 42:498-526.2003). 
Tokumura A, Carbone LD, Yoshioka Y, Morishige J, Kikuchi M, Postlethwaite A, Watsky MA (Elevated serum levels of arachidonoyl-lysophosphatidic acid and sphingosine 1-phosphate in systemic sclerosis. Int J Med Sci 6:168-176.2009).

Tokumura A, Harada K, Fukuzawa K, Tsukatani H (Involvement of lysophospholipase D in the production of lysophosphatidic acid in rat plasma. Biochimica Biophysica Acta 875:31-38.1986).

Tokumura A, Majima E, Kariya Y, Tominaga K, Kogure K, Yasuda K, Fukuzawa K (Identification of human plasma lysophospholipase D, a lysophosphatidic acidproducing enzyme, as autotaxin, a multifunctional phosphodiesterase. J Biol Chem 277:39436-39442.2002).

Tokumura A, Miyake M, Yoshimoto O, Shimizu M, Fukuzawa K (Metal-ion stimulation and inhibition of lysophospholipase $\mathrm{D}$ which generates bioactive lysophosphatidic acid in rat plasma. Lipids 33:1009-1015.1998).

Tokumura A, Yamano S, Aono T, Fukuzawa K (Lysophosphatidic acids produced by lysophospholipase D in mammalian serum and body fluid. Ann N Y Acad Sci 905:347-350.2000).

Tsukahara T, Tsukahara R, Fujiwara Y, Yue J, Cheng Y, Guo H, Bolen A, Zhang C, Balazs L, Re F, Du G, Frohman MA, Baker DL, Parrill AL, Uchiyama A, Kobayashi T, Murakami-Murofushi K, Tigyi G (Phospholipase D2-dependent inhibition of the nuclear hormone receptor PPARgamma by cyclic phosphatidic acid. Mol Cell 39:421-432.2010).

Umezu-Goto M, Kishi Y, Taira A, Hama K, Dohmae N, Takio K, Yamori T, Mills GB, Inoue $\mathrm{K}$, Aoki J, Arai $\mathrm{H}$ (Autotaxin has lysophospholipase D activity leading to tumor cell growth and motility by lysophosphatidic acid production. J Cell Biol 158:227-233.2002).

Valentin E, Lambeau G (Increasing molecular diversity of secreted phospholipases A(2) and their receptors and binding proteins. Biochimica Biophysica Acta 1488:5970.2000).

van Meeteren LA, Ruurs P, Christodoulou E, Goding JW, Takakusa H, Kikuchi K, Perrakis A, Nagano T, Moolenaar WH (Inhibition of autotaxin by lysophosphatidic acid and sphingosine 1-phosphate. J Biol Chem 280:2115521161.2005)

van Meeteren LA, Ruurs P, Stortelers C, Bouwman P, van Rooijen MA, Pradere JP, Pettit TR, Wakelam MJ, Saulnier-Blache JS, Mummery CL, Moolenaar WH, Jonkers J (Autotaxin, a secreted lysophospholipase D, is essential for blood vessel formation during development. Mol Cell Biol 26:5015-5022.2006). 
Verheij HM, Slotboom AJ, de Haas GH (Structure and function of phospholipase A2. Rev Physiol Biochem Pharmacol 91:91-203.1981).

Vogt W (The chemical nature of Darmstoff. J Physiol 137:154-167.1957a).

Vogt W (Pharmacologically active lipidsoluble acids of natural occurrence. Nature 179:300-304; passim.1957b).

Waggoner DW, Gomez-Munoz A, Dewald J, Brindley DN (Phosphatidate phosphohydrolase catalyzes the hydrolysis of ceramide 1-phosphate, lysophosphatidate, and sphingosine 1-phosphate. J Biol Chem 271:1650616509.1996).

Wang A, Loo R, Chen Z, Dennis EA (Regiospecificity and catalytic triad of lysophospholipase I. J Biol Chem 272:22030-22036.1997).

Wang DA, Du H, Jaggar JH, Brindley DN, Tigyi GJ, Watsky MA (Injury-elicited differential transcriptional regulation of phospholipid growth factor receptors in the cornea. Am J Physiol Cell Physiol 283:C1646-1654.2002).

Watanabe N, Ikeda H, Nakamura K, Ohkawa R, Kume Y, Tomiya T, Tejima K, Nishikawa T, Arai M, Yanase M, Aoki J, Arai H, Omata M, Fujiwara K, Yatomi Y (Plasma lysophosphatidic acid level and serum autotaxin activity are increased in liver injury in rats in relation to its severity. Life Sci 81:1009-1015.2007).

Williams JR, Khandoga AL, Goyal P, Fells JI, Perygin DH, Siess W, Parrill AL, Tigyi G, Fujiwara Y (Unique ligand selectivity of the GPR92/LPA5 lysophosphatidate receptor indicates role in human platelet activation. J Biol Chem 284:1730417319.2009).

Wolf MJ, Gross RW (Expression, purification, and kinetic characterization of a recombinant $80-\mathrm{kDa}$ intracellular calcium-independent phospholipase A2. J Biol Chem 271:30879-30885.1996).

Xu Y, Gaudette DC, Boynton JD, Frankel A, Fang XJ, Sharma A, Hurteau J, Casey G, Goodbody A, Mellors A, et al. (Characterization of an ovarian cancer activating factor in ascites from ovarian cancer patients. Clin Cancer Res 1:12231232.1995).

Xu Y, Shen Z, Wiper DW, Wu M, Morton RE, Elson P, Kennedy AW, Belinson J, Markman M, Casey G (Lysophosphatidic acid as a potential biomarker for ovarian and other gynecologic cancers. JAMA 280:719-723.1998).

Yamada T, Ohoka Y, Kogo M, Inagaki S (Physical and functional interactions of the lysophosphatidic acid receptors with PDZ domain-containing Rho guanine nucleotide exchange factors (RhoGEFs). J Biol Chem 280:19358-19363.2005). 
Yanagida K, Ishii S, Hamano F, Noguchi K, Shimizu T (LPA4/p2y9/GPR23 mediates rho-dependent morphological changes in a rat neuronal cell line. J Biol Chem 282:5814-5824.2007).

Yanagida K, Masago K, Nakanishi H, Kihara Y, Hamano F, Tajima Y, Taguchi R, Shimizu T, Ishii S (Identification and characterization of a novel lysophosphatidic acid receptor, p2y5/LPA6. J Biol Chem 284:17731-17741.2009).

Yin H, Chu A, Li W, Wang B, Shelton F, Otero F, Nguyen DG, Caldwell JS, Chen YA (Lipid G protein-coupled receptor ligand identification using beta-arrestin PathHunter assay. J Biol Chem 284:12328-12338.2009).

Yokoyama K, Kudo I, Inoue K (Phospholipid degradation in rat calcium ionophoreactivated platelets is catalyzed mainly by two discrete secretory phospholipase As. J Biol Chem 117:1280-1287.1995).

Yuki K, Shindou H, Hishikawa D, Shimizu T (Characterization of mouse lysophosphatidic acid acyltransferase 3: an enzyme with dual functions in the testis. J Lipid Res 50:860-869.2009).

Zebrowski BK, Liu W, Ramirez K, Akagi Y, Mills GB, Ellis LM (Markedly elevated levels of vascular endothelial growth factor in malignant ascites. Ann Surg Oncol 6:373-378.1999).

Zhang C, Baker DL, Yasuda S, Makarova N, Balazs L, Johnson LR, Marathe GK, McIntyre TM, Xu Y, Prestwich GD, Byun HS, Bittman R, Tigyi G (Lysophosphatidic acid induces neointima formation through PPARgamma activation. J Exp Med 199:763-774.2004).

Zhang H, Bialkowska A, Rusovici R, Chanchevalap S, Shim H, Katz JP, Yang VW, Yun CC (Lysophosphatidic acid facilitates proliferation of colon cancer cells via induction of Kruppel-like factor 5. J Biol Chem 282:15541-15549.2007a).

Zhang H, Wang D, Sun H, Hall RA, Yun CC (MAGI-3 regulates LPA-induced activation of Erk and RhoA. Cell Signal 19:261-268.2007b).

Zhang YY, Deems RA, Dennis EA (Lysophospholipases I and II from P388D1 macrophage-like cell line. Methods Enzymol 197:456-468.1991).

Zhang YY, Dennis EA (Purification and characterization of a lysophospholipase from a macrophage-like cell line P388D1. J Biol Chem 263:9965-9972.1988). 


\section{VITA}

Alyssa Lynn Jefferson Bolen was born in 1982 in Lincoln, Nebraska. She received her bachelor degree in chemistry from Doane College in Crete, Nebraska in May, 2005. She entered the Integrated Program in Biomedical Sciences at the University of Tennessee in August 2005. She is also currently working towards a Masters of

Business in finance from the University of Nebraska-Lincoln and will earn her degree in August 2011. 